\title{
Principles of Learner Autonomy in Action: Effects and Perceptions in a College-Level Foreign Language Class
}

Heiko Everwien ter Haseborg

West Virginia University

Follow this and additional works at: https://researchrepository.wvu.edu/etd

\section{Recommended Citation}

ter Haseborg, Heiko Everwien, "Principles of Learner Autonomy in Action: Effects and Perceptions in a College-Level Foreign Language Class" (2012). Graduate Theses, Dissertations, and Problem Reports. 3577.

https://researchrepository.wvu.edu/etd/3577

This Dissertation is protected by copyright and/or related rights. It has been brought to you by the The Research Repository @ WVU with permission from the rights-holder(s). You are free to use this Dissertation in any way that is permitted by the copyright and related rights legislation that applies to your use. For other uses you must obtain permission from the rights-holder(s) directly, unless additional rights are indicated by a Creative Commons license in the record and/ or on the work itself. This Dissertation has been accepted for inclusion in WVU Graduate Theses, Dissertations, and Problem Reports collection by an authorized administrator of The Research Repository @ WVU.

For more information, please contact researchrepository@mail.wvu.edu. 
Principles of Learner Autonomy in Action:

Effects and Perceptions in a College-Level Foreign Language Class

Heiko Everwien ter Haseborg

Dissertation submitted to the

College of Human Resources and Education

at West Virginia University

in partial fulfillment of the requirements

for the degree of

Doctor of Philosophy

in

Education

Cynthia S. Chalupa, Ph.D., Dissertation Chair

Samuel F. Stack, Ph.D., Committee Chair

Sheila Benson, Ph.D.

Jane S. Cardi, Ed.D.

Reagan P. Curtis, Ph.D.

Department of Curriculum \& Instruction

Morgantown, West Virginia

2012

Keywords:

Autonomy, Foreign Language Teaching, German as a Foreign Language, Learner Responsibility Copyright 2012 Heiko Everwien ter Haseborg 


\section{ABSTRACT \\ Principles of Learner Autonomy in Action: Effects and Perceptions in a College-Level Foreign Language Class}

\section{Heiko Everwien ter Haseborg}

This study was designed to investigate how college learners of a foreign language perceived learner autonomy, its effects on student motivation, and its benefits to different parts of language learning. It utilized a mixed-methods design. Participants were 90 undergraduate students in German courses of different levels. During the course of instruction, principles of learner autonomy were implemented in the instruction. Qualitative as well as quantitative data were collected in the form of a self-assessment survey, learning journals, reflective statements, and an autonomous learning survey. The analysis was focused on (1) how students perceived the ability to make autonomous learning choices, (2) how the ability to make autonomous choices regarding format, content, and timing affected motivation, and (3) which areas of language learning were most benefited by autonomous learning choices. The findings showed evidence that a majority of the students involved in this study reacted very positively to an autonomous learning environment, especially to the opportunity to make choices in regards to content. The students unanimously reported an increase in their level of motivation based on the autonomous learning choices. There was also a contrast between appreciation for autonomous learning choices on the one hand, and requests for more targeted instruction and practice on grammar, as well as more frequent assessments like quizzes and tests. 


\section{Acknowledgements}

This work would not have been completed if it were not for the loving and generous contributions of many people. They contributed to this work in very different forms and it is difficult for me to put my appreciation of their support in words. Nevertheless, this is my attempt.

First and foremost, I want to express my deep gratitude to Sara Elizabeth ter Haseborg. My wife's unwavering support throughout the years of my doctoral work, her ability to motivate me, and her steadfast belief in the eventual completion of this work have encouraged me to keep working on this project when it was difficult. Elizabeth, I could not have done this without you.

I would like to acknowledge the role of my parents, Ephard ter Haseborg and Ursula ter Haseborg, in the completion of this work in German: Lieber Papa, Liebe Mama, ich verdanke euch sehr viel. Eure Liebe, Unterstützung und Ermutigung, auf die ich mich zu jedem Zeitpunkt meines Lebens verlassen konnte, haben einen großen Anteil am Zustandekommen und der Fertigstellung dieser Arbeit.

I also would like to thank Robert and Sara Bailey. I am deeply grateful for their loving support of me as a son-in-law and student. I am blessed with amazing parents.

Last but not least, I would like to acknowledge the members of my doctoral committee. Each committee member supported and contributed to this project in a unique way. While working with my committee, I always knew that I was working with a group of scholars who cared about my work and success as a doctoral student. For this, I am very thankful. My committee chair, Dr. Cynthia Chalupa, has supported this project with her inspiring ideas and her great instinct for connections that were not always initially apparent to me. Cynthia - it is fun to work with you and I am thankful for the opportunity to complete this project with your guidance and support. I admire your ability to encourage and motivate people. I also want to thank Dr. Sheila Benson, whose competence in the field of critical theory and inspiring way of teaching have helped me to grow as a researcher and as an instructor. Dr. Jane Cardi has contributed to this work with her creative way to teach foundations of curriculum design, her appreciation of foreign language learning, and her insights into the challenges of foreign language teaching. I want to thank Dr. Reagan Curtis for his dedication to this project by being available for our regular meetings. Throughout the work on this project, they motivated me to stay on task and always think about the next step in the research process, because I always wanted to have something to show or talk about for our meetings. Finally, I want to thank and acknowledge the help by Dr. Sam Stack, who has guided and advised me over the years as a doctoral student.

Every one of these people made a unique contribution to this work and I am deeply thankful for the support and care they showed over and over again. It would not have been possible without you - thank you.

Heiko ter Haseborg 
Principles of Learner Autonomy in Action:

Effects and Perceptions in a College-Level Foreign Language Class

\section{Heiko Everwien ter Haseborg}

Dissertation submitted to the

College of Human Resources and Education

at West Virginia University

in partial fulfillment of the requirements

for the degree of

Doctor of Philosophy

in Education

\section{APPROVAL OF THE EXAMINING COMMITTEE}
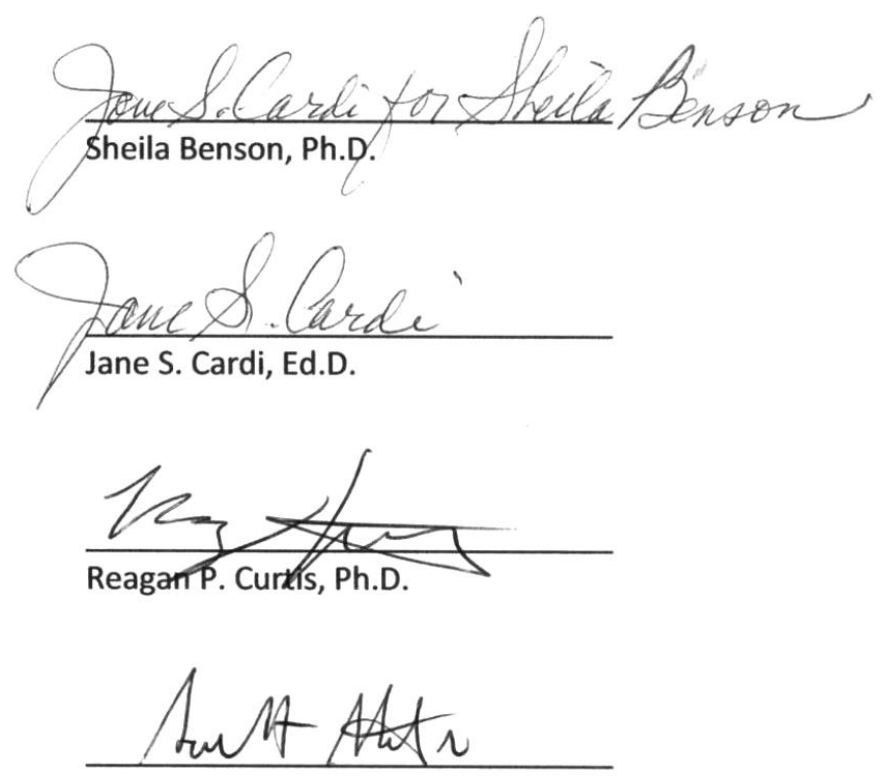

Samuel F. Stack, Ph.D.
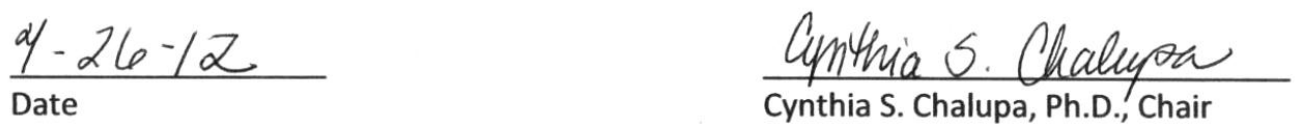


\section{Table of Contents}

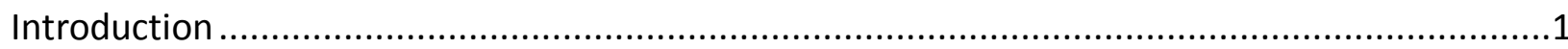

Chapter 1: Philosophical Foundations of Learner Autonomy .........................................

Chapter 2: Learner Autonomy and Foreign Language Learning .........................................23

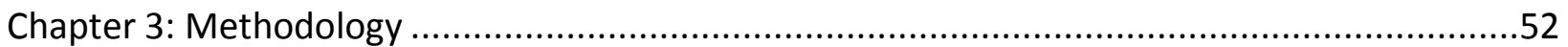

Chapter 4: Learner Responses to Autonomous Learning and Their Significance for the Foreign

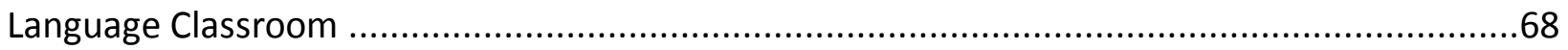

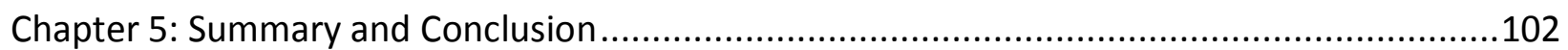

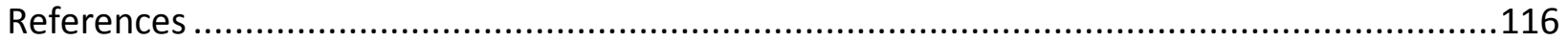

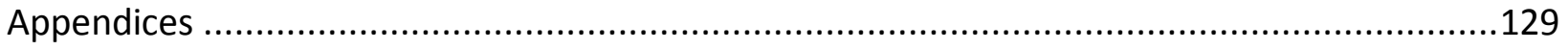




\section{Introduction}

Power relationships are at the basis of institutional learning. Members of particular groups have the power to decide which content is of sufficient importance to be part of the curriculum and members of other groups have to accept that this content represents the knowledge that is worthy to be learnt. Therefore, decisions about pedagogical approaches, curriculum content, class structure and size, as well as the logistics of institutional learning are made based on power. The concept of learner autonomy challenges this distribution of power. In the literature, it is most often defined as the "ability to take charge of one's own learning" (Holec, 1981, p. 3). It is then the ability to take charge of every part of the learning process, from the setting of learning goals through decisions on forms of assessment. By putting an emphasis on control over the learning process, learner autonomy affects the increasingly important skill of lifelong learning. The skill of independent and lifelong learning is necessary in times when more and more people do not necessarily stay in one profession for the duration of their whole professional lives, but instead more often change careers. More and more, people need to be able to adapt to changes on their own, given that the pace at which changes occur is ever increasing, and formal education cannot anticipate all the changes that might take place over a person's lifetime. Yet, educational institutions, especially at the tertiary level, can try to teach the skills that are necessary for lifelong learning and for people to adapt, react effectively to, and even bring about changes. Developing these skills is a central goal of autonomous learning.

Nowhere is the ability to direct one's own learning more important than in the area of foreign language study. This is especially clear at more advanced stages of the language 
learning process, where learners often stay within the target culture (for example as part of a study abroad experience). Independent learning skills are imperative in these situations in order to cope with the demanding situation. Furthermore, due to the increasing importance of international business relations and the fact that it is no longer an unusual situation to work with people from a foreign country, speaking a foreign language as well as the ability to learn a foreign language independently is a valuable skill. Hence, learner autonomy should be an important goal in foreign language teaching and learning throughout the $\mathrm{K}-16$ sequence. The ability to take responsibility for one's own learning is a central part of life-long learning, a goal that is essential to education in the $21^{\text {st }}$ century. This is evident, for example in the goals that have been postulated by the National Standards for Foreign Language Education Project (1999). The goals are Communication, Cultures, Connections, Comparisons, and Communities (they are also known as "the five Cs"). Principles of learner autonomy are reflected in all five goals, but are most explicitly mentioned in the goal called communities. Contained in this goal are two standards, namely that the students use the foreign language they are learning within as well as beyond the learning context (i.e., the classroom), and that the students show evidence of becoming life-long learners (Shrum \& Glisan, 2005). The role of foreign language education and independent learning are thus two important reasons to foster language learner autonomy.

\section{This Study}

The amount of literature on learner autonomy in the field of foreign language learning is considerable (for example, Barfield \& Brown, 2007; Broady \& Kenning, 1996; Cotterall \& Crabbe, 1999; Lamb \& Reinders, 2008; Little, Ridley, \& Ushioda, 2003; O’Rourke \& Carson, 2010). However, there are still questions that are left unanswered. Benson $(2001,2007)$ and 
Little (2007) suggest that "the empirical knowledge base on autonomy in language learning remains somewhat weak" (Benson, 2007, p. 34). Benson (2001) points out that "a great deal of the research on autonomy to date has been based on reflection and reasoning", but that on the other hand "far less research has been based on systematic analysis of data" (p. 182). The call for the need of data-based research on autonomy has been reiterated by Luke (2006), stating that "subsequent studies need to make quantitative comparisons between inquiry based techniques and other accepted or adopted instructional methods" (p. 83).

The lack of this type of research is probably due to the abstractness of the term autonomy, which makes it a difficult construct to measure. Benson (2001) has raised this concern in his book. One of them main reasons that make measuring autonomy difficult is "the fact that autonomy is clearly a multidimensional construct" (p. 51). Dimensions inherent to autonomy are, for example, the degree of metacognitive awareness by the learners, the level of control exercised on the learning process by the teacher and the learners, or even cultural factors playing a role in the context of learning. The dimensions that play a role in the development of autonomy will be further elaborated in chapters 1 and 2 . A second factor that makes measuring autonomy difficult is the nature of the construct. As has been pointed out above, autonomy in language learning is a capacity of the learner, namely to take control of their learning. As is often the case when measuring cognitive skills, just because a learner does not show a certain performance in an assessment does not mean that the learner does not possess the capacity intended to be measured. It is therefore difficult to discern when learners are acting in an autonomous fashion and when they are not. This also brings up a third point, which is the learners' willingness to display their capacity. This is an important yet complicating 
factor, since the ability to make self-directed decisions is a fundamental part of autonomy. A fourth factor that complicates researchers' ability to measure autonomy is "the nature of the acquisition of autonomy as a developmental process" (Benson, 2001, p. 53). In institutional settings, such as the one of this study, this process can be particularly difficult, as the contributions by Luke (2006) and Marsh, Richards, and Smith (2001) have shown.

Despite these complexities it is still possible to research language learner autonomy, and even, to some degree, to measure it. It is possible to implement certain factors that comprise autonomy and observe the effects. The aspects emphasized in this study are (1) control over the content, format, and timing of learning and assessment activities, as well as (2) developing the ability to reflect on one's own learning process. It is an attempt to find out how students perceive these changes to the class format and how it affects their language proficiency in terms of communicative competence (Celce-Murcia, Dörnyei, \& Thurrell, 1995). Communicative competence includes five different areas of language proficiency: discourse competence, linguistic competence, actional competence, sociocultural competence, and strategic competence. This study will contribute to the empirical knowledge base of autonomy and help fill some of the gaps in the body of research. To this end, three research questions are addressed:

1. How do students perceive the ability to make autonomous learning choices?

2. How does the ability to make autonomous choices regarding format, content, and timing affect motivation?

3. Which areas of language learning are most benefited by autonomous learning choices? 
In other words, this research is essentially focused on the question whether learner autonomy can contribute to more effective and successful learning in a college-level foreign language class. For several reasons, the methodological framework of participatory action research (PAR) lends itself best for this study. For example, the study is divided into two parts. The first half was carried out in the spring of 2011 and the second half in the following semester in the fall. The reflections, suggestions, criticisms, and ideas included in the data from the spring semester formed, to a considerable degree, the basis on which the second phase in the fall semester was carried out. This process of "building on the knowledge gained, and planning further action" (Kidd \& Kral, 2005, p. 189) is one of the unifying characteristics of the otherwise heterogeneous kinds of research subsumed under the label of PAR. This feature of this work points to a broader goal, namely to add to the knowledge base that will cause practical changes and improvements in the field of language pedagogy. This is another commonality with the PAR community, which puts a large emphasis on taking action. A third common assumption that situates this study in the framework of PAR is the focus on agency (Kidd \& Kral, 2005, p. 188). Setting the emphasis of this research on the learners' views of autonomy is an attempt to create future avenues for language learners to make their voices heard in the planning of language curricula.

\section{Professional Significance of This Project}

This study is carried out assuming that the learning and the teaching of foreign languages will stay an important field of research in an ever more connected world. Within the context of the $21^{\text {st }}$ century learning goals (Partnership for $21^{\text {st }}$ Century Skills, 2011), world languages are listed among the core subjects. Learning a foreign or second language also 
addresses learning and innovation skills like creativity and innovation, as well as communication and collaboration. The psychological capacities involved in language learning and learner autonomy are furthermore reflected in the area of life and career skills, which include flexibility and adaptability, initiative and self-direction, as well as social and cross cultural skills. The broad consensus on the learning of world languages as an important skill in the $21^{\text {st }}$ century stresses the ongoing need to advance research in this field in an attempt to better understand and eventually improve pedagogical practice in language education.

This study can benefit the community of language educators in several ways. First, it can serve as an example of curriculum design which can in turn provide a foundation for further development and research in the field of foreign language curriculum. The findings might also benefit other related areas of educational research, such as the field of motivation in learning. The correlation of autonomy and motivation is a hot topic in educational research, as shown by the fact that the American Educational Researcher Association (AERA) devoted an entire session of their 2010 annual meeting to this topic. It is therefore desirable for practitioners as well as researchers in the field of language education to explore ways in which the variety of interests and motivations that our students bring to the classrooms can be integrated into the foreign language curriculum. Fostering learner autonomy is one way to make progress in this direction. The recent rise in the number of publications on this topic (as pointed out by Benson, 2007) shows that many within the field of language education have recognized the potential of learner autonomy.

\section{Organization of This Dissertation}


This dissertation is organized as follows: In the first chapter, I will lay out the philosophical and theoretical foundations that are at the root of learner autonomy. While the first chapter focuses on the theoretical underpinnings of autonomy, the second chapter is a review of the literature specifically on autonomy in foreign language learning. The practical applications of autonomy in foreign language learning will be organized according to a framework developed by Benson (2001), who came up with a number of approaches in which different aspects of learner autonomy are realized. These approaches consist of (1) resourcebased approaches, (2) technology-based approaches, (3) curriculum-based approaches, (4) classroom-based approaches, (5) learner-based approaches, and (6) teacher-based approaches. Definitions as well as studies that provide examples of these approaches will be given in chapter 2. I will also discuss other factors connected to the implementation of learner autonomy, such as inevitable changes of the teacher and learner role, and the link between autonomy and motivation. Based on the review of the literature, I will explain the design of this present study in the third chapter. Chapter 3 also includes an explanation of how the nature of the construct of autonomy, as well as the guiding research questions, lend itself to a mixed methods approach. This includes an explanation of the epistemological assumptions underlying this research. It is my hope that this study will help to start a discussion and a time of experimentation aimed at transforming college-level foreign language instruction in the United States and thereby play a part in elevating institutional foreign language learning to another level. 


\section{Chapter 1}

\section{Philosophical Foundations of Learner Autonomy}

A large portion of the work that has been done in the field of autonomy in foreign language learning can be divided in two broad categories. One category is primarily concerned with the conception of the theoretical notion of autonomy, which includes questions of philosophy, definition, structure, and possible effects of autonomy. The second category includes work that aims at practical applications of autonomy in foreign language learning. Teachers and researchers who have done work in the latter category are concerned with ways of implementing autonomy in foreign language learning in different ways in teaching practice and the effects of this implementation. The focus of this chapter will be on the first category, while the practical applications of autonomy in foreign language learning will be the subject of the second chapter of this dissertation. The connection between the two areas of research has been made clear by Benson (2001), who stated "that our decisions will be more satisfactory to ourselves and to our learners if the philosophical and political grounds on which they are based are made explicit" (p. 46). Hence, it is these underlying foundations that I will now turn to.

Much of the initial work on learner autonomy in adult education is based on the ideological foundation of democratization and participation. Everyone who is interested in these also needs to critically evaluate power structures in institutional settings, in this case the power structures at work in higher education. One of the writers who have made these topics prominent in the field of education is Paulo Freire. According to researchers in the field of autonomy in language learning (e.g., Benson, 2001; Gremmo \& Riley, 1995), Freire's work 
contributed significantly to the intellectual groundwork on which the idea of autonomy emerged and continues to develop.

\section{Freire's Pedagogy of the Oppressed}

The underlying assumption of Freire's (1970) arguments in Pedagogy of the Oppressed is the existence of two groups, the oppressed and their oppressors. The oppressors have the power to control the circumstances to which the oppressed are merely left to react. One of the reasons for the continued existence of these two groups, according to Freire, is the fact that "the oppressed, having internalized the image of the oppressor and adopted his guidelines, are fearful of freedom" (p. 31). He therefore calls for conscious reflection on the circumstances that create the inequalities of the status quo in order to become fully aware of and eventually overcome these power differences.

Freire (1970) states that one method used by the oppressors to maintain and secure their position is the "banking" concept of education (p. 58). By this he means the view of education where the teacher "deposits" knowledge in the students, who merely hold the knowledge like containers. This view is common in many areas of higher education, especially in large introductory courses where the students have to know a certain amount of content at the end of the semester. The instructor's responsibility is to make sure that the students hold the required amount of knowledge by the time of the final exam.

Freire (1970) presents alternatives to the banking concept. In his framework, which sees true education as essentially dialogical, the program content is constituted and organized by the students' view of the world (p. 101). He claims that "it is inadmissible to present pictures of reality unfamiliar to the participants" (p.107), and concludes that the dialogical nature of 
education begins with thematic investigation into the learners' life situation and needs (p. 112). This close relationship between what is happening in the classroom and the life world of the students is a crucial aspect of learning that has also been emphasized by John Dewey (1966), wrote that the "learning in school should be continuous with that out of school" (p. 358). A more recent conceptualization of this very ideal can be found in the work of Moll, Amanti, Neff, and González (2005). They developed the notion of Funds of Knowledge as a tool to connect classroom learning and the learners' home life, in particular in the context of Mexican communities. In line with the claims of Freire and Dewey, the purpose of their work was to "develop innovations in teaching that draw on the knowledge and skills found in local households" (Moll, Amanti, Neff, \& González, 2005, p. 71). The thoughts of practitioners like Moll et al. and Dewey have also been influential in the conceptualization of autonomy. Thus Benson (2001) wrote that "Dewey's view of education is a precursor of the view that informed the early Council of Europe work on autonomy in language learning" (p. 25).

Freire's claims have implications that go beyond the particular context in which his writings originated. His work continues to have a strong influence in the field of educational research. How do his claims translate to the context of learning in American institutions of higher education? The gap between Freire's far-reaching political claims and the specific context of this study has been bridged by Janne, who stated that the underlying idea of autonomy is to move from man "product of his society" to man "producer of his society" (as cited in Holec, 1981, p. 1). The underlying idea is that the subjects who are in a specific situation should have the power to influence and shape their circumstances in this specific situation. While Freire wrote about Brazilian peasants who were to be educated to become independent 
and self-determined farmers, Holec and his fellow researchers apply these principles to foreign language learners, who are to become independent, intrinsically motivated, and thus more successful, learners of their target language.

Looking at the reality of learning at American higher education institutions, at least at the undergraduate level, it is obvious that stakeholders in the field are still ways away from putting these principles into practice. First, learners, at least in introductory classes, are presented with material on whose selection they have essentially no influence. Usually, content as well as materials are preselected by the curriculum designers, the teacher or program coordinator, or just by way of being included in a textbook. At the end of a course, a certain amount of content or a certain number of chapters in the textbook have to be completed. The resemblance with the "banking" concept of education is obvious, since all the learners are left to do is absorb the content presented to them. Teachers who want to align their instruction with the background and interests of their students have only few opportunities to do so, since time is limited and the material is already selected, before the students and the teacher get to know each other. Second, the reasons why students want to learn a particular content are often neglected. For example, when deciding to learn a new language, most students have specific reasons for that choice, for example learning more about their family history, being able to communicate with their grandparents, or getting a better understanding of their major field of study. Because of prescribed curricula, students do not have the power to choose to pursue these interests in their learning process. The "investigation into the learners' life situation and needs" (Freire, 1970, p. 112) does not take place. 
A framework to put Freire's philosophy into perspective within the context of language teaching has been developed by Ribé (2003). He conceptualized three perspectives on autonomy which are located on a convergence-divergence continuum. The perspective closest to Freire's ideal of education is called the convergence-divergence position. According to this position, autonomy is manifested in the learners' power to control the entire process of learning, from curriculum design to final outcomes and assessments of learning. Proponents of this position support "fully-developed forms of autonomous learning, like creative project work, where negotiation leads to an end-product which is almost totally system- or learnerdependent and unpredictable" (Ribé, 2003, p. 15). On the other end of the continuum, Ribé sees the convergence position. According to this perspective, learning is mainly shaped by institutional guidelines over which the learners do not have control, yet there is room for choices. It stands for a pedagogy that is, according to Ribé, "opening spaces to areas of personal choice having to do with individual differences, while at the same time providing the safety of a pre-established curriculum" (p. 14). Considering the form of basic foreign language programs at American institutions of higher education it needs to be stated that even the convergence position would be a decent step towards greater autonomy for language learners.

Notions like empowerment of the learner, learner centeredness, and participation are central in Freire's writing. These concepts were subsequently transferred to the emerging theory of autonomy in language learning. Freire's main contribution to the theory of autonomy "lies mainly in its emphasis on the need to address issues of power and control in the classroom within broader social and political contexts" (Benson, 2001, p. 29). In order to arrive at a deeper 
understanding of the distribution of power in the classroom context, a closer look at the work of Michel Foucault, who is widely known for his work on this topic, will be useful.

\section{Foucault's Discipline and Punish}

Compared to Freire, Foucault approaches the issue of institutionalized power from a judicial perspective. In Discipline and Punish (1995), he describes the historical changes in the judicial and educational systems and how these developments have led to the birth of prisons and schools as people today know them. Of central importance to his history is the way in which power is manifested in society. He sets out by arguing that in the $17^{\text {th }}$ and early $18^{\text {th }}$ century, public executions were a political ritual - a ceremony through which the power of the ruler was manifested (pp. 47-48). The way in which public executions were "put on" was to reactivate the power of the ruler who had been insulted by the breaking of the law. The liturgy of torture included the parading of the condemned through the streets, a ring of soldiers around them, and the most brutal forms of death one can imagine. Over the course of the second half of the $18^{\text {th }}$ century however, there were several movements wanting to reform the judicial system. According to Foucault, excess cruelty was not the primary reason for the call to reform, but rather an inefficient economy of power (p. 79). Precisely, the inefficiency lay in the fact that the political apparatus of the monarch had to make big efforts only to achieve a small impact in terms of manifestation of power. In fact, even at the public executions, which were staged solely to demonstrate to the people who had the right to rule, riots sometimes broke out when people in the crowd disagreed with the verdict and wanted to show solidarity with the condemned. Thus, the executions sometimes had the opposite of the intended effect; they became an opportunity for the people to challenge the ruler's primacy of power. 
Consequently, a new economy and technology of power to punish was needed (Foucault, 1995, p. 89). It was supposed to be minimal for the one who was punished (at least compared to the public executions of the $17^{\text {th }}$ and early $18^{\text {th }}$ century) and, in order to prevent imitation, maximal for the one who imagined it. This meant that the focus of power shifted from the body to the mind. Ultimately, the demands of the new economy of power resulted in the birth of prisons as they are known nowadays. This "political anatomy of power" (p. 138) can also be found in other institutions, for instance in hospitals and schools. Foucault gives several examples of how power is manifested in these institutions. One refers to the physical arrangement of spaces. In what Foucault calls panopticism, the ruler, or for the purpose of this work the teacher, is positioned so that all students can be seen. The students in turn can see the teacher, but not their classmates. One reason to organize classrooms in this way is to avoid overcrowding. It also has the effect that the students are constantly aware of the fact that the teacher is able to see them and that they have to act in a way that is appropriate to the setting. In today's educational settings, the students know (even though they might not seem like it) that they are not supposed to cheat, text, or chat with their neighbor, unless the teacher tells them to do so. This gives the teacher the power to keep the students disciplined and on task. The constant awareness of being seen by the teacher results in self-surveillance, which in turn means that the teacher does not constantly have to enforce the disciplinary rules that are expected. The result of the panopticon and self-surveillance is a shared understanding of what appropriate instruction (i.e., teaching and learning) is. This concerns, for example, the types of activities that are done in class, the duration of individual activities, and the interaction of the teacher's questioning and the students' answering. It leads to another way to establish 
discipline: The "genetic" technique (p. 167), referring to the organization of time and the imposition of exercises. Both concepts are essential to the trade of teaching, for it is important to time and sequence exercises and activities well in order to deliver coherent instruction. In the field of education, many people would agree that a good teacher makes efficient use of time in terms of completion of exercises. According to Foucault, the timed sequence of presentation of content, practice of concepts, and application of newly learned material is also a way of instilling discipline. It is a procedure that is to be followed by teachers and students when they are in school.

When combining the different aspects of the mechanics of power as described by Foucault, it is evident that they are still at work in classrooms and lecture halls of higher education institutions. In introductory classes, a predestined amount of content is worked through in a preset sequential order in a fixed amount of time. In all institutions of higher education, these are mechanisms placing professors, lecturers, language teachers, and students in particular power relationships. These relationships can negatively influence the motivation of students when they have decided that they want to learn a certain language, but have in fact little power to decide how they want to go about this task (Dickinson, 1995). While it needs to be acknowledged that some of the mechanisms of power cannot be overcome because they are inherent to the institutional context (for example the duration, location, and size of a class), the concept of autonomy can be applied in ways which alter other variables in power structures. A central part of the work on autonomy is concerned with these ways to alter the traditional distribution of power among the "participants" in education.

\section{Edelsky's With Literacy and Justice for All}


In an institutional context like the one conceptualized by Foucault, the learners are told what to do and how to behave. Due to their self-surveillance nobody even has to tell them anymore, because they already know how to act and what to do just by being in a classroom or lecture hall. According to Edelsky's (2006) view of literacy, this makes them objects. However, according to Edelsky it ought to be the goal of education to see and treat students as subjects, which she describes as an individual "making text meanings with considerable control over one's own reading [and writing] in events that are about something other than instruction for instruction's sake or evaluation for evaluation's sake" (p. 130). This contrasts with the banking concept of education as well as the view of education as panopticism, but corresponds with Freire's idea of the dialogical approach. Edelsky sees the reason preventing students from being seen as subjects in a corporate agenda which has shaped school curricula and continues to do so. This has changed learning in schools in a way that mostly focuses on scanning text for facts in order to use these skills in the technology driven economy of the $21^{\text {st }}$ century. As a literacy theorist, Edelsky is concerned with breaking the political power structures between corporate interest groups, government, and curriculum designers, much as Freire was concerned with breaking the cycle of oppression through his pedagogy of the oppressed. Both, Freire and Edelsky, see education dominated by one group or discourse (the oppressors or the corporate education agenda), causing a disadvantage to a subordinate group (the oppressed or students who do not conform to the prescribed way of learning). Both offer ways to change these social circumstances; Freire in the form of the dialogical approach, Edelsky in the form of whole language. 
The political stance of whole language is that "systemic social inequality is undesirable" and that "education must work to end rather than to perpetuate a stratified society" (Edelsky, 2006, p.165). Whole language does not mean that teachers need to use particular instructional methods, but it does combine certain beliefs or characteristics under its umbrella, such as access to local libraries, giving primacy in reading instruction to meaning, using alternative sources as reading material other than textbooks, using authentic texts for communicative purposes, and honoring individual differences. These values are meant to facilitate inductive learning that is embedded in a context that is meaningful to the individual learner. They stand in contrast to deductive phonics-based learning, which begins with isolated, decontextualized parts of information in order to arrive at a larger structure (for example, combining phonemes to form a whole word, or discrete parts of speech to form a complete sentence). Some of the beliefs of whole language relate specifically to reading instruction in the first language while others can be expanded easily into the area of foreign language education, for example the individuality of the learning process and the use of alternative, especially authentic resources as learning material. Through the inclusion of technology in classrooms, especially the use of authentic materials has become much easier for teachers.

The work of Freire, Foucault, and Edelsky plays out in learner autonomy in that it challenges and aims to overcome the imbalance of power by making the needs and interests of the learners the driving force of curriculum. For example, one can call into question why classrooms are arranged with the teacher in the front of the room, or why only certain people have the power to decide what content is important enough to be part of the curriculum. Schmenk (2005) has traced back these central aspects of autonomy to the European 
enlightenment. Connecting the tenets of the enlightenment and critical pedagogy, she writes that "one often encounters pedagogies focusing on critical reflection, emancipation, and empowerment-all of which are explicitly or implicitly linked to an education for autonomy" (p. 109). The actual implementation of autonomy in formal educational contexts is complex, given that they are traditionally characterized by a rigid power structure. Given these complexities, a shared understanding of the meaning of autonomy in the specific context of foreign language learning is necessary.

\section{Defining Learner Autonomy}

According to Holec (1981), the ability to take charge of one's own learning entails the responsibility for all aspects of the learning process, namely the determination of learning goals, definition of the content of learning, selection of methods, monitoring of the process of language acquisition, and assessment of one's achievement. After Holec's initial definition, Leni Dam (as cited in Sinclair, 2000) contributed what has become known as the "Bergen definition": Learner autonomy is characterized by a readiness to take charge of one's own learning in the service of one's needs and purposes. This entails a capacity and willingness to act independently and in co-operation with others, as a socially responsible person. (p. 6)

While Holec and Dam seem to be concerned mostly with the organization of the learning process, Little's definition (as cited in Benson, 2001) aims more at cognitive processes involved in the development of learner autonomy:

Essentially, autonomy is a capacity - for detachment, critical reflection, decision making, and independent action. It presupposes, but also entails, that the learner will develop a particular kind of psychological relation to the process and content of his learning. The 
capacity for autonomy will be displayed both in the way the learner learns and in the way he or she transfers what has been learned to wider contexts. (p. 49)

Based on these definitions, Sinclair (2000) has drawn several conclusions. She stated that autonomy is a capacity that involves the learner's willingness to take responsibility of their own learning. Also, Sinclair claimed that complete autonomy is an idealistic goal. Instead, it is something that exists in unstable and variable degrees on a continuum from teacher-controlled to learner-controlled environments. Furthermore, autonomy requires reflection on, and the ability to make decisions about one's own learning process. Sinclair also points out that "autonomy has a social as well as an individual dimension" (p. 11). Given the common association of autonomy with concepts like independence and individuality, it is important to emphasize the social aspect of learner autonomy. Most of the researchers in the field relate the social aspect of learner autonomy (i.e., the aspect of autonomy that is realized in personal interaction) back to the Vygotskyan principle of the zone of proximal development. Vygotsky (1978) stated that

An essential feature of learning is that it creates the zone of proximal development; that is, learning awakens a variety of internal developmental processes that are able to operate only when the child is interacting with people in his environment and in cooperation with his peers. (p. 90)

This view is supported by Little (2007) and Benson (2001), who agreed that learner autonomy is not just a skill of the learner, but essentially a product of an ongoing process of interaction between the learners and the teacher. Marsh, Richards, and Smith (2001), concluded their account on learner autonomy in higher education declaring that 
Our search for 'independence and autonomy' in learning has led us to acknowledge the need to re-frame our original educational philosophies towards the recognition that learning arises from collaborative and co-operative activities either in groups or from the study of the ideas and discoveries of others. (p. 394)

While autonomy has an important social dimension, it also has political implications that are dependent on the particular learning context (Sinclair, 2000). The many different facets of learner autonomy have sometimes resulted in contradictions in the literature. While Little (2007) stated that "learner autonomy is the product of an interactive process in which the teacher gradually enlarges the scope of her learners' autonomy by gradually allowing them more control of the process and content of their learning" (p. 26), Pennycook (1997) opposed this view that reduces autonomy simply to "a matter of handing over the reigns, of giving students greater control over the curriculum, of giving them greater control over or access to resources." (p. 46) Pennycook furthermore criticized that autonomy that is merely seen as the teachers generously giving students more power over their learning does not encourage students to question the status quo and operates with a reductive version of power. In her observations, Pennycook refers to literature on critical pedagogy (Freire, 1970). The goals laid out in the original literature on critical pedagogy aim beyond the scope and the context of this study, which is why I will use a definition which might be criticized by writers like Pennycook, but builds on the other literature described above.

Based on the theoretical foundations discussed above, a working definition of learner autonomy for the present study will be this: Learner autonomy is an ever increasing awareness of one's own learning process, which is achieved through negotiation with others and enables 
learners to make their own decisions as to what goals, contents, and methods are most beneficial for their learning. In light of this definition, students with a high degree of learner autonomy could be characterized as follows: They are aware of their personal learning goals and select activities that are helpful in order to achieve these goals. They are aware of their own content interests and preferences and adapt the procedure and process of learning accordingly. They also know which format of activity and which learning method is most beneficial for them. Moreover, they use, but do not rely on, the teacher's instruction and suggestions and evaluate them on the basis of their own understanding of their personal learning preferences.

\section{Conclusion}

The variety of definitions shows that learner autonomy can be conceptualized in different ways and on different levels. Consequently, there are also different approaches aiming at its development. Critical theory, as informed by the writings of Freire and Foucault, form the very foundation of the concept of learner autonomy. They have emphasized that "knowledge is not a neutral reflection of objective reality, but rather expressing the interests of different social groups" (Benson, 1997, p. 22). It is this notion that necessitates a new understanding of the roles of teachers and learners, if a pedagogy that is based on equal opportunities for knowledge construction is to be accomplished. The ways in which this is to be realized differ considerably. Educators like Wenden $(1995,2002)$ have emphasized that learners need to be trained to take more responsibility in the learning process. Benson (1997) has described these approaches, according to which autonomy is seen as a capacity that needs to be developed, as "psychological versions of autonomy" (p. 19). He claimed that psychological 
versions of autonomy draw on constructivist theories of learning and stand in contrast to political versions of autonomy, which build on critical theory. Benson also criticized that psychological, along with what he describes as technical approaches to autonomy, neglect the political dimension of autonomy which was originally emphasized by the proponents of critical theory. This tension, however, might be a constant feature of any theory of learner autonomy. If learner autonomy is to be fostered in institutional education settings, both the political as well as the psychological version of autonomy will continue to play a role. Although the political outcomes of learner autonomy are still relevant, teachers who attempt to create a learning environment which allows students to develop their autonomy as individuals and learners also need to be concerned with the particulars of instructional methods which encourage this development to take place. In the second chapter, I will turn to these practical issues involved in the development of learner autonomy in foreign language learning. 


\section{Chapter 2}

\section{Learner Autonomy and Foreign Language Learning}

\section{Beliefs About Language Learning}

It has been emphasized in the literature that learners' as well as teachers' beliefs about the nature and the process of language learning play a key role in readiness for autonomy (Cotterall, 1995). Because these beliefs can be seen as a starting point, something that exists prior to a specific learning situation and that learners bring to the classroom, it is feasible to look at literature on beliefs before looking at practical applications of learner autonomy.

The rationale for the central role of learner beliefs has been provided by Cotterall (1995), who contended that learner beliefs are important for planning autonomy "because the beliefs and attitudes learners hold have a profound influence on their learning behavior" ( $p$. 195). Therefore, Cotterall carried out a study where she investigated the beliefs of 139 adult ESL learners. She collected data through a self-developed questionnaire and subsequently analyzed the data using factor analysis. The factors identified herewith were role of the teacher, role of feedback, learner independence, learner confidence in study ability, experience of language learning, and approach to studying. One exemplary detail of Cotterall's findings was that many of the participants agreed with statements like "I like the teacher to tell me what my difficulties are" (p. 197) or "I find it helpful for the teacher to give me regular tests" (p. 198). While the first statement concerns the role of the teacher, the latter clustered with beliefs about the role of feedback. Cotterall claimed that students who agreed with these statements will have a hard time becoming autonomous learners. It is therefore "an essential foundation of learner autonomy" (p. 203) for teachers to be aware of the beliefs of their students, so that 
they can align their instruction and level of support, at least in the beginning stages, with the assumptions of their students.

Gan (2004) has conducted a study which can further illuminate the conclusions drawn from Cotterall's (1995) work. Gan explored the beliefs and learning strategies of 357 Chinese learners of English. In a first step, a self-designed questionnaire was used to investigate learner attitudes and strategies specific to self-directed language learning. In a second step, the attitudes and strategies were correlated with test scores on a standardized English proficiency test. In the study, the attitudes towards self-directed language learning were divided in four factors: (1) attitudes towards the role of the teacher, (2) attitudes towards the role of the learner, (3) perceptions of confidence and abilities to carry out self-directed language learning, and (4) general orientation towards independent language learning. Gan found that "students appeared to predominantly value the learner's role in language learning" (p. 395). This can be due to the fact that the participants, by the time of the study, had learned English for 8 eight years, assuming that learners increase in degree of autonomy as they progress in their language learning. When looking at correlations of beliefs and the participants test performance, the study revealed some surprising results, namely that positive attitudes towards self-directed language learning were not significant predictors for students' performance on the standardized test. Thus, Gan concluded that "positive attitudes [...] are not sufficient for the development of language proficiency" (p. 403). Furthermore, it was stated that "students need to have both the right attitudes and skills to be successful in language learning, and skills in cognitive learning and effort-management in particular" (p. 403). Even though Gan did not 
establish a direct connection between attitudes and test performance, the importance of the teacher role as a factor of students' beliefs established by Cotterall (1995) was confirmed.

\section{Teacher-Based Approaches}

The role of the teacher. Several researchers have acknowledged that teachers play an instrumental role in the development of autonomy within their learners (Breen \& Mann, 1997; Ho \& Crookall, 1995; Little, 1995; Smith \& Vieira, 2009). Also, "the ever-increasing necessity for teaching students how to become independent and autonomous learners [...] changed the traditional ideas about language teachers' roles" (Yang, 1998, p. 128). What kind of role must teachers assume to be as effective as possible in this capacity? Little (1995), as well as Burkert and Schwienhorst (2008) argue that teachers must become autonomous themselves, in order to help their students to develop as independent and responsible learners. This can be achieved by understanding the curriculum as the teacher's own curriculum - a curriculum which is inevitably shaped by the teacher's personality, background knowledge, and experience. Being aware of the personal nature of the curriculum makes it possible to determine areas which provide room for learner autonomy. These will be areas which lend themselves to negotiation of content, materials, and activities, which in turn will foster learner responsibility.

The point of negotiation leads to dialogical interaction (Freire, 1970) between the teacher and the students. This interaction of negotiating is an integral part of learner autonomy and thus part of the role of the teacher and learner. It requires a change of traditional learner and teacher roles. Ciekanski (2007) claimed that this change in roles also requires new terminology. She stated that "the educational relationship included in the term teacher is no longer adapted to the definition of the autonomous learning relationship" (p. 113). Given this 
claim, she prefers the term "adviser" in her writing. In one of her studies, she aimed to "determine the nature and the role played by the specific relationship established between adviser and learner in relation to the fostering of autonomous learning" (p. 113). The context in which the study was conducted was a language resource center where students could meet with advisers on a voluntary basis. In respect to the role of the adviser, she found that "advisers assume multiple pedagogical roles when supporting autonomous language learners, and they switch between these roles frequently" (p. 123). Ciekanski called the different roles postures. From the analysis of her data she found that advisers frequently switched between the advising posture, tutoring posture, teaching posture, companion posture, and accompanying posture. The notion of the teacher role as being multi-faceted has been confirmed by Yang (1998), who stated "new roles for teachers include helpers, facilitators, advisors, and guides" (p. 128). Yet another confirmation of this finding is provided by the work of Chiu (2008), who carried out a qualitative analysis of the content of teacher emails written over the course of an online EFL class. Chiu identified that the teacher was taking on different roles in the online conversation with the students. It was found that the teaching role diminished over the course of the class and that the counseling role, which was "essential" (Chiu, p. 106) to the development of learner development, persisted in the communication. The change in the role of the teacher, from the traditional notion of provider of knowledge to one of facilitator of and advisor in the learning process has also been treated by Voller (1997), and by Akaranithi and Panlay (2007). In the more recent literature on learner autonomy, teacher education for the development of learner autonomy has increasingly become a focus of interest (Dam, 2008; Vieira, 2007; Smith \& Vieira, 2009; Chiu, 2008). This development in the research is a necessary 
next step, because teachers who themselves have never learned to be autonomous learners will have a harder time to establish teaching principles that require their students to take responsibility for their own learning. Furthermore, in order to be effective as a language teacher in fostering autonomy in our learners, it is necessary to be able to empathize with them and to have a sense of how they must feel in their situation as autonomous learners. Given the increasing acceptance of learner autonomy as a desirable goal of language education, the question about particular competences and conditions required for teachers to promote learner autonomy (Smith \& Vieira, 2009, p. ) thus becomes more pressing.

Teacher education for autonomy. The fact that learner autonomy and teacher autonomy are linked is widely acknowledged in the literature (see Kohonen, 2003; Lamb \& Reinders, 2008; Sinclair, McGrath, \& Lamb, 2000; Vieira, 1999; Vieira, 2007; Vieira, 2009; Young, Hafner, \& Fisher, 2007). McGrath (2000) defined teacher autonomy as self-directed professional action and freedom from control by others. An exemplary view of teacher education for autonomy is presented Little's (1995) paper, which he concluded with the words that "teacher education should be subject to the same processes of negotiation as are required for the promotion of learner autonomy in the language classroom" (p. 180). The aspect of negotiation has been taken up by Voller (1997). To the principle of negotiation he added (1) the assumption that an autonomous approach requires a transfer of control to the learner, and (2) the need of teacher self-monitoring and reflection.

In fact, there are certain values that keep recurring in the literature and thus seem to represent a consensus among researchers as to what needs to happen in teacher education for autonomy. These values are reflection, collaboration, and action research. An example of how 
the principles of reflection and action research can be implemented in a teacher education program was presented by Vieira (1999). She described the Pedagogy for Autonomy project, a Portuguese teacher education project established based on the premise that "reflective teaching and learner autonomy are perhaps like the two sides of the same coin" (p. 151). The project had two goals. The first was to use a reflective approach of teacher education in order to prepare secondary language teachers for the implementation of a pedagogy for autonomy. The second was to use action research projects to encourage learner autonomy in EFL learning. The program extended over a period of three years and was broken up into three stages: preparing for innovation, preparing for action research, and doing action research (i.e., implementing innovation). At the first stage, the teachers attended a course which focused partly on "the critical analysis of information on autonomy as a pedagogical goal in EFL teaching/learning contexts" (p. 152). The purpose of the second stage was to guide the teachers in the development of action research projects. During the third stage, the teachers implemented their action research project in one of their classes. Vieira evaluated the Pedagogy for Autonomy project based on the research journals written by the teachers, project reports, and questionnaires. Overall, the results (even though the process of data analysis is not specifically described) showed that the effects on learner training towards autonomy and teacher training towards reflective practice are very encouraging. The students demonstrated a more effective use of learning strategies and a better understanding of what it means to learn a foreign language (p. 154). Also, the teachers agreed on the effectiveness of the collaborative action research projects. The importance of collaboration in teacher education has been highlighted also by Kennedy and Pinter (2007). Smith (2000) has confirmed the value of 
"collaborative reflection" on second language learning and pointed out its significant effects on his own teaching and teacher education work (p. 98). On the whole, the work that has been done points to the necessity of teacher autonomy in order to make progress towards a sustained pedagogy for learner autonomy. Key principles for teacher education thus seem to be collaboration and ongoing self-reflection, for example by means of action research. To some extent these principles are already part of teacher education programs. Maybe all that is missing is a shared commitment to autonomy?

\section{Learner-Based Approaches}

As it has been described in the introduction, learner autonomy is defined as the students' ability to take control over their own learning. In relation to this, "learner-based approaches focus directly on the production of behavioral and psychological changes that will enable learners to take greater control over their learning" (Benson, 2001, p. 142). Sheerin (1997) distinguished two ways in which this can be attempted: through learner training and learner development. While learner training is described as the teaching of a certain skill set, for example how to use a dictionary most effectively or how to develop techniques to learn vocabulary most effectively, the term learner development is used in reference to cognitive and affective skills that help learners to become more independent and self-directed. Importantly, Sheerin posits that "learner development is not something that teachers do to learners, although there may be ways the process can be encouraged and facilitated" (Sheerin, 1997, p. 60). Recently, the different approaches have come to be summarized under the term learner development (Wenden, 2002), which is generally defined as the process "to help learners learn how to learn" (Wenden, 2002, p. 34). 
Learner development. As far as skills and competencies which should comprise learner development are concerned it is useful to look at some of the literature on successful language learners. One of the most influential works on this topic has been conducted by Rubin (1975). Rubin posited seven characteristics of good language learners: They (1) are willing and accurate guessers, (2) have a strong drive to communicate, (3) are rarely inhibited, (4) attend to form, (5) use as many opportunities as possible to practice their language skills, (6) monitor their own speech and the speech of others, and (7) attend to meaning (pp. 45-47). Looking at this list gives the impression that successful language learners simply do everything. In order to make these findings more applicable and useful in terms of autonomy the work of Gremmo and Riley (1995) is helpful. In response to research like the one carried out by Rubin, they stated that the aim of learner training is not to transform all learners into 'successful' language learners $[\ldots]$, but rather to help learners to come to terms with their strengths and weaknesses, to learn a language efficiently in ways which are compatible with their personalities. (Gremmo \& Riley, 1995, p. 158)

The awareness of one's own strengths and weaknesses leads to the realm of metacognition. Without explicitly mentioning metacognition, Rubin's (1975) sixth characteristic of successful language learning relates to this part of learning. He stated that "part of his [the successful language learner's] monitoring is a function of his active participation in the learning process" (p. 47). Monitoring can also be seen as self-assessment, which is one of two parts of the metacognitive realm of language learning, next to self-management (Rivers, 2001). According to Victori and Lockhart (1995), metacognitive knowledge applied to second language learning "refers to the general assumptions that students hold about themselves as learners, 
about factors influencing language learning and about the nature of language learning and teaching" (p. 224). In their study they focused learner training on metacognition and combined it with contact classes (traditionally instructed classes) and self-directed learning in resource centers. They found that this resulted in "some degree of autonomy" (Victori \& Lockhart, 1995, p. 232) in 40 out of 41 cases and that the learners perceived an increased rate of progress. Nevertheless, the importance of metacognition still does not answer the question which actual skills should be part of learner training. Ho and Crookall (1995) noted that five skills are considered key to self-directed or autonomous learning, namely (1) choosing instructional materials, (2) settings learning objectives and prioritizing them, (3) determining when and how long to work on each objective, (4) assessing progress and achievements, and finally (5) evaluating the learning program (p. 236). Any pedagogical approach aiming at fostering learner autonomy needs to allow learners to some extent to practice these skills. Obviously, there are many different ways of achieving this.

Pedagogical applications. One tool to aid learner development is the use of learning diaries or task sheets (Grima, 2000; Porto, 2007). These tools can be used to assist learners in learning to reflect on their learning process and find out what kind of activities work best for them. They are also easily integrated into work cycles, where they can be used at the end of a sequence to self-evaluate the effectiveness of the most recent work.

One example of a learner-based approach is Natri's (2007) report of the implementation of a self- and peer-evaluation system in a French class at a university in Finland. Natri's goal was to raise her "students' awareness as learners and their ability to evaluate their own language skills" (p. 109). The evaluation system consisted of different parts: First, at the beginning of the 
course, the students were asked to write a short history of themselves as language learners. In this history, they addressed questions like how long and where they had studied French. The second component was the students' self-evaluation of their linguistic skills in relation to the Common European Frame of Reference (the European equivalent to the proficiency guidelines of the American Council of Teachers of Foreign Languages). They were given a self-assessment grid which gave criteria according to which the students could determine their proficiency level in each linguistic skill (in this case, the skills were reading, listening, spoken interaction, spoken production, and writing). Also, at the beginning of the class, Natri explained to the students the desired linguistic proficiency in reference to the common proficiency guidelines.

This self-evaluation served the purpose of learner autonomy in different ways. It helped the students to become more aware of their own strengths and weaknesses (i.e., maybe they thought themselves to be strong in reading comprehension and weak in spoken interaction). The fact that the students were told which proficiency level was desired for the class, helped them to set realistic goals for themselves. As Natri (2007) points out, the students' selfevaluation also benefits the teacher in that it provides valuable feedback on the students' perceived strengths and weaknesses and their history as language learners. It would be relatively easy to include in their history as language learners (given that they have experience learning a second language) questions about their preferred types of activities and modes of language learning. This feedback could in turn be used for the further development of an ideas and activity bank that serves as a starting point for the work cycle. As a result of her selfevaluation system, Natri found that students generally rated their reading skills higher than their listening skills, although this might be due to factors specific to the Finish education 
system. She also reports that "from the beginning of the course and the first self-assessment, students pay more attention to their weaker skills and tend to devote more time to developing them" (Natri, 2007, p. 114). The ability to evaluate and self-direct one's own process of learning is confirmed by other studies as well (Porto, 2007; Rivers, 2001). While Rivers (2001) did not implement any instruments for learner development, he used survey data collected from experienced language learners to examine their metacognitive behaviors. The results indicated that experienced language learners have a high tendency toward learner autonomy, "based upon the learners' self-assessments of learner style, learning strategy preferences, and their progress in the language" (Rivers, 2001, p. 287). It has also been shown that teachers play a significant role in raising their students' awareness of the learning process (Ridley, 2003). Overall, this shows that learner-based approaches can well be integrated with classroom-based approaches to encourage learner autonomy.

\section{Resource-Based Approaches}

Resource-based approaches aim at offering language learners the freedom to independently interact with language and learning resources. One of the most widely used ways of implementing a resource-based approach is through self-access. Sheerin (1997) describes self-access as learning materials and organizational systems which are designed for direct access by learners. Alternatively, it has been defined as "a mode of language learning in which learners work without direct teacher supervision, at their own pace, and often at times of their own choosing" (Little, 2000, p. 539). Self-access learning can be a supplementary part of a language class, or it can be a course in its own right. Ideally, the learners have the power to determine the way in which they use the resources (often organized in the form of a library of 
various language learning materials and media), as well as the when and where of their learning. Thus, the potential for autonomy in resource-based approaches is high. Furthermore, resource-based approaches lend themselves to extensive use of authentic language learning materials, for example when the instructor provides a resource bank that organizes authentic materials according to topic or language skills. There have been particularly strong claims for the autonomy potential of self-access learning. Gardner and Miller claim that "self-access is probably the most widely used and recognized term for an approach to encouraging autonomy" (as cited in Benson, 2001, p. 113).

Although there has been evidence that self-access is instrumental in promoting learner autonomy, the provision of self-access learning opportunities does not automatically lead to autonomous learners. This has been shown by Darasawang, Singhasiri, and Keyuravong (2007), who studied self-access learning at a Thai secondary school. They found that several factors were at work which obstructed the development of independence and empowerment of the students. The first factor is a focus on grades. The students were assigned tasks to be completed in the self-access learning center. Their final grade was determined based on evidence that they had completed the assigned tasks. This leads to the second factor, namely that the students were not developing their own sense of direction in learning, but were merely following the teachers direction. This circumstance deprived the students to develop one of the key features of autonomy. The third factor was conflicting roles of the teacher. In this particular situation, the teachers served as the students' guides, facilitators, and counselors. As has been shown, these roles are important for teachers to help their students to become autonomous. However, the teachers in this study also served as assessors, which, according to the authors, 
stifled the increase of self-direction (Darasawang et al., p. 176). The fourth factor identified as hindering the development of learner autonomy was the fact that the teachers did not see the self-access learning center as a means to help their students becoming autonomous in their learning. They saw it only as a room for extension of class activities, where students could practice. The findings of Darasawang et al. are a good illustration of the caveat stated by Sheerin (1997). She wrote that "it is the way teachers and learners use self-access facilities which determines whether independent learning takes place" (Sheerin, p. 54). To put these findings into perspective, it is important to remember that this study was carried out in the context of secondary education in Thailand; a rather specific context. However, many of the problems identified by the authors seem to be fairly universal and are thus warnings to other language educators who want to promote autonomy through self-access learning. Given that the present study will be carried out at an institution of higher education, some of the issues identified by Darasawang et al. might be less of a problem. For example, referring to the fact that the students were mostly extrinsically motivated by grade pressure, they state that "because of the restrictions of the grade-oriented curriculum in the secondary school, making project work a requirement for students was the safest way for them" (Darasawang et al., p. 178). At a higher education institution, curriculum design is more flexible and will more likely allow reducing this factor by designing a grading system that will not interfere with the development of autonomy.

Sheerin (1997) has clearly stated what is necessary in order for self-access learning to effectively foster autonomy: First, it is necessary that learners are prepared for independent learning before they start working with self-access materials. Second, support structures need 
to be in place while they are working with self-access materials. Third, the materials provided in the self-access library should be geared towards learner independence instead of just being an extension of in-class activities which provide "teacher direction by remote control" (Sheerin, p. 59). The first of these requirements refers to the need of metacognitive or learner training, which was discussed in the part on learner-based approaches above. The second and third factors fall within the realm of resource-based approaches.

Support structures in self-access learning. The need for support structures for selfaccess learning has also been described by Toogood and Pemberton (2007), who have designed self-access courses for EFL learners at the Hong Kong University of Science and Technology. The support structures used for their courses consist of student-created language learning plans, recurring entries in a learning diary, and meetings with peers and teachers. They also introduced certain structural elements to provide more support for their students: They introduced their students to the concepts of general and fundamental language skills. The general skills are listening, speaking, reading, and writing. According to Toogood and Pemberton, problems with the general skills are caused by a lack of knowledge in the fundamental skills, which are pronunciation, grammar, and vocabulary. By introducing this concept, students are given supportive guidance in respect to areas they should focus on in their learning. The authors also introduced a framework of language practice which recommended a sequence of focused, transfer, and general practice (see Toogood \& Pemberton, p. 187). When they evaluated the support structures using questionnaires, interviews, and recorded student-teacher consultations, Toogood and Pemberton received mostly positive feedback from their students. However, more reliable research on the efficiency 
of these support structures would have to be designed so that students have the opportunity to submit feedback anonymously, because the use of interviews might prompt students to give answers they feel their teachers desire to hear (i.e., positive feedback). Nonetheless, the structures implemented by Toogood and Pemberton are examples of how learners can be supported in self-access learning.

Materials in self-access learning. According to Dickinson (as cited in Benson, 2001), three kinds of materials lend themselves to use in self-access learning: materials specifically designed for independent learning, commercially produced materials, and authentic materials. In order for learning materials to be effective in supporting independent learning, certain requirements have to be fulfilled. Reinders and Lewis (2006) conducted a study of existing quality guidelines for self-guided learning materials in general education as well as language learning. Based on their review, they constructed an evaluation checklist for self-access language learning materials. The applicability of their list was tested and validated in a later study, where staff working in a self-access center was asked to use the checklist to evaluate 25 resources (Reinders \& Lewis, 2008). The criteria of the evaluation checklist are organized in five sections: selecting the resource, accessing the parts of the resource, the learning process, learning to learn, and other features. The criteria categorized in the section "selecting the resource" address the need of directors and staff at self-access centers to quickly sort the resource into a category, for example a certain language proficiency level or in a certain position within a learning sequence. The section titled "accessing the parts of the resource" contains criteria that address the need of staff and learners to quickly find relevant parts within the resource (for example through an index, a table of contents, or a glossary). The section 
titled "the learning process" includes criteria such as objectives, examples, and answer keys provided for tasks. The fourth section, "learning to learn", aims most directly at learner autonomy. It includes the criteria (1) notes on the learning process, and (2) shows how to set goals. Considering the fact that these features are very important in making learners more aware and independent of their own learning process, it is surprising that the section "learning to learn" is so short, compared to the rest of the evaluation checklist.

The criteria developed by Reinders and Lewis (2006) can be applied to all sorts of language learning material that is to be used as part of a self-access learning program. The checklist does not contain a criteria aiming at the authenticity of learning material. Authentic language learning materials and texts are generally defined as "genuine samples of language in use not specifically produced for the purpose of language teaching" (Rüschoff, 2010, p. 125). The value of using authentic materials to promote learner autonomy has been emphasized by Little (1997), who claimed that authentic resources can help foster learner autonomy in two ways. The first is that "learners who from the beginning have been exposed to authentic texts rapidly develop confidence in the face of the target language" (Little, p. 231). These learners know that they are able to understand not only texts or activities that have been developed for language learners, but that they are actually able to understand language that is used by the target culture to communicate. This leads to the second factor, namely that "authentic texts accommodate the two-way relation between language learning and language use" (Little, p. 231). Furthermore, authentic resources can be a motivational factor for students. It makes a big difference for students to know that the language they are interacting with has real significance to a wider community (i.e., the community of target language speakers) instead of just being 
produced for their use as language learners who are not yet able to understand the "real version" of the target language. Also, it is important for students, who are often interested in the target culture at least as much as they are interested in learning the language, to know that their learning process brings them closer to the culture as it really is. To conclude, the benefits of authentic resources warrant that they play a central role in resource-based approaches to learner autonomy.

The literature on resource-based approaches reviewed in this section is by no means exhaustive, but, considering that the focus of this study is not primarily to foster learner autonomy through a resource-based approach, this section will be kept rather brief. It is also important to note that the effectiveness of resource-based approaches in developing autonomous learners has not been documented very well (Benson, 2001). It has rather been shown that the mere provision of self-access learning opportunities is not sufficient to help learners to be empowered and become more independent (Darasawang, Singhasiri, \& Keyuravong, 2007; Sheerin, 1997).

\section{Technology-Based Approaches}

Technology-based approaches are similar to resource-based approaches in their focus on learning materials and learning content. However, as the name suggests, technology-based approaches emphasize the function of technology in the provision and access to learning

material. These approaches further autonomy through the learners' independent use and interaction with technology. The potential for autonomy is given in that the way of using technology for learning purposes is always to a certain degree autonomous. After all it is hardly imaginable that a teacher would direct his students in each click they do. Technology-based 
approaches overlap considerably with the field of computer-assisted language learning (CALL). The two approaches to language teaching are not identical though, considering that not all forms of CALL explicitly aim at fostering autonomy. Gremmo and Riley (1995) raised this point as well, when stating that "CALL applications . . . are at best a useful but not essential tool, at worst thoroughly counter-productive" (p. 160).

The possible benefits of a technology-based approach have been illustrated by Schwienhorst (2003). He tried to foster learner autonomy through the implementation of tandem learning. In tandem learning, two learners of complementary L1-L2 combinations are brought together and "will then learn from each other, alternating between the role of L2 learner and L1 expert" (Schwienhorst, 2003, p. 431). This learner-expert relationship, which is also at the center of Vygotsky's (1978) model of collaborative achievement, can be established in a face-to-face situation, but constellations where the two individuals converse through email, chat systems, and video- or audio-conferencing are also common. Of particular interest in respect to the development of learner autonomy is O'Rourke and Schwienhorst's (2003) examination of metalinguistic reflection by language learners who were interacting with a tandem partner via a multi-user domain (MOO). However, he found that learners will not automatically use the possibilities afforded them by the technology. Rather, "learners will only exploit these affordances for what they perceive as good and pressing reasons - such as reviewing and correcting their L2 utterances in order to save face" (O'Rourke \& Schwienhorst, 2003, p. 56). These results show that the use of technology does not necessarily lead to the development of more autonomy, which is in part achieved through a higher degree of metalinguistic awareness. 
Another example of a study that used technology to foster autonomy was written by Luke (2006), who conducted a qualitative study in a fourth-semester university Spanish course. It has to be noted, however, that Luke used computers and material on the internet to supplement his classroom instruction. The approach is thus a hybrid version of a technologyand classroom-based approach to learner autonomy. He designed his intermediate-level Spanish course according to principles of inquiry-based learning and created several opportunities for his students to take responsibility for their own learning - one of the key aspects of learner autonomy. As part of the inquiry-based learning, a large portion of class time was devoted to students' individual projects which they had chosen from a number of content options. Over the course of a project, the students worked through an inquiry cycle. These inquiry cycles consisted of seven phases: (1) exploring the chosen topic, (2) brainstorming questions to be explored, (3) investigating multiple perspectives about the topic, (4) researching and revising, (5) assessment of learning, (6) presentation of the learning, and (7) reflection on the learning process (p. 75). Obviously, the inquiry cycles included several key aspects of learner autonomy, for example choice of content and activities, self-assessment, and reflection on one's own learning process.

Throughout the semester, Luke (2006) collected data through field notes from class observations and interviews with the students. He also used student-produced documents, like course reviews, self-assessment, and self-reflection, as a data source. The findings showed that the students' responses varied considerably. Through the analysis of the data, he identified four main themes: students' requests for more grammar and vocabulary instruction, the perception of the class as a waste of time, interest and engagement, and a different way of learning. The 
responses were thus clearly divided into negative reactions (the first two themes) and positive reactions (the latter two).

One explanation of the students seeing the class as a waste of time can lay in the fact that Luke (2006) specifically included student-directed free time as a way to foster autonomy in each class session. However, learner autonomy does not result from simply giving students free time during class, as shown by this finding. It also reemphasizes the need for learner training, if one hopes to reach a level where students are able to use self-directed free time in a productive way. Still, the fact that interest and engagement emerged as one of the "most prevalent and pervasive themes" (p. 81) from the study shows once again the effect of learner autonomy, if implemented in an effective way.

\section{Curriculum-Based Approaches}

In curriculum-based approaches to learner autonomy, the ideal underlying autonomy in language learning, namely that learners can develop the ability to exercise control over their learning, is extended from particular classroom situations to the curriculum as a whole. Thus, the fundamental question in curriculum-based approaches is: "What should be included in the curriculum to make it conducive to fostering the development of learner autonomy and to giving learners opportunities to pursue their own directions and make fruitful choices for their own learning progress?" (Trebbi, 2003, p. 170)

An example of a curriculum-based approach to autonomy is Trebbi's (2003) account of curriculum reform in Norwegian secondary schools. She contrasts the traditional curriculum, with an experience-oriented curriculum, which leaves room for learner control and flexible goal setting. Besides the aims to develop the students ability to use spoken and written modes of 
the foreign language (in this case French or German), and to develop understanding of the target culture, one of the three explicit aims of the curriculum described is to "promote pupils' insight into what it is to learn French/German and the development of their capacity to take charge of their own learning" (Trebbi, p. 172). The concept of taking control over one's own learning is also evident in the approach to learning grammar, an area many critics of learner autonomy see as one where teacher direction is essential. According to Trebbi's description, learners are to observe and experiment with grammatical structures and functions of certain words and are expected to familiarize themselves with the forms and functions of particular grammatical structures. After the implementation of the curriculum, the missing structure in respect to grammar teaching, as well as the unrealistic expectation that students would learn grammatical rules by themselves, was some of teachers' biggest criticisms of the newly implemented curriculum (Gjørven, as cited in Trebbi, 2003). Trebbi reports that five years after the implementation of the new curriculum common teacher responses were rejection, relabeling of traditional concepts, and innovative approaches. Two out of the three reaction patterns are negative. This clearly shows how difficult it is to implement principles of learner autonomy on a curricular level - a challenge that every attempt to foster learner autonomy has to stand. The difficulty of curriculum reform for autonomy has also been confirmed by Nix and Barfield (2009), who have described their experience with the implementation of a literacyfocused English curriculum at a Japanese university.

Another example of a curriculum-based approach at the tertiary level is Carson's (2010) description of the language modules curriculum at Trinity College Dublin. As in the example by Trebbi (2003), the promotion of learner autonomy (with the sub-skills that are necessary for it) 
is an explicit goal of their task-based curriculum. The language modules consist of individual and group projects, which "allow students to focus on their own interests" (Carson, 2010, p. 154). The learning projects encourage the learners to plan, reflect critically upon, and evaluate their learning process. Overall, the goal of the language program is to develop the students' communication skills. While Carson does not elaborate on the difficulties of implementing such a curriculum, her account still provides valuable information concerning options for curriculum design at institutions of higher education. For example, the ultimate goal of developing communicative competence is a commonality of many departments of foreign languages, not only in Europe but also in the United States.

One way in which autonomy can be promoted on the curricular level is through the process syllabus (Breen \& Littlejohn, 2000a). Central to the model of the process syllabus is the concept of learner control through negotiation. According to Breen and Littlejohn (2000b), the idea of negotiation in the context of language teaching is based on these beliefs: First, learning takes place in the greater societal context. Taking responsibility in the learning process is a skill that can translate to the bigger context of a democratic society in the form of participating citizens. Second, within the framework of negotiation, learning is seen as an emancipatory process instead of a process of transmission of knowledge from the powerful to the powerless. Third, learning is interwoven in social and cultural action, which means that not only what is learnt, but how it is learnt matters. Finally, in the framework of negotiation, the learner is regarded as an "active agent of his or her learning in which the interpretation and control of knowledge is an attribute of the learner" (Breen \& Littlejohn, 2000b, p. 19). 
It is clear that learner autonomy and negotiation share the same theoretical basis. Based on this understanding of negotiation, the interpretation of Slembrouck's (2000) report of the implementation of a negotiated syllabus for an EFL course at a Belgian university becomes clearer. He faced several difficulties as he found that "only very few students made use of the classroom floor for the purpose of planning [...], let alone evaluating" (Slembrouck, 2000, p. 147). Slembrouck interpreted his findings referring to a culture of silence that is gradually established among students as they go through the process of education. Confronted with these difficulties during the implementation of a process syllabus, he concluded his report wondering about what it is in a negotiated syllabus that would help to overcome the existing "speech-silence regime" (p. 149) and students' established norms of classroom behavior. One aspect worth considering for the evaluation of Slembrouck's findings is the fact that the students in his class still had to take a language exam at the end of the class. The conflict between the anticipation of an important upcoming exam and the expectation to make decisions about the structure of the class might explain the disappointing results to a considerable degree. This once more shows that learner autonomy can be implemented at the curricular level successfully, only if it is part of a coherent approach extending from the negotiation of content to the (at least partly) negotiation of assessments. Slembrouck's study is also an example of problems that can come up when the teacher's approach to teaching is in conflict with the students' beliefs and expectations. Another example that illustrates the challenges resulting from a mismatch of beliefs and expectations comes from McDevitt (2004), who taught students from Oman English. 
Curriculum-based approaches are difficult to implement, given the number of decisionmakers involved in the process of syllabus design. Especially in larger educational systems like school districts or entire states, there are powerful stakeholders who are not in favor of learner autonomy on a curricular level. For example, textbook companies have an interest in offering comprehensive textbook series that can easily be used in their entirety as a coherent all-in-one solution. Often, this is also in the interest of administrators and teachers, who have to worry less about finding and organizing appropriate learning materials. In light of these obstacles to curriculum-based approaches to learner autonomy, the significance of teacher autonomy in the development of learner autonomy has gained broad recognition (Breen \& Mann, 1997; Ho \& Crookall, 1995; Little, 1995; Smith \& Vieira, 2009). In the work on teacher autonomy, the emphasis is on the teacher's freedom to implement principles of learner autonomy without being restrained by prescriptive curricula.

\section{Classroom-Based Approaches}

Classroom-based approaches aim at introducing principles of learner autonomy to institutional contexts of education. Given the many possibilities in which autonomy can be implemented, there is a considerable amount of literature on classroom-based approaches (Legenhausen, 2003; Legenhausen, 2010; Newstetter, 2000; Nicoll, 2007; Thomsen, 2003) as well as material to support teachers who want to encourage autonomy in their students (Scharle \& Szabo, 2000). A concept that is particularly helpful in introducing aspects of autonomy in foreign language classrooms is the work cycle (Legenhausen, 2003). The work cycle approach was also adapted for the design of this study and will therefore be described in further detail in chapter 3. 
Another example is Cotterall's (2000) account of implementing learner autonomy in the classroom. In accordance with other writers in the field, she stresses that language classes aiming at promoting learner autonomy need to provide opportunities for learners to take responsibility for aspects of their own learning process. This goes along with a shift of power from the teacher to the learner and a redefinition of the roles. Cotterall arrived at five principles: (1) learner goals, (2) the language learning process, (3) tasks, (4) learner strategies, and (5) reflection on learning (p. 110). She elaborated on the implementation of each principle in two language courses. The first principle was implemented in the first class session, where the students were asked to specify personal goals in reading and speaking. Cotterall also used peer interviews to gather information about her practices. Those revealed that "few learners had experience of goal-setting or of monitoring or evaluating their learning, and that they were unlikely to acquire this without extensive support practice" (p. 112). This finding confirms the need for learner training that focuses on those aspects of strategic learning (Wenden, 2002). In order to address this need, Cotterall implemented the second principle and introduced a simplified model of language learning including the elements goals, needs, motivation, input, language knowledge and awareness, form-focused practice, meaning-focused output, feedback, and reflection. All course tasks were explicitly linked to this model. The third principle, tasks, was implemented by explicitly relating the activities in the course to the communicative goals identified by the learners at the beginning of the class. The fourth principle, learner strategies, was addressed by learners sharing language learning strategies and the teacher modeling other strategies, for example expressions for constructing paraphrases. In order to implement the fifth principle of reflection, Cotterall used techniques that were similar 
to Luke's (2006) inquiry-based approach. Thus, learners completed a journal at the end of each class session addressing questions like: What did you do today? What did you learn today? What are you going to do differently as a result of today's class? Reflecting on her application and the effect of these principles, Cotterall notes that "by making the language learning process salient, the course helped learners understand and manage their learning in a way which contributed to their performance in specific language tasks" (p. 115). Through observations of learners and the comments on the journals, Cotterall also found that the explicit link between course tasks and learner goals "resulted in an unprecedented level of motivation" (p. 115). In fact, the link between learner autonomy and motivation has been the subject of several studies and it has repeatedly been shown that learner autonomy plays a significant part in learner motivation. (Cheng \& Dörnyei, 2007; Dickinson, 1995; Dörnyei \& Csizer, 1998; Spratt, Humphreys \& Chan, 2002; Ushioda, 2003).

A second example of a classroom-based approach to learner autonomy is Nicoll's (2007) account on his restructuring of an introduction to American studies lecture course at a Japanese university. He became increasingly critical of the class' prescribed text-based syllabus and recognized that "it silenced the students" (Nicoll, 2007, p. 122). In order to effect change and give his students more control, he introduced poster sessions as a part of the class. He then used questionnaires in order to find out about the students' perceptions of this instrument and make further changes to the class. In a later semester, the students were also asked to make a summative self-assessment. Nicoll received varying, sometimes contradicting, feedback, but arrived at the conclusion that "it is in the gaps, misunderstandings, and mistakes that we can find the space to negotiate the curriculum" (p. 129). This view can serve in some respects as a 
warning for every educator who attempts to make changes towards learner autonomy. Given the degree of individual freedom that is possible in some models of classroom-based approaches, teachers have to be willing to receive different kinds of feedback (negative as well as positive) which, as Nicoll has shown, can be used to initiate further negotiation.

\section{Unanswered Questions}

Benson's (2001) system of organizing approaches to foster autonomy has proven to be useful for the purpose of this literature review of practical applications of learner autonomy. However, there are still some aspects which have not been investigated and questions which have been left unanswered. Some of these shall thus come into focus in the present study. One gap in the research so far is represented by the fact that research on autonomy has been extensive in Europe and Asia. Benson (2007) ascribes the attention to autonomy in European language education to the interest in sociocultural theory, yet points out that "autonomy is yet to have any great impact on North American language education, where sociocultural theory is strongest" (p. 34). In fact, systematic investigation of the perceptions and effects of autonomy in the context of formal higher education in the United States is rare, with the exceptions of the studies by Luke (2006) and Rivers (2001). Luke concluded his study with two specific suggestions for further research: (1) how do teachers encourage and facilitate the students' transition from traditional settings to environments that focus on learner autonomy, and (2) how can teachers support their students in using their heightened level of autonomy effectively? The present study is an attempt to contribute to the knowledge base necessary to answer these questions conclusively. 
Furthermore, research in the field "often fails to provide convincing empirical evidence that the practices associated with autonomy are effective either in helping learners to take greater control over their learning or in improving their language learning." (Benson, 2001, p. 112) While one reason for the fact that Benson's claim is still valid might be the difficulty of measuring autonomy, another reason is simply the lack of studies which specifically investigate how learner autonomy helps students to take a greater degree of control of their own learning. Benson also stated that there is a lack of research showing how learner autonomy affects language learning in terms of increase in language proficiency. In other words, it is so far not documented that learners learn a language better and faster when they are in an environment which fosters learner autonomy. Again, it is difficult and problematic to objectively measure this. Because the concept of learner autonomy is based on the underlying assumption that learners have individual interests and that they go about language learning in individual ways, it is problematic to use a standardized instrument to measure their learning achievement after a given period of time. On the other hand, measurements that shed light on the efficiency of learner autonomy in terms of language proficiency are an important area of research, if autonomy in learning is to be developed further. If a systematic investigation into learning gains reveals that autonomy contributes to better language proficiency, it would be likely that more practitioners in the field of language education would follow such an approach. Conversely, negative findings would also advance research on learner autonomy because they would indicate the need to find other ways of assessment, instigate new directions concerning the conception of learner autonomy, or point to a more realistic understanding of the potential effects of learner autonomy. 
Consequently, this study is an attempt to contribute information to these questions that have not sufficiently been researched. How can it be located within the topography of the approaches discussed in this chapter? It is in some ways a fusion of a classroom-based and learner-based approach to learner autonomy. Classroom-based in the sense that the setting for this study is the German classroom at an American university, where there is a particular time and place for the class to take place, as well as a curricular context in which this class is embedded (i.e. the university's department of foreign languages, as well as the General Education Curriculum). In order to accommodate the surrounding circumstances and the limitations they pose in regards to the level of autonomy that can realistically be implemented, the class is organized in work cycles (Legenhausen, 2003). It is a learner-based approach in the sense that it aims at emphasizing metacognitive knowledge that helps the students to become more aware of their own language learning process, their strengths and weaknesses. 


\section{Chapter 3}

\section{Methodology}

\section{Epistemological Considerations}

In the history of scientific research, the effect of the underlying worldview of the researcher on the object of study has been the topic of controversial debates. Specifically, the controversy has been about the relationship of the knower and the known. In the field of social science research, matters regarding this relationship are discussed under the term epistemology. At this point, it is a widely established consensus that the researcher's beliefs about truth and whether it can be known by humans are of central importance in the process of doing research. Bentz and Shapiro (1998) posited that beliefs about questions such as "What is knowledge?" and "What is reality?" shape how researchers do research and what they might find (p. 32). Based on Kuhn's (1996) work, Morgan (2007) discussed the issue of paradigms. Although the term paradigm is used and understood in different ways, it clearly refers to the "beliefs and practices that influence how researchers select both the questions they study and the methods that they use to study them" (p. 31). In order to give the reader of this study sufficient background knowledge about the epistemological foundation on which this study has been carried out, it is therefore necessary to elaborate on my beliefs.

I hold the belief that an ultimate truth does exist. This means that I believe that there is a fundamental truth which underlies everything that exists and that this truth can be known as well. While this is in accordance with ontological assertions of positivism (Tashakkori \& Teddlie, 1998), I also acknowledge that humans have individual ways to research and discover the truth. This is in accordance with Bentz and Shapiro (1998), who stated that "there is no universally 
right or wrong culture of inquiry; each has its own strengths and limitations, providing a spotlight that illuminates a particular facet of reality" (p. 87). Thus, it follows that generalizations from research are bound to the context in which they are made, for example, the particular research environment in which the research was conducted. It also follows that the effectiveness of the research is viewed differently by individuals. Some ways of research might be very effective and easy to understand by some individuals while it might be altogether irrelevant and superfluous for others. This means that the approach taken to research depends on the individual researcher and the context in which this person is conducting their investigation.

The views described above are part of different paradigms, namely the positivist and constructivist paradigms. By embracing these different perspectives, I disagree with paradigm purists like Smith (1983), and Guba and Lincoln (1994), who hold that the paradigms are fundamentally incompatible. Instead, I agree with the proponents of pragmatism. According to Tashakkori and Teddlie (2003), "pragmatism rejects the either/or choices associated with the paradigm wars, advocates for the use of mixed methods in research, and acknowledges that the values of the researcher play a large role in interpretation of results" (p. 713).

However, individual values and preferences are not the only factors which play a role in the choice of methodology. A second and no less important factor is the object of inquiry and the research questions asked about it. Another well-established consensus among the community of social science researchers, and the group called pragmatists in particular, is the position that the phenomenon under investigation and the questions the researcher tries to answer are the driving force for the particular method of research. This point has been made by 
Bentz and Shapiro (1998), Gay, Mills, and Airasian (2009), and Teddlie and Tashakkori (2009), among others. Specifically, this means that there are certain research topics which lend themselves more to quantitative inquiry and other topics which lend themselves more to qualitative inquiry. In some instances, however, a combination of both can be most practical. While the group of researchers that has been labeled the "purists" believes that research can only be purely quantitative or purely qualitative, pragmatists believe that the research problem is the driving factor in the decision of research method and that there are problems warranting a mixed methods approach.

\section{Why a Mixed Methods Approach?}

There are several reasons why this study's topic of investigation calls for a mixed methods approach as the most effective method to find answers to the research questions. Being a fairly broad concept, learner autonomy can be investigated in many different ways, all of which can potentially contribute to a more comprehensive and thorough understanding of learner autonomy. For example, learner autonomy can be investigated in terms of its impact on learner achievement (i.e., Are students learning more when they have more autonomy over the learning process?). Another aspect worth studying is the learners' perceptions of autonomy, for example asking questions like: How do learners make use of autonomy in learning? While the second question lends itself to qualitative inquiry, the first question lends itself to quantitative measures. However, findings in regard to the second question will potentially be very informative in the analysis of the findings in regard to the first question, in that there might be a correlation between the learners' perception of autonomy and their achievement in an autonomous learning environment. Thus, a mixed methods approach to this research problem 
is most useful in order to uncover the connections existing within the broad concept of learner autonomy.

There are many different ways to conduct mixed methods research and various mixed methods research designs which serve different purposes (Plano Clark \& Creswell, 2008; Teddlie \& Tashakkori, 2009). Greene, Caracelli, and Graham (1989) distinguished between five basic purposes for mixed methods designs: triangulation, complementarity, development, initiation, and expansion. While the purpose of triangulation is the "convergence, corroboration, correspondence of results from the different methods" (Plano Clark \& Creswell, 2008, p. 127), complementarity seeks to use the results from one method to illustrate, clarify, and elaborate on results from the other method. The purpose of development is to use the results from one method and use them in the development of the other method, for example for sampling, implementation, or measurement purposes. The purpose of initiation is to contrast possibly contradicting findings from the different methods in order to increase the depth and breadth of the overall results. Lastly, the purpose of expansion is to expand the scope of inquiry by using different methods. In the present study, the primary purpose of the mixed methods design is to achieve complementarity and expansion.

The phenomenon under study, learners' perception and effects of learner autonomy in foreign language learning, could be investigated either purely quantitatively, for example by the administration of a survey, or purely qualitatively, for example by observing learner behavior in an autonomous environment. However, each of these methods will have certain limitations when it comes to particular parts of this study. Because of this problem, it is feasible to use different methods for different components of this research in order to expand the scope of the 
inquiry (Greene, Caracelli, \& Graham, 1989, p. 127). Additionally to the purpose of expansion, the mixed methods approach to this study will also serve the purpose of complementarity. Findings which are gained from qualitative instruments, for example learning journals or reflective statements, can be used for illustration and clarification of findings gained from quantitative measures, for example scores used to evaluate the different components of the students' perceived level of motivation. These scores might in turn be used to get a better understanding of the students' perceptions of autonomy. According to Greene, Caracelli, and Graham (1989), mixed methods designs can be instrumental in order to fulfill this purpose of complementarity. Hence, this methodology will be most appropriate to answer these research questions:

1. How do students perceive the ability to make autonomous learning choices?

2. How does the ability to make autonomous choices regarding format, content, and timing affect motivation?

3. Which areas of language learning are most benefited by autonomous learning choices?

\section{Participatory Action Research}

The methodological approach to this research is guided by the framework of participatory action research (Kemmis \& McTaggart, 2000; Kidd \& Kral, 2005). Participatory action research is consistent with critical perspectives on education from which the concept of learner autonomy was developed. Kemmis and McTaggart (2000) describe the ideal of participatory action research as a "social process of collaborative learning realized by groups of people who join together in changing the practices through which they interact in a shared social world in which, for better or for worse, we live with the consequences of one another's 
actions." (p. 563) In the university setting, students and teachers join together in the process of learning and are affected by each other's actions. Therefore they play equal parts in the undertaking of changing learning practices. The active involvement of the participants is thus of critical importance in this research where the teacher's voice and the students' voices are equally valued. Participatory action research also aligns well with the topic and setting of this study because it involves a sequence of self-reflective cycles. Each cycle involves the following steps: planning a change, acting and observing the process and consequences of the change, reflecting on these processes and consequences, re-planning, and then acting and observing again. The repetition of this self-reflective cycle in each of the two phases of this study led to some changes in the design and measures used in the second phase. These changes will be explained in more detail below.

The philosophical strands outlined in chapter 1 shine through the seven key features used by Kemmis and McTaggart (2000) to further characterize participatory action research. They see participatory action research as (1) a social process, (2) participatory, (3) practical and collaborative, (4) emancipatory, (5) critical, (6) reflexive, and (7) aiming to transform both theory and practice. These values are reflected in this research in several ways: The social process of this study is the interaction of individuals and groups in the context of an institution of higher education. The research relies on collaboration of the involved individuals and aims to investigate their practices in modern language learning with the aim to change these practices. It attempts to be emancipatory by empowering foreign language learners to take more control of their learning process. This can be achieved by critically assessing the traditional power structures of higher education learning and making changes where possible. The ultimate goal 
of this process is the initiation of a transformation of the theory and practice of modern language teaching and learning at the university level.

\section{Setting and Participants}

The data for this study was collected at a large university in the mid-Atlantic region of the United States. The university's foreign languages department offers classes in Arabic, Chinese, French, German, Italian, Japanese, Portuguese, Russian, and Spanish. Most of the basic language classes, i.e. the classes taken by students in the first four semesters, are taught by teaching assistants who are in most cases native speakers and graduate students enrolled at the university.

The participants of the study were 90 undergraduate students enrolled in five separate intermediate-level German classes. The study was carried out in two phases (phase 1 in the spring semester and phase 2 in the fall semester of 2011). In the first phase of the study, 55 students participated in the study. Of the 55, 36 took a fourth-semester German class (German 204) that is usually taken as the final class of the four semester foreign language requirement. The 36 students were enrolled in two separate sections (204 001 and 204 003). The remaining 19 students participating in the first phase were enrolled in a higher-level intermediate class (German 304) usually taken by students in the seventh to eighth semester of their language sequence. Both levels included students who either began the language sequence with the first semester, or placed into the courses coming out of high school. In the second phase of the study, 53 students participated. They were all enrolled in the fourth-semester German class (German 204) and were divided into two separate sections (204 001 and 204 004). Throughout 
the two phases of the study, several principles of learner autonomy were implemented in the instructional design of the courses.

\section{Design}

Despite the significant body of literature on learner autonomy, there is still a considerable need for research on the actual effects as well as the learners' perception of learner autonomy. Along these lines, Little (2007) states that, despite the work that has been done so far "the practical realization of language learner autonomy remains elusive" (p. 15). Furthermore, Little makes the point that a better understanding of the integration of learner autonomy and target language proficiency is necessary in order to "implicate learner autonomy in a theory of language teaching" (p. 15). Thus, it is the goal of this study to provide valuable information concerning the role of learner autonomy within the theory of language learning and teaching.

In the instruction of the class, several principles of learner autonomy were implemented. Given that the class is part of a general curriculum, a certain structure was still needed for the overall organization and structure of the class. I acknowledge that these organizing principles created restrictions that limit the autonomy of the students. At the beginning of the semester, the students in the class were given the class syllabus which described the concept of the work cycle and laid out the rationale for using it. The syllabus also contained details about the grading procedure of the class. In order to provide some structure on the one hand, but still allow for the biggest development potential for learner autonomy on the other hand, the classes were structured in work cycles (Figure 1), which were originally developed by Legenhausen (2003) and Luke (2006). 
Figure 1

The Work Cycle

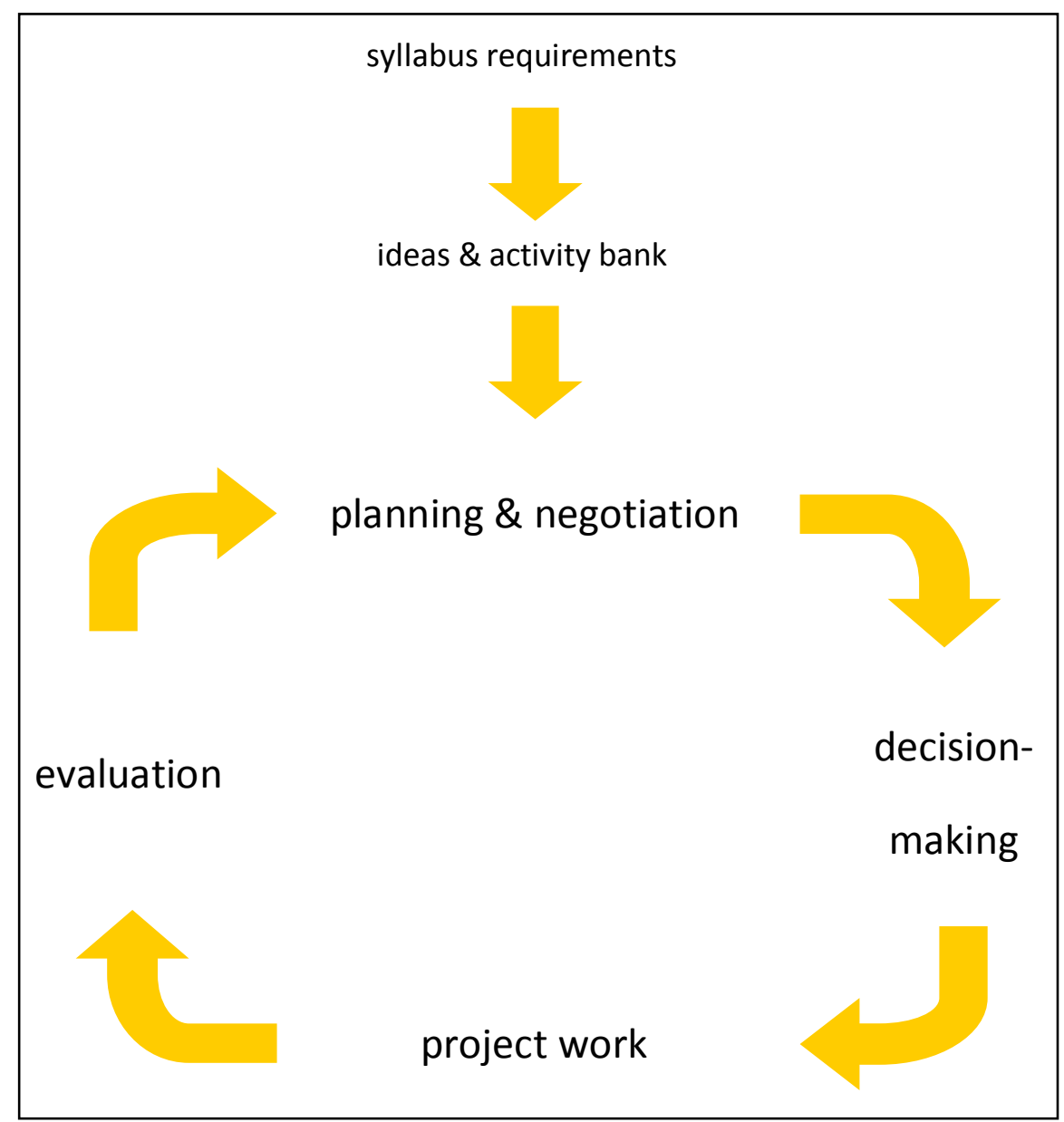

adapted from Legenhausen (2003)

A resource that guided students through the work cycle, and in fact through the whole semester, was the ideas and activity bank (see Appendix A) designed by the teacher and handed out at the beginning of each work cycle. The students were required to produce one written presentational and one spoken presentational project for each work cycle. The ideas and activity bank distributed at the beginning of each work cycle contained suggestions for possible written and spoken class projects related to the overall topic of the particular work cycle. Although the students could use the ideas and activity bank as a resource, the teachers 
also encouraged the students to come up with their own projects based on their personal interests.

After the ideas and activity bank had been handed out and discussed, the students progressed to the planning and negotiation phase. This phase included activities like discussing several project options, finding possible partners for the spoken presentational projects, or explaining and negotiating project ideas with the teacher. At this step, the students also completed the first section of the learning journal (see Appendix B), where they stated their goals for this work cycle. The students then proceeded by deciding on a particular work cycle project they wanted to work on and which would help them to accomplish their work cycle goals. At this particular point, teacher assistance was often needed to guide students to a decision and to help them getting started with a plan or outline for a project. The teacher also assisted by directing students to more and better resources that were necessary to get project work started (for example, a certain section in the textbook, or internet resources relating to the students' project). The third step in the learning cycle is called project work. While the students in this study worked on their projects mostly outside of the regular class time, there was always a certain portion of class time dedicated to progress updates and help by the teacher, where necessary. The project work stage was completed with the presentation of the products the students had created. Spoken presentational projects like video clips, PowerPoint presentations, or role plays were presented in class and written presentational projects were handed in to the teacher. Each project, whether written or spoken presentational, was graded by the teacher and was part of the overall grade of the class. In the evaluation stage, the students used the learning journals to check whether they had achieved the goals set by 
themselves, self-evaluate their own progress over the course of the work cycle, and reflect on the learning process. Once the class completed a work cycle, a new work cycle was started. In each of the two phases of this study, the work cycles were repeated 4 times. While the work cycles usually lasted 4 weeks, the last one lasted only 2 weeks, due to time constraints. Table 1 provides an exemplary overview of the course calendar and the work cycle structure over the course of the semester.

\section{Table 1}

\section{Course Calendar}

\begin{tabular}{|c|c|c|c|c|}
\hline week & work cycle & Monday & Wednesday & Friday \\
\hline \multicolumn{5}{|l|}{ W1 } \\
\hline W2 & 1 & recess & & \\
\hline W3 & 1 & & & $\begin{array}{l}\text { Work cycle } 1 \text {, project } 1 \text { due } \\
\text { (either written or spoken } \\
\text { presentational) }\end{array}$ \\
\hline W4 & 1 & & & \\
\hline W5 & 1 & & & $\begin{array}{l}\text { Work cycle } 1 \text {, project } 2 \text { due } \\
\text { (either written or spoken } \\
\text { presentational) }\end{array}$ \\
\hline W6 & 2 & & & \\
\hline W7 & 2 & & & $\begin{array}{l}\text { Work cycle } 2 \text {, project } 1 \text { due } \\
\text { (either written or spoken } \\
\text { presentational) }\end{array}$ \\
\hline W8 & 2 & & & \\
\hline w9 & 2 & & & $\begin{array}{l}\text { Work cycle } 2 \text {, project } 2 \text { due } \\
\text { (either written or spoken } \\
\text { presentational) }\end{array}$ \\
\hline W10 & 3 & & & \\
\hline W11 & 3 & & & $\begin{array}{l}\text { Work cycle } 3 \text {, project } 1 \text { due } \\
\text { (either written or spoken } \\
\text { presentational) }\end{array}$ \\
\hline W12 & & recess & recess & recess \\
\hline W13 & 3 & & & \\
\hline W14 & 3 & & & $\begin{array}{l}\text { Work cycle } 3 \text {, project } 2 \text { due } \\
\text { (either written or spoken } \\
\text { presentational) }\end{array}$ \\
\hline W15 & 4 & & & \\
\hline W16 & 4 & $\begin{array}{l}\text { Work cycle } 4 \text { project } \\
\text { (Abschlusspräsentationen) }\end{array}$ & $\begin{array}{l}\text { Work cycle } 4 \text { project } \\
\text { (Abschlusspräsentationen) }\end{array}$ & $\begin{array}{l}\text { Work cycle } 4 \text { project } \\
\text { (Abschlusspräsentationen) }\end{array}$ \\
\hline W17 & & FINALS WEEK & FINALS WEEK (final & FINALS WEEK \\
\hline
\end{tabular}




\begin{tabular}{|l|l|l|l|l|}
\hline & & & portfolios due) & \\
\hline
\end{tabular}

Over the course of each work cycle, the students had to produce and submit one written presentational and one spoken presentational project. The students were able to choose the order in which they wanted to complete the projects. While both of the work cycle projects mostly required the presentational mode of communication (presenting information and meaning to others in a spoken or written form, for example in an essay, an email, a speech, etc.), the rest of the in-class activities were focused on the interpersonal mode (exchange of information among two or more people that involves the opportunity to interact and react instantly) and interpretive mode of communication (communication that relies on listening and reading skills to gather information). The overall goal of the teacher was to provide balanced practice of all modes of communication (interpretive, interpersonal, and presentational).

Several principles of learner autonomy were in action during the work cycles. Firstly, the students were involved in the goal setting process. They could decide which aspect of the work cycle topic they needed more practice on and thus wanted to focus on. Secondly, they also had the opportunity to determine which content and which format they wanted to use to achieve their personal goals. Thirdly, the students were involved in the assessment of their own learning in that they could decide on which kind of product they want to be evaluated. Lastly, by keeping a learning journal, the students had the opportunity to plan and reflect on their learning.

When the students were working on the work cycle projects, the role of the instructor was mainly to serve as a facilitator of learning. In this capacity, the instructor helped the students with useful material, suggested helpful activities, and answered questions. Also, a 
significant part of the instructors' role consisted of organizational tasks, since the different activities as well as presentations of the students had to be coordinated. The students' role also changed. Their responsibility was not merely to listen and obeying the teacher's instructions. Instead, they had to decide upon their goals for language learning and then take charge of their own learning by using their time with the teacher as a resource in the most beneficial way.

\section{Data Collection}

The study was designed in a way that allowed for a simultaneous mixed methods design, meaning that qualitative as well as quantitative data was collected over the same period of time. The quantitative portion of data was collected through two surveys. The first survey was called the self-assessment survey (see Appendix C) and it was administered at the beginning of each study phase. The purpose of the self-assessment survey was to collect data that allows for a detailed description of the study's participants and the self-assessment of their own language competence. The broad concept of language competence was divided into sub-categories based on the different parts of communicative competence (Celce-Murcia, Dörnyei, \& Thurrell, 1995). The sub-categories were linguistic competence, socio-cultural competence, actional competence, and strategic competence. The survey also included two categories referring to the goals posited by the National Standards for Foreign Language Education Project (1999). These two categories were titled "making connections" and "lifelong learning". While the administration of the self-assessment survey provided important information about the participants and their use of German, it also initiated the metacognitive process of selfreflection as the students were evaluating the different parts of their language skills and thereby detecting their strengths and weaknesses. Based on the data collected over the entire 
course of this study, a reliability analysis of the survey's Likert-scale items was conducted. It showed that the internal consistency (Cronbach's alpha) of the survey items was at an acceptable level $(\alpha=.90)$.

The second instrument of data collection was a learning journal kept by each participant in the study and completed for every work cycle. The journal was designed to give the learners opportunities to reflect on their own learning process, their perceived role in the learning process, the role of the teacher in their learning process, and suggestions they have for improvements of the class. Collecting data on the learners' views on these topics provided information on how their motivation changed and how they perceived their own improvement over the course of the semester. As part of the self-reflective process of participatory action research, the format of the learning journal was changed from the first to the second phase of the study. The most obvious change was the change in language. While the journals were written in English during the first phase, they were written in German in the second phase. This change is based on the rationale that the reflective process should by itself be a part of the language learning process and should thus be conducted in the target language. Because of this function, a section on vocabulary learning was added to the learning journal as well. While the learning journals were meant to be an instrument aiding the process of language learning, they were also used as a data collection. Thus, in the second phase, their overall format became more structured and closely aligned with the research questions of this study.

The third instrument of data collection was a reflective statement (for the instructions distributed to the students prior to the composition of the reflective statement, see Appendix D). The purpose of the reflective statement was to include into the study a culminating 
document showing students' measurement of their own learning and their perspectives on the structure of the course. The reflective statements were collected with the students' portfolios that were turned in at the end of each of the semesters.

The fourth instrument for data collection was the autonomous learning survey (Appendix E) administered at the end of each of the phases of the study. This measure contained items designed to shed light on the students' perception of the different ways in which learner autonomy was implemented within the course design (for example, level of teacher guidance, flexibility in terms of format, content, and timing of projects, flexibility in terms of homework assignments, etc.). All items measuring the perception of autonomous learning were designed in a Likert-scale format. A reliability analysis of this part of the survey revealed an acceptable level of internal consistency at $\alpha=.81$. The second part of the autonomous learning survey was designed in a different format and focused on different aspects of language learning and asked the participants to indicate which parts they thought had benefited most from the autonomous learning environment.

\section{Analysis}

This section outlines how the different types of data were coded and then used in the process of analysis and how this process informed the research questions. Also, potential for the transformation and integration of the qualitative and quantitative data in the analysis will be discussed.

Analysis of qualitative data. Before the process of analysis, the potential application of qualitative data software was explored. It was then decided to utilize HyperRESEARCH 3.0 and Microsoft Excel software to help with the transcription, coding, and analysis of the learning 
journals and reflective statements. The first step thereafter was the transcription of the learner's weekly journals and the reflective statements. The transcribed data was then coded according to categories emerging through the process of analysis (see Appendix $\mathrm{F}$ for code book).

Coding the survey items. For the purpose of the quantitative analysis, the survey items were coded from 1 (strongly disagree) to 5 (strongly agree). Item 4 of the autonomous learning survey was reverse coded in order to be able to create a coherent scale to represent a participant's affinity for autonomous learning (with a score of 5 representing the highest level and a score of 1 representing the lowest level of fondness for autonomous learning). All data sets were linked by the participants 700 number. The survey items of the self-assessment survey were coded from 1 (below expectation for my level) to 4 (above expectation for my level). Thus, a higher score indicates a higher self-assessment of that particular skill. The remaining items of the self-assessment survey focused on additional characteristics that described the students' status as foreign language learners in more detail. These characteristics were analyzed in terms of their impact on perception of autonomous learning. The results of this analysis are part of chapter 4. 


\section{Chapter 4 \\ Learner Responses to Autonomous Learning and Their Significance for the Foreign Language Classroom}

\section{Introduction}

This chapter examines student reactions to the autonomous learning project conducted for this study and offers overall statements about autonomous student learning based on quantitative and qualitative analysis. For the purpose of this analysis, all students participating in the first and second phases of this study were treated as one group. If a measure showed a significant difference between the different sections (four sections of German 204, and one section of German 304), the differences will be addressed in the analysis and discussion of the results. The following pages offer insights into the effects of autonomous learning choices on learner motivation and the development of linguistic and cultural proficiency among students by answering in more detail the research questions guiding this study:

1. How do students perceive the ability to make autonomous learning choices?

2. How does the ability to make autonomous choices regarding format, content, and timing affect motivation?

3. Which areas of language learning are most benefited by autonomous learning choices?

The chapter is organized into sections based on these questions and provides analyses of the results gathered using the different measures as they relate to the respective research question. In the overall analysis of the learner responses, three themes can be identified: (1) the students' appreciation of choices in regards to content and format of project work, (2) the need for further training to articulate specific learning goals and challenges, and ( 3 ) an 
apparent tension between appreciation of choices and requests for a structured learning environment in terms of grammar instruction and assessments. These themes will be examined in more detail below.

\section{Self-Assessment Survey}

Before turning to the analysis of the research questions, it is necessary to give further information about the participants in this study. The self-assessment survey administered at the beginning of the semester yielded important background information about how the participants perceived their language proficiency, areas of strength and weakness, as well as their reasons for taking the class. This section begins with an overview of these results and is followed by a discussion of the factors relevant in terms of their impact on autonomous learning.

The self-assessment survey focused on the students' perception of their language proficiency. Two influential frameworks guided the survey structure and design of the individual items: First, the concept of communicative competence (Canale \& Swain, 1980; Celce-Murcia, Dörnyei, \& Thurrell, 1995) was used to organize items that pertained to the students' level of proficiency in the language. The communicative competence framework consists of five areas of proficiency: linguistic competence, socio-cultural competence, actional competence, strategic competence, and discourse competence. The area of discourse competence is comprised of a number of factors that are also associated with other, more specific, areas of communicative competence. For the purposes of the study, characteristics of discourse competence were therefore included in the areas of linguistic, socio-cultural, and actional competence. In the category of linguistic competence, the survey items related to language 
control, vocabulary usage, and analysis of language. The students' perception of their sociocultural competence was assessed through items referring to the ability to understand targetlanguage products, practices, and perspectives and to analyze how they relate to the students' home culture. Survey items involving the speaker's (or writer's) comprehensibility and comprehension based on the communicative intent were designed to assess the discourse and actional competencies. In this context, comprehensibility refers to the speakers' or writers' ability to convey the intended meaning of a message (in speaking or writing), whereas comprehension focuses on the ability to understand and interpret spoken or written language. The items in the section on strategic competence referred to the knowledge of communication strategies (for example, circumlocution, gesturing, or asking for clarification). The overall concept of communicative competence lends itself to the application to the concept of autonomous learning because it includes and gives equal weight to several non-linguistic factors that play a role in language learning, for example socio-cultural or actional competence. This corresponds with the openness of autonomous learning environments, which provide various opportunities for students to focus their language learning on different aspects. In some cases the emphases set by the students will likely have a closer connection to strategic competence, socio-cultural competence, or actional competence, rather than being limited to features of linguistic competence.

In addition to the areas included within communicative competence, the students also rated their ability to relate their language learning to other disciplines ("making connections") and their interest to continue language learning beyond the institutional setting of the classroom ("lifelong learning"). These skills have been postulated as integral parts of foreign 
language learning by the National Standards for Foreign Language Education (1999) and were

included in the self-assessment survey based on their relevance for autonomous learning. Using

a Likert-scale format, the participants rated the items concerning their language proficiency,

their ability to make connections, and their desire for lifelong language learning on a scale from

1 (is below expectation for my level) to 4 (is above expectation for my level). A higher score for

a particular item indicates a participant's higher ranking of perceived proficiency. Table 1

provides an overview of the Likert-scale items on the first page of the survey and shows how

the students in the different sections scored their own language proficiency.

Table 1

Student Responses to Self-Assessment Survey of Language Proficiency

\begin{tabular}{|c|c|c|c|c|c|c|c|c|c|c|c|c|}
\hline & \multicolumn{12}{|c|}{ section } \\
\hline & \multicolumn{2}{|c|}{$\begin{array}{l}204001 \\
\text { Spring } 2011 \\
(n=11)\end{array}$} & \multicolumn{2}{|c|}{$\begin{array}{l}204003 \\
\text { Spring } 2011 \\
(n=6)\end{array}$} & \multicolumn{2}{|c|}{$\begin{array}{l}304 \\
\text { Spring } 2011 \\
(n=18)\end{array}$} & \multicolumn{2}{|c|}{$\begin{array}{l}204001 \\
\text { Fall } 2011 \\
(n=9)\end{array}$} & \multicolumn{2}{|c|}{$\begin{array}{l}204004 \\
\text { Fall } 2011 \\
(n=19)\end{array}$} & \multicolumn{2}{|c|}{$\begin{array}{l}\text { Total } \\
(\mathrm{N}=63)\end{array}$} \\
\hline & Mean & SD & Mean & SD & Mean & SD & Mean & SD & Mean & SD & Mean & SD \\
\hline $\begin{array}{l}\text { Language control: My ability to engage in } \\
\text { basic conversations and provide/obtain } \\
\text { detailed information with grammatically } \\
\text { accurate language... }\end{array}$ & 2.82 & .405 & 2.67 & .516 & 2.94 & .639 & 3.00 & .707 & 2.68 & .749 & 2.83 & .636 \\
\hline $\begin{array}{l}\text { Language control: My ability to express } \\
\text { feelings and emotions and exchange opinions } \\
\text { in German with grammatically accurate } \\
\text { language... }\end{array}$ & 2.64 & .505 & 2.33 & .516 & 2.61 & .502 & 2.89 & .601 & 2.74 & .733 & 2.67 & .596 \\
\hline $\begin{array}{l}\text { Vocabulary usage: My ability to recognize and } \\
\text { produce common words and concepts } \\
\text { necessary for carrying on conversations in } \\
\text { German... }\end{array}$ & 2.91 & .539 & 3.00 & .632 & 2.94 & .416 & 3.00 & .500 & 3.11 & .809 & 3.00 & .596 \\
\hline $\begin{array}{l}\text { Analyzing language: My ability to understand } \\
\text { how the grammar of the language works ... }\end{array}$ & 3.00 & .447 & 3.00 & .894 & 3.00 & .767 & 2.67 & .707 & 2.95 & 1.026 & 2.94 & .801 \\
\hline $\begin{array}{l}\text { My understanding of the practices (i.e., } \\
\text { behavior, attitudes, values, rituals) and } \\
\text { products (i.e., music, food, art, films, tv } \\
\text { programs) of German-speaking cultures... }\end{array}$ & 2.64 & .809 & 3.00 & .632 & 3.17 & .857 & 2.89 & .782 & 2.95 & .705 & 2.95 & .771 \\
\hline $\begin{array}{l}\text { My understanding of the perspectives and } \\
\text { viewpoints of members of German-speaking } \\
\text { cultures on a variety of topics (the } \\
\text { environment, media, holidays, family, } \\
\text { relationships, history, multicultural society)... }\end{array}$ & 2.36 & .809 & 3.00 & 1.095 & 3.17 & .707 & 3.11 & .782 & 3.05 & .621 & 2.97 & .782 \\
\hline $\begin{array}{l}\text { My understanding of how the products, } \\
\text { practices, and perspectives of my home } \\
\text { culture relate to those in the German-speaking } \\
\text { culture... }\end{array}$ & 2.55 & .820 & 2.67 & 1.033 & 3.17 & .857 & 3.22 & .667 & 3.06 & .725 & 2.98 & .820 \\
\hline $\begin{array}{l}\text { Comprehensibility: My ability to make myself } \\
\text { understood on a variety of topics using spoken }\end{array}$ & 2.73 & .467 & 2.83 & .408 & 2.78 & .647 & 3.00 & .707 & 2.68 & .478 & 2.78 & .552 \\
\hline
\end{tabular}


language...

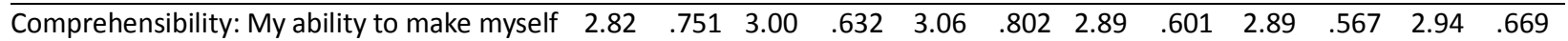

understood on a variety of topics using written

language...

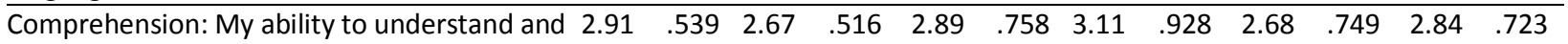

interpret spoken language on a variety of

topics...

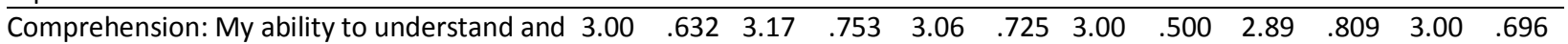

interpret written language on a variety of

topics...

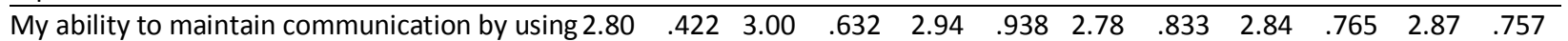
circumlocution (i.e., using other words to

describe what I want to say in German)...

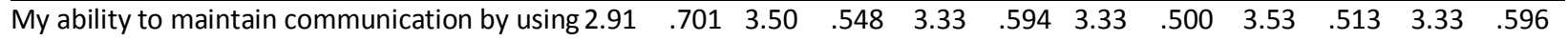

gestures, body language, and other

strategies...

\begin{tabular}{lllllllllllll}
\hline My ability to clarify something I have not & 2.91 & .701 & 3.17 & .408 & 3.56 & .511 & 3.33 & .500 & 3.26 & .653 & 3.29 & .607
\end{tabular}

understood by asking someone to repeat or

rephrase what was said...

\begin{tabular}{lllllllllllll}
\hline My ability to use what I have learned in & 3.00 & .447 & 3.17 & .753 & 3.44 & .511 & 3.22 & .833 & 2.89 & .809 & 3.14 & .692
\end{tabular}

German class to understand better what I am

learning in other subject areas...

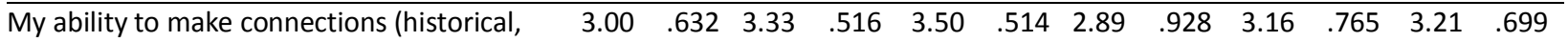

artistic, cultural, political, etc.) between what I

have learned in German class and in other

subject areas...

\begin{tabular}{lllllllllllll}
\hline My interest and confidence in using the & 2.45 & .688 & 2.50 & .837 & 3.17 & .924 & 2.67 & 1.118 & 2.47 & .772 & 2.70 & .891
\end{tabular}

language outside of class (e.g., at Stammtisch

or during other extracurricular activities)...

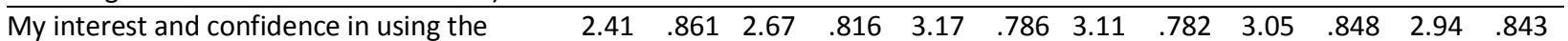

language for personal enjoyment (e.g. at

concerts, while surfing the web, for reading

pleasure, in German-speaking cultures, etc.)...

Overall

$\begin{array}{llllllllllll}2.77 & .44 & 2.93 & .44 & 3.10 & .42 & 3.01 & .52 & 2.94 & .42 & 2.96 & .44\end{array}$

Students in German 304 rated their overall competence, which is influenced by all aspects of

language learning and the ability to interact on a variety of levels in the target culture, higher

than did students in the 204 courses. This is not surprising, given that they have generally taken

two to three semesters more German than the 204 students; some have traveled abroad and

most have gone on to major or minor in German, which ultimately reflects their intrinsic

motivation for learning the language. A consistent trend across all language levels and sections,

however, is that all students rated either their ability to make connections to other disciplines

the highest. The high ratings across courses and sections in the area of making connections

(mean=3.17 on a scale ranging from 1 to 4) suggests that in an autonomous learning setting, 
students may choose activities or subjects that relate to other areas of studies or activities out of pure interest rather than based on extrinsic motivation. For example, a theater student taking German might be more likely to benefit from or more interested in the opportunity to create a short film as part of a final project. Students of political science might choose topics relating to the political history of Germany or Germany's role in the European Union as their point of focus because it relates well to their other areas of interest.

An additional item on the self-assessment survey supported the students' high rating of their ability to make connections. Table 2 shows that in each section a majority of students indicated that they were able to draw connections between their learning of German and other subject areas and that these connections benefited their learning in other subject areas.

Table 2

Responses to Item "My study in German has helped me in my learning of other subjects" (in percent)

\begin{tabular}{lllllll}
\hline & \multicolumn{7}{c}{ section } \\
\cline { 2 - 7 } & $\begin{array}{l}204001 \\
\text { Spring 2011 } \\
(\mathrm{n}=11)\end{array}$ & $\begin{array}{l}\text { 204 003 } \\
\text { Spring 2011 } \\
(\mathrm{n}=6)\end{array}$ & $\begin{array}{l}304 \\
\text { Spring } 2011 \\
(\mathrm{n}=18)\end{array}$ & $\begin{array}{l}\text { Fall 2011 } \\
(\mathrm{n}=9)\end{array}$ & $\begin{array}{l}\text { Fall 2011 } \\
(\mathrm{n}=19)\end{array}$ & $\begin{array}{l}\text { Total } \\
(\mathrm{N}=63)\end{array}$ \\
\hline No & 41.7 & 44.4 & 11.1 & 33.3 & 38.9 & 33.88 \\
\hline Yes & $\mathbf{5 8 . 3}$ & $\mathbf{5 5 . 6}$ & $\mathbf{8 8 . 9}$ & $\mathbf{6 6 . 7}$ & $\mathbf{6 1 . 1}$ & $\mathbf{6 6 . 1 2}$
\end{tabular}

In contrast to the positive perception of their ability to make connections, the 204 students rated the questions on lifelong learning the lowest (see Table 1). The results of the survey suggest that students are less interested in using the language for personal enjoyment outside of class and therefore may not seek out situations in the classroom that would increase their ability to use or explore the language beyond the classroom. The low levels of personal interest in the language outside of the classroom may also suggest a lower degree of interest in making choices about instructional materials and projects in an autonomous framework in the 
classroom. In contrast to the 204 students, learners in the 304 course rated their interest level in using the language outside of class and for personal enjoyment much higher (mean=3.17). This suggests that they might be more likely to take advantage of autonomous choices in language learning both in and beyond the classroom. The effects of these differences on reactions to autonomous learning by the students in the different levels will be discussed further below.

Tables 3- 5 give insight into the students' reasons for taking German. Table 3 shows that a large number of students in the 204 courses took German to fulfill the foreign language requirement for their program of study. This differs from 304 students who had chosen to take the class out of enjoyment or because they were majoring or minoring in German.

Table 3

Responses to Item "Are you taking German to fulfill the foreign language requirement?" (in percent)

\begin{tabular}{|c|c|c|c|c|c|c|}
\hline & \multicolumn{6}{|c|}{ section } \\
\hline & 204001 & 204003 & 304 & 204001 & 204004 & Total \\
\hline & $\begin{array}{l}\text { Spring } 2011 \\
(n=11)\end{array}$ & $\begin{array}{l}\text { Spring } 2011 \\
(n=6)\end{array}$ & $\begin{array}{l}\text { Spring } 2011 \\
(n=18)\end{array}$ & $\begin{array}{l}\text { Fall } 2011 \\
(n=9)\end{array}$ & $\begin{array}{l}\text { Fall } 2011 \\
(n=19)\end{array}$ & $(\mathrm{N}=63)$ \\
\hline No & 15.4 & 0 & 70.6 & 25 & 22.2 & 26.64 \\
\hline Yes & 84.6 & 100 & 29.4 & 75 & 77.8 & 73.36 \\
\hline
\end{tabular}

Since most 204 students took German to fulfill the university's foreign language requirement, their reasons for completing the course differed from their peers who had taken the course to increase their knowledge of the language or to fulfill the requirements for a self-selected area of study. Unlike the 304 students, many of the 204 students did not plan on majoring, double majoring, or minoring in German (see Tables 4 and 5). The 304 course was a course requirement for German majors and thus included students who were either currently or planning on majoring or double majoring in German. 
Table 4

Responses to Item "I am majoring or plan to (double) major in German" (in percent) section

\begin{tabular}{lllllll}
\cline { 2 - 6 } & $\begin{array}{l}204001 \\
\text { Spring 2011 } \\
(n=11)\end{array}$ & $\begin{array}{l}\text { 204 003 } \\
\text { Spring 2011 } \\
(n=6)\end{array}$ & $\begin{array}{l}\text { S04 } \\
\text { Spring 2011 } \\
(n=18)\end{array}$ & $\begin{array}{l}\text { Fall 2011 } \\
(n=9)\end{array}$ & $\begin{array}{l}\text { Fall 2011 } \\
(n=19)\end{array}$ & $\begin{array}{l}\text { Total } \\
(\mathrm{N}=63)\end{array}$ \\
\hline No & 100 & 100 & 27.8 & 77.8 & 94.4 & 80.00 \\
\hline Yes & 0 & 0 & 72.2 & 22.2 & 5.6 & 20.00
\end{tabular}

Table 5

Responses to Item "I am minoring or plan to minor in German" (in percent)

\begin{tabular}{lllllll}
\hline & \multicolumn{7}{c}{ sections } \\
\cline { 2 - 7 } & $\begin{array}{l}204001 \\
\text { Spring } 2011 \\
(n=11)\end{array}$ & $\begin{array}{l}204003 \\
\text { Spring } 2011 \\
(n=6)\end{array}$ & $\begin{array}{l}304 \\
\text { Spring } 2011 \\
(n=18)\end{array}$ & $\begin{array}{l}\text { Fall 2011 } \\
(n=9)\end{array}$ & $\begin{array}{l}\text { Fall 2011 } \\
(n=19)\end{array}$ & $\begin{array}{l}\text { Total } \\
(N=63)\end{array}$ \\
\hline No & 57.1 & 50.0 & 80.0 & 85.7 & 77.8 & 73.9 \\
\hline Yes & 42.9 & 50.0 & 20.0 & 14.3 & 22.2 & 26.1
\end{tabular}

Despite the different reasons for the students' enrollment in the courses and the high number of students who took German to merely fulfill a requirement, 97.78 percent of all participants in the study described their interest level in learning German as either "interested" or "very interested" (Table 6).

Table 6

Responses to Item "Describe your interest level in learning German" (in percent)

\begin{tabular}{|c|c|c|c|c|c|c|}
\hline & \multicolumn{6}{|c|}{ sections } \\
\hline & $\begin{array}{l}204001 \\
\text { Spring } \\
2011 \\
(n=11)\end{array}$ & $\begin{array}{l}204003 \\
\text { Spring } \\
2011 \\
(n=6)\end{array}$ & $\begin{array}{l}304 \\
\text { Spring } \\
2011 \\
(n=18)\end{array}$ & $\begin{array}{l}204001 \\
\text { Fall } 2011 \\
(n=9)\end{array}$ & $\begin{array}{l}204004 \\
\text { Fall } 2011 \\
(n=19)\end{array}$ & $\begin{array}{l}\text { Total } \\
(\mathrm{N}=63)\end{array}$ \\
\hline indifferent & 0 & 0 & 0 & 0 & 11.1 & 2.22 \\
\hline interested & 46.2 & 55.6 & 11.1 & 22.2 & 27.8 & 32.58 \\
\hline very interested & 53.8 & 44.4 & 88.9 & 77.8 & 61.1 & 65.2 \\
\hline
\end{tabular}

The results from the self-assessment survey show that the participants of this study can be categorized into different groups, for example by the level of their language proficiency or by their reasons for taking the language courses. Such differences in motivation for taking the 
courses also influence the students' perception of the purpose and efficacy of autonomous learning choices in language learning. For example, students who perceive their language proficiency as very low and have an extrinsic or low motivation to take the language may find it more difficult to work independently on projects than a student who is a highly motivated to study the language and/or research a topic in another discipline that is of interest to them. Students who took German to fulfill the university's requirement may be unwilling to exert the efforts needed to direct their own learning and create their own project ideas.

To test these hypotheses, a correlation analysis of the self-assessment survey and the autonomous learning survey was performed. It did not reveal significant correlations between items on the self-assessment survey and the autonomous learning survey. It is also important to note that an independent samples t-test showed that the reasons for taking the course produced no significant differences in terms of how students responded to the autonomous learning survey. This means that those students who cited an extrinsic motivation as the reason for taking the course (i.e., requirement) responded similarly to students who were taking the course for intrinsic reasons (i.e., personal enjoyment or advanced study). While this finding runs somewhat contrary to what was expected, it stresses the impact autonomous learning choices can have on a variety of students.

\section{Discussion of Research Questions}

The following segment provides an overview of how the measures used in this study inform the research questions. The measures include the autonomous learning survey, the learning journals, and the reflective statements written at the end of the semester. 


\section{Research question 1: How Do Students Perceive the Ability to Make Autonomous Learning Choices?}

In regards to the first research question, the data collected with these measures were analyzed in terms of the students' perception of their ability to make autonomous choices in their learning. This includes whether or not the students generally liked making choices, how they made their choices, which goals they set for themselves, and how they perceived individual benefits and challenges. The autonomous learning survey and the reflective statements were designed to give an overall picture of the students' perception. The learning journals, on the other hand, were a format that gave the students the opportunity to reflect on their goal setting, challenges, and most beneficial activities.

Autonomous learning survey. The students' reaction to the autonomous learning components implemented in the 204 and 304 courses has been measurably positive. Table 7 shows the mean scores and standard deviation for each item pertaining to the first research question. The students rated each item on a scale from 1 (strongly disagree) to 5 (strongly agree).

Table 7 Means and Standard Deviation of Autonomous Learning Survey Scores by Section

\begin{tabular}{|c|c|c|c|c|c|c|}
\hline & \multicolumn{6}{|c|}{ section } \\
\hline & 204001 & 204003 & 304 & 204001 & 204004 & Total \\
\hline & $\begin{array}{l}\text { Spring } 2011 \\
(n=16)\end{array}$ & $\begin{array}{l}\text { Spring } 2011 \\
(n=18)\end{array}$ & $\begin{array}{l}\text { Spring } 2011 \\
(n=17)\end{array}$ & $\begin{array}{l}\text { Fall } 2011 \\
(n=8)\end{array}$ & $\begin{array}{l}\text { Fall } 2011 \\
(n=21)\end{array}$ & $(\mathrm{N}=80)$ \\
\hline & Mean SD & Mean SD & Mean SD & Mean SD & Mean SD & Mean SD \\
\hline $\begin{array}{l}\text { I enjoy having the opportunity to make } \\
\text { individualized choices about how I learn } \\
\text { German. }\end{array}$ & $4.56 \quad .512$ & $\begin{array}{ll}4.67 & .485\end{array}$ & 4.71 & 4.38 & 4.71 & $4.64 \quad .484$ \\
\hline $\begin{array}{l}\text { The ability to make individualized choices } \\
\text { about the format, content, and timing of } \\
\text { projects has improved my awareness about } \\
\text { the way I learn best. }\end{array}$ & $4.06 \quad .680$ & $\begin{array}{ll}4.22 \quad .878\end{array}$ & $4.24 \quad .664$ & $\begin{array}{ll}4.38 & .744\end{array}$ & $4.24 \quad .700$ & $4.21 \quad .724$ \\
\hline $\begin{array}{l}\text { I would like to have more teacher guidance in } \\
\text { choices about the format and content of } \\
\text { projects. (reverse coded) }\end{array}$ & $3.00 \quad .966$ & $2.94 \quad .998$ & 3.12 & $2.75 \quad .886$ & $3.29 \quad .561$ & $3.06 \quad .862$ \\
\hline
\end{tabular}




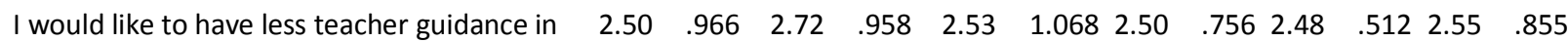
choices about the format and content of

projects.

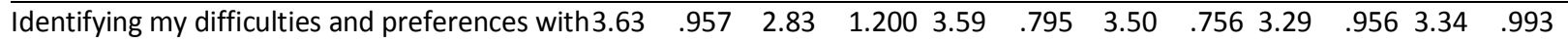
regard to course materials in the form of a journal has helped me to identify how I learn best.

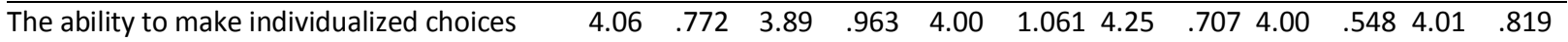
about the format of projects has increased my awareness about how I learn best.

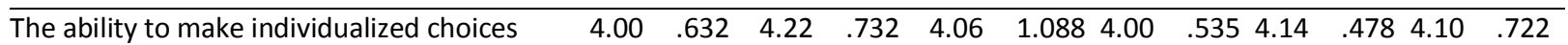
about the content of projects has increased my awareness about how I learn best.

\begin{tabular}{lllllllllllll}
\hline The ability to make individualized choices & 4.00 & .816 & 4.00 & .767 & 3.88 & .928 & 3.63 & .518 & 3.71 & .717 & 3.86 & .775
\end{tabular}
about the timing of projects has increased my awareness about how I learn best.

\begin{tabular}{lllllllllllll}
\hline overall & 3.73 & .34 & 3.69 & .52 & 3.76 & .51 & 3.67 & .36 & 3.73 & .33 & 3.72 & .41
\end{tabular}

The analysis of these values shows that the students rated the indicators of autonomous learning very high. A one-way ANOVA shows that there are no significant differences in how students in the different sections and at different levels rated the items on the survey. In all courses and sections, students rated item 1 ("I enjoy having the opportunity to make individualized choices about how I learn German.") the highest. The lowest scores were closest to the descriptor "neither agree nor disagree" and were given in response to items 3 and 4 , in which students were asked if they would like to have more teacher guidance in the course. The mean scores of responses to the teacher guidance item indicate that the students generally agreed with the amount of teacher guidance they were receiving and did not believe that significantly more or less direction provided by the teacher would improve their learning in the course.

Across all sections, the students rated item 2 dealing with learner awareness ("The ability to make individualized choices about the format, content, and timing of projects has improved my awareness about the way I learn best.") with a mean score of 4.21 , which indicates that their awareness about the ways in which they learn best was improved by their 
ability to make autonomous learning choices. Students rated the effect of the learning journals on their ability to identify their learning strengths with a mean score of 3.34 (item 5). While this is a positive rating, it does not suggest overwhelmingly that students believed the learning journals raised their awareness about how they learn best. Instead, it indicates that the students perceived the journals as an enjoyable part of the class requirement, rather than as a tool to identify their personal strengths and weaknesses in learning.

Learning journals. The purpose of the learning journals was to complement and triangulate the results from the autonomous learning survey and to provide further insight into how the students perceive and make use of autonomous learning. They were also designed to guide the students through the processes of setting goals, identifying personal challenges, and evaluating the helpfulness of activities. While the 204 students in the first phase of this study wrote the learning journals in English, all learning journals in the second phase of the study were originally written in German and then translated for the purpose of analysis. In very few instances, parts of the learning journals could not be included in the analysis because they were incomprehensible due to the linguistic barrier. The codes that were used in the analysis of the learning journals are further described and illustrated in the coding book (see Appendix F). Throughout the process of conducting analysis and coding of the learning journals, several categories emerged.

Goal setting. The analysis of the learning journals revealed that the students' articulated goals for the course fell into one or several of the following codes: form/grammar, vocabulary, language skill, content, or culture. Responses falling into the category of form/grammar typically revealed students' desires to improve their linguistic accuracy. For example, students 
stated: "I would like to become better with grammar," or "I would like to improve my use of the genitive case." These are examples of the same category, but they differ in terms of specificity. Overall, it can be said that the goals articulated for grammar were stated in general terms. In fact, the discrepancy in terms of specificity about areas for improvement that students wrote about in their learning journals is evident in all areas. Goals that fell into the category of vocabulary were generally stated in concrete terms: "I would like to learn twenty new words," or "I would like to learn many verbs."

The goals in the category of language skill related to the students' abilities in the three modes of communication: interpersonal, presentational, and interpretive. The three modes of communication include different combinations of the skills of speaking, writing, listening, or reading. The interpersonal mode of communication is used in any kind of direct and spontaneous spoken or written personal interaction. The presentational mode of communication refers to situations in which people use language in a deliberate and planned fashion in order to present information, for example, when giving a speech or writing an essay. The interpretive mode of communication is used whenever people listen to or read language. The students stated their goals mostly in terms of the language skills rather than the modes of communication. This suggests the desire to improve specifically one or more aspects of language production or processing in isolation. One student commented: "I want to understand other people when they are speaking. I think that speaking helps to understand more." While this student indicates a desire to improve language skills, he or she understands the interrelatedness of the modes of communication and identifies the improvement of one skill a factor based on the betterment of another. 
Students who articulated goals relating to content expressed a specific desire to achieve more depth in topics of the course rather than breadth in terms of the number of topics covered. One student commented: "I wanted more about the German media, like their similarities and differences with America." Another said, "I want to learn about history." A few students articulated goals that related to learning more about German culture. For example, a student stated: "I would like to learn a little bit more about German culture." The fact that the student goals were stated specifically in these areas indicates the students' recognition of linguistic as well as cultural learning as important components of language study.

Perceived challenges. It is not surprising that the analysis and coding of the students' perceived challenges showed that they organized their comments about points of difficulty according to the areas in which they had set goals for themselves: form/grammar, vocabulary, language skill, content, and culture. The way in which the students articulated their challenges differed greatly in terms of their level of specificity. While many students mentioned a general area that was difficult for them (for example, grammar, vocabulary, or content), others described a specific grammatical form or a particular category of vocabulary as an area that needed to be improved. The following is an example of a specific grammatical point listed by a student: "I think subjunctive I and II was [sic] difficult, because it was difficult to determine when to use it in the sentences." By contrast, another student expressed her challenges relating to grammar in broader terms: "I find learning new grammar difficult because of the complexity." The range in specificity of student responses to grammar points can be attributable to different factors. First, it is possible that the students simply did not choose to describe specifically their goals and the challenges they saw in achieving them. A second factor 
is that the students were willing to describe in detail their goals and challenges but did not know how to articulate them based on a limited understanding of language and language learning. The trend of generality in the learning journals was evident in the journals written in English as well as in German, suggesting that the language of the learning journal did not make a difference in terms of the students' ability or willingness to identify their goals and challenges more specifically. This finding indicates, however, that more effort is needed to effectively identify, describe, and address weak areas of the students' language learning. On the side of the teacher, this could be addressed by being more specific when giving feedback on student work, for example by pointing out and specifying areas where a high number of errors were made (e.g., verb conjugation, adjective endings, etc.). On the side of the student, this feedback can then be used to rework the essay or project in the form of a second draft, addressing the areas identified by the teacher. With more practice, this feedback process can then become more autonomous, for example by asking the student to identify weak areas when turning in the work.

Most helpful activities. The analysis of the part of the learning journals pertaining to the most helpful activities to reach the work cycle goals yielded some insightful findings. During the process of analysis, it became clear that the activities mentioned by the students fit into three categories. The first category consisted of aspects related to class work, the in-class environment, and interaction during class time. Typical examples of this category are time spent in class, help by the teacher, grammar exercises, and homework. In their learning journals, many students emphasized these aspects, suggesting that they capture the essence of what students perceive to be effective language learning. One student wrote that "time in class 
is always the most important." The fact that the overwhelming majority of students relied on these activities to reach their work cycle goals is an example of a more traditional view of language learning, where learning takes place during class time, because of what the teacher does, and because of what the students do to fulfill the class requirements. While in-class activities and homework activities can be approached by students in an autonomous way, for example by independently changing activities to make them more interesting or by deliberately skipping homework activities if they seem unhelpful, it is more likely that students who rely heavily on class-related work and interaction find it difficult to make autonomous decisions.

A second, considerably smaller, category of activities considered most-helpful related to the students' individual work cycle projects. While the projects were a requirement of the class, the students were free to choose the subjects they addressed, as long as they were related to the course topic, and the format of the projects. Activities in this category indicate the demonstration of a higher degree of learner autonomy because neither the curriculum nor the teacher dictated them. One student reported that "searching for information for the projects" helped him the most. Another student stated: "When I need a new word for my paper, I look up synonyms in my dictionary." A third example is a student, who stated that the work he did with his partner helped him most.

The third item in the learning journals related to what the students were doing outside of class in order to improve their German skills and to achieve their goals for the work cycle. These activities are more individualized, self-motivated forms of language practice, for example talking German to friends or family, watching movies in German, studying German with peers, or searching the internet for grammatical exercises. Clearly, these self-directed learning 
activities are more in line with an autonomous approach to language study. In these instances, the students saw opportunities to use and practice their language skills and utilized the resources they had at their disposal. Of all 204 students, who participated in the second phase of the study ( $n=37), 12$ students referred to activities of this kind at some point during the study. This represents about a third of the 204 students in the second phase and confirms the high scores on the self-assessment survey that showed that the students are, in fact, willing and able to make connections between their learning in the classroom and their self-initiated actions of learning outside of the institutional learning setting. In order to encourage this kind of learning more, foreign language teachers can draw their students' attention to these kinds of activities and strategies, for example by providing a list with online resources, explaining learning strategies, and including external resources, for example library resources like movies, into their teaching.

Reflective statements. Students wrote reflective statements to include with their course portfolios at the end of the semester; these statements served as a personal narrative on the students' learning throughout the semester. With regard to the first research question, the most prominent trend in the analysis of the reflective statements was positive reactions to the ability to make autonomous learning choices. A second trend was an apparent contrast between positive responses to autonomous learning on the one hand, and requests for more direct grammar instruction and tests on the other hand. While not representing a general trend, two students were very outspoken about their dislike of the class structure. However, based on the fact that most students articulated a clearly positive perception of the 
autonomous learning environment, it is only appropriate to illustrate this point first. For example, one 204 student explains:

Having the ability to choose what type of material and activities helped me be creative with projects and make the projects my own. It made the projects more interesting because we were given so much freedom as long as a few certain guidelines were followed. No one person had the same project. We were able to bring our creative side to the table and make learning fun. I enjoyed having the ability to take my knowledge and put it into a project or activity that interests me.

The 304 students highlighted similar points about the freedom to choose and personal interest and investment in their reflective statements. For example, in one of the reflective statements from German 304, a student wrote:

Having the opportunity to decide about materials and activities was very helpful. It is important when students want to do good work and not only get good grades. The opportunity to make decisions gives the students more reasons to do good work, because it is more interesting for them. Sometimes students say that it is more difficult when the work is not concrete. But when we can decide by ourselves, it is more interesting for everybody.

These two examples focus mainly on the freedom to choose the topics (i.e., the content) of the work cycle projects. When referring to the "concreteness of work", the 304 student raises the issue of structure in autonomous learning environments. Although, the flexibility in the learning environment did not pose difficulties for this student, there were other students who expressed a desire for more structure. This theme will be discussed below. In terms of other positive 
perceptions of autonomous learning, students also emphasized the flexibility in the timing of the projects, as this excerpt from the reflective statement of a 204 student shows:

Because we were able to make decisions on which homework activities fit into our schedule the best and choose which portion of the Work Cycles we wanted to do first writing or presenting- I feel like this allowed us to take the full responsibility of our grades and progress in the course, instead of being led by an instructor or syllabus.

In these examples, the students provided feedback that reveals an increased level of connectedness to their own learning, which is one of the goals of learner autonomy. Generally, students valued being able to take charge of their own learning, explaining that it enabled them to take on a higher level of responsibility for their own learning. This is one of the central characteristics of learner autonomy. The student who wrote the following excerpt also illustrates this point.

I found the format of the course very helpful. I liked that we met together and learned topics but with the aid of the work cycle projects we were able to also teach ourselves. I also liked that these were in place of tests. Sometimes with the stress of tests and studying, a grade just doesn't really show what a student knows. But with the work cycle projects we were able to cover the same subjects that were tested for comprehension in previous German classes, but with a more relaxed and telling atmosphere. In comparing the work cycle projects and more traditional tests, this student emphasized the different format of assessment and stressed that the work cycle projects are a better representation of what a student really knows. This statement thus highlights the importance of assessment that is perceived as valid and fair by the students. 
Not all students, however, viewed the assessments in the autonomous learning framework positively. Of all students who participated in the study over the course of the two semesters, two students had an explicitly negative view of the autonomous learning environment. This student expressed her views very directly:

Overall I truly did not like this class at all. Although a lot of new vocabulary and grammar techniques were taught, I feel that I actually retained very little. I think that this fact is due to not having IPA's [Integrated Performance Assessments - a form of assessment used in the lower classes of the sequence]. These oral projects did not help build on the new skills that we learned during class. They were also extremely stressful and time consuming. I also feel like the grading was extremely harsh on them. This is only our fourth semester of German, and four semesters do not add up to much. As far as my opinion about the materials and topics used in class - the topics were interesting, but I do not think the materials were helpful. I feel like we used entirely too much time during warm ups. For example, when we listen to a song and fill in the words - that is not helpful at all. Maybe if we would be given an answer key at the end of it, that would help more, because when we go around the room and give answers, it is difficult to understand what the answer was. I think that we should have spent much more time doing pages out of the book, followed by going over it as a class and WRITING [sic] it on the board.

In contrast to the previous passage, this student did perceive the format of assessment as neither helpful nor fair. She also expresses her disapproval of the materials used in class and criticizes the typical sequence of the class, which always started with a warm-up activity. Her 
criticism of the use of songs as a warm-up activity is unusual, as most students greatly enjoy this type of warm-up. However, the second student uttering a negative view of the class structure raised similar points:

I also think that the so-called "Arbeitstag" were [sic] a complete waste of time. We spent too much time on the warm up, and by the end we had very little time to actually work on our project. I honestly didn't like anything about this class. At first, I thought that the new layout would be nice - not to have IPA's. I soon found out that the oral projects were much more stressful and time consuming and not nearly as beneficial to my learning as a test is.

Both of these students have clearly struggled with the autonomous learning format and express a strong preference for a more structured work environment, activities, and forms of assessment. Although not representative of the overwhelming majority of students in this study, the points these two students raised allude to a recurring theme in the suggestions several students made in regards to possible changes and improvements to the course structure: There was an evident tension in the student responses between being enthusiastic about the possibilities of learner autonomy and the desire to write more quizzes as well as focus more instructional time on explicit grammar instruction. These two quotes from reflective statements exemplify the students' love-hate relationship with quizzes:

I also thought that there should have been more quizzes. As much as I hate taking them, quizzes force me to study more than any other project we had. I think that if there were weekly quizzes, I would have studied a lot more frequently. 
Adjective endings, case changes, and some verb tenses are difficult for me to perfect. I would have liked to have concentrated more on grammar in German 204. I understand that 203 tends to be the more grammar intensive course, but having more classes in 204 devoted to grammar would have been helpful. Occasional review sessions throughout the semester, rather than reviewing only at the beginning of the semester, would help students hone their reading and writing skills.

These requests for more explicit grammar instruction and more frequent assessments, such as quizzes, correspond with the results obtained by Cotterall (1995). Her study of adult ESL learners' beliefs about language learning produced evidence that language learners regard regular tests as a necessary part of language learning and she concluded that any implementation of learner autonomy in institutional language learning must take these learner expectations into consideration. In the context of the present study, regular short tests on specific grammar points were part of the curriculum. Yet, as a result of these student reactions, the curriculum has been changed according to the students' suggestions and now includes more frequent assessments.

The request for more specific grammar instruction also points to another notion that can help to explain the negative or mixed reactions of certain students, namely the relationship between tolerance of ambiguity (Ely, 1989) and learner autonomy. As applied to second language learning, Ely defined tolerance (or intolerance, for that matter) of ambiguity as the relative degree of discomfort associated with thinking: that one does not know or understand exact meaning; that one is not able to express one's ideas accurately or 
exactly; that one is dealing with overly-complex language; that there is a lack of correspondence between the L1 and the L2. (1989, p. 439)

Based on the data in the reflective statements, it stands to reason that students with a low level of tolerance of ambiguity are more likely to feel uncomfortable in a setting with a high degree of learner autonomy. This passage from the reflective statements of one of the 204 students that were very outspoken about their criticism exemplifies the emphasis on accuracy and correctness.

It would have been much more beneficial to spend less time on warm ups and "A, B activities". Those activities are not helpful, because more often than not, we are simply practicing incorrectly. I would have liked to see more time on practicing the vocabulary and grammar with exercises from the book and with IPA's.

Furthermore, the desire for more specific and less open-ended grammar and vocabulary activities is corroborated by results obtained by Luke (2006), who identified student requests for more grammar and vocabulary instruction as a theme in his qualitative study on inquirybased learning in a fourth-semester university Spanish course. Luke's and the findings of this study can therefore help to explain the gap that seems to exist between the students' concerns about not learning what they should be learning or not being tested enough on the one hand, and, on the other hand, the enjoyment and motivation students seem to get out of working on projects they have conceptualized and created.

Research Question 2: How Does the Ability to Make Autonomous Choices Regarding Format, Content, and Timing Affect Students' Motivation? 
While the first research question focused on the general perception of the ability to make autonomous learning choices, the second research question was designed to stress the students' ability to make connections between their foreign language learning and their personal interests and the possible effect of this autonomy on their motivation to use and learn the language. The analysis of the different measurements, in particular the autonomous learning survey and the reflective statements, has shown that the autonomy to make choices about the format, content, and timing of the work cycle projects had an explicitly positive effect on the students' motivation. This effect was evident in the overwhelming majority of data, across all sections and courses. There was no indication of an explicitly negative effect of learner autonomy on motivation.

Autonomous learning survey. Table 8 provides an overview of the scores for the items pertaining to the students' level of motivation. A one-way ANOVA showed no significant differences in how the students in the different sections scored the items.

Table 8

Means and Standard Deviation of Motivation Items by Section

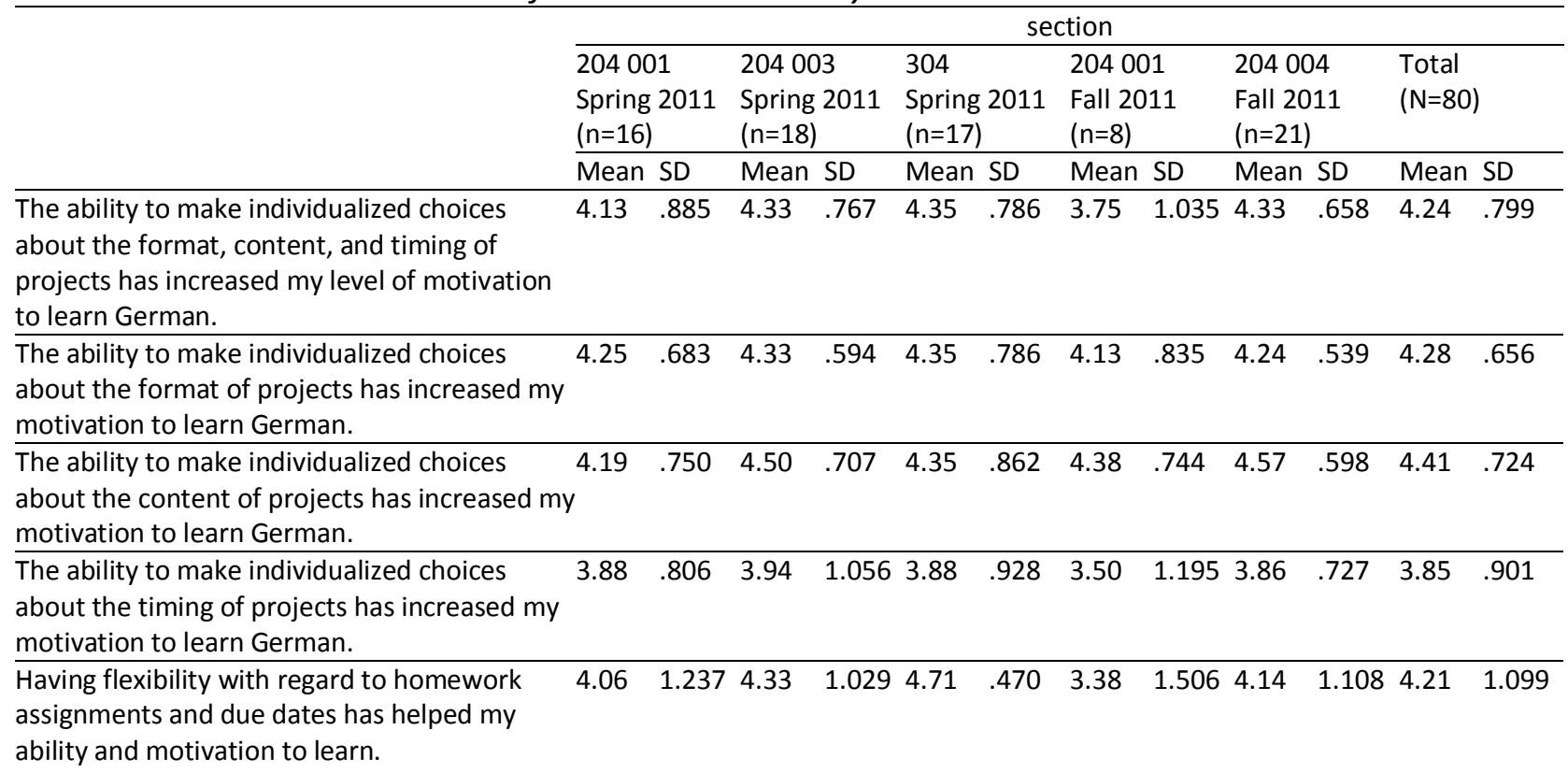


Overall, the students reported their motivation to be affected most by being able to choose the content of the work cycle projects (mean=4.41). The item that focused on the impact of format and timing of work cycle projects was scored lower (format mean=4.28, timing mean=3.85). The students also rated flexibility with regard to homework activities and due dates as positive (mean=4.21), in particular the 304 students. The 304 students rated this item ("Having flexibility with regard to homework assignments and due dates has helped my ability and motivation to learn.") higher (mean=4.71, SD=.470) than the 204 students (mean=4.08, SD=1.182). An independent samples $t$ test showed that this difference was significant at $t(78)=-2.133, \mathrm{p}<$ .05. This might be due, for example to the higher level of commitment to learning the language, as reflected by the fact that the 304 students had made a decision to pursue German in their studies as opposed to taking it to fulfill a requirement.

Reflective statements. In the analysis of the reflective statements, motivation also played an important role. They showed that several students established a direct connection between the autonomy they had in their work cycle projects and their level of motivation to learn and use German. One student, who participated in the study during the second phase, simply put it this way: "The ability to choose the topics that my project was on made it far easier to do and made me more involved with my work." A student who was part of the 204 003 section in the second phase of the study further elaborated:

Being able to make my own decisions only increased my commitment to learn. To use another analogy, it was something like owning a business. If one owns a business, one is much more likely to put in more work with more enthusiasm. If I owned a business, I 
would not grumble at putting in fourteen hour days, because it would be mine, and therefore, I would be devoted in a less begrudgingly way. The freedom to make my own decisions and to be creative made me invest in learning on a different level than I had previously experienced, and what I did learn about German culture, history, and language skills will not soon be forgotten.

The statement above is an excellent example of how learner autonomy can open up a way for students to be more invested in their learning. In fact, in the majority of their reflective statements, the students directly linked their increased level of motivation to the ability to connect the work in their language class to their personal interest. This excerpt is another good example of this connection:

The ability to make my own decisions on the topics you would cover in the presentation projects was a great idea and I loved it. I loved that I could pick a topic in which I felt more comfortable and interested in speaking about in German. I would have hated just doing a biography on a famous German inventor or something like that. I got to pick my project on the role of Germany in the European Union. It gave me more of a "drive" to learn about a favorite topic of mine while speaking German.

The theme of increased motivation ran across sections and levels. While the students in the 204 classes wrote their reflective statements in English, the students in the 304 class wrote them in German. Below is a translated excerpt from the reflective statement of a 304 student.

I was able to make my own decisions about materials and assignments and that improved my experience, because I enjoyed the creative control it gave me over the projects. Especially with the videos I worked harder on projects that I chose and wanted 
to do than I would on projects that would simply be assigned to me. Although the oral projects were usually PowerPoint presentations, I appreciated the other options and the opportunity to work alone or in small groups.

Again, this student mentions the positive effect of the creative freedom and the control over his own work that motivated him to work harder. This powerful relationship between learner autonomy and motivation to learn a language was a big trend in the reflective statements that confirms previous claims by other authors (for example Dickinson, 1995; Dörnyei \& Csizer, 1998; Cheng \& Dörnyei, 2007; Spratt, Humphreys, \& Chan, 2002; Ushioda, 2003).

The psychological connection between autonomy and motivation was described by Deci and Ryan (1985) in their fundamental work on self-determination theory. They wrote, that "the psychological hallmark of self-determination is flexibility in managing the interaction of oneself and the environment. When self-determined, one acts out of choice rather than obligation or coercion." (p. 38) In an education setting like the one of this study, there is obviously not total freedom for self-determination. Instead, self-determination, like learner autonomy, is best conceptualized on a continuum, ranging from very controlled learning environments with no room for self-determination and autonomy to environments with total freedom in learning choices. In the present context, there was considerable scope for autonomy in terms of the students' work cycle projects and homework activities. This, according to self-determination theory, helps explain the responses of the students, who generally agreed that their ability to make choices in regards to content, format, and timing of work cycle projects had increased their motivation. Applying self-determination theory to the realm of education in a later work, Deci, Vallerand, Pelletier, and Ryan (1991) identified autonomy as one of three basic 
psychological needs, among competence and relatedness (p. 327). It follows that autonomy plays a central role in motivation, because "motivation, performance, and development will be maximized within social contexts that provide people the opportunity to satisfy their basic psychological needs for competence, relatedness, and autonomy." (p. 327-328)

Although this claim was confirmed by the overwhelmingly positive reactions in the students' reflective statements, a few students expressed a somewhat more differentiated view of the freedom to set one's own emphasis in learning. For example, one student noted:

The ability to choose materials and activities helped in some ways but was less effective in others. It helped by letting us pick the things we were interested in and needed to learn. Because we were interested in learning the material we chose, it made learning more fun and therefore more effective. One reason I think it's less effective is because we might not always pick the material we need to learn. I think if the teacher picks the material then he or she would probably pick the material the students need to learn instead of the material they want to learn.

The two perspectives described in this statement are a good example of the students' discerning evaluation of their own learning and motivation. While there is acknowledgement that the ability to work on topics of personal interest increased the effectiveness of learning, there is also doubt and uncertainty about learning the "right" thing; a juxtaposition of needing to learn versus wanting to learn. This contrast relates to the aforementioned theme of intolerance of ambiguity, but it also expresses a somewhat dubious attitude toward having the freedom to make choices in learning. It shows that learner autonomy is to some degree 
contrary to the understanding of many learners' about what learning in educational institutions is supposed to be like.

\section{Research Question 3: Which Areas of Language Learning Are Most Benefitted by Autonomous}

\section{Learning Choices?}

The purpose of this study's third research question was to create a focus for analysis in regards to different ways in which learner autonomy benefits language learning. In other words, it examined whether students identified specific areas that benefited most from their ability to make choices. To address the third research question, data from the autonomous learning survey and the reflective statements were used. The autonomous learning survey contained items that asked the students specifically about the benefits of the spoken and written projects. Not surprisingly, the students saw the biggest gains in the areas of writing and speaking, due to the fact that these were the most directly addressed skills when working on the spoken and written projects. Due to their more general nature and the wide range of formats and topics where the skills of writing and speaking are applied, these skills can be addressed and practiced more easily in a learner autonomy curriculum, as compared to, for example, discrete skills focusing or based on grammar. The students expressed this contrast in the reflective statements.

Autonomous learning survey. Two items on the autonomous learning survey questioned students about the benefits of the work cycle projects to their language learning. One item related to the spoken projects and one item related to the written projects. Tables 9 and 10 show how the students evaluated the benefits of the spoken and written work cycle projects. 
Table 9

Percentage of Students Answering "Yes" to "Making individualized choices about the format, content, and timing of spoken presentations has helped me most in these areas..."

\begin{tabular}{|c|c|c|c|c|c|c|c|c|c|c|c|c|}
\hline & \multicolumn{12}{|c|}{ section } \\
\hline & \multirow{2}{*}{\multicolumn{2}{|c|}{$\begin{array}{l}204001 \\
\text { Spring } 2011 \\
(n=16)\end{array}$}} & \multirow{2}{*}{\multicolumn{2}{|c|}{$\begin{array}{l}204003 \\
\text { Spring } 2011 \\
(n=18)\end{array}$}} & \multirow{2}{*}{\multicolumn{2}{|c|}{$\begin{array}{l}304 \\
\text { Spring } 2011 \\
(n=17)\end{array}$}} & \multirow{2}{*}{\multicolumn{2}{|c|}{$\begin{array}{l}204001 \\
\text { Fall } 2011 \\
(n=8)\end{array}$}} & \multirow{2}{*}{\multicolumn{2}{|c|}{$\begin{array}{l}204004 \\
\text { Fall } 2011 \\
(n=21)\end{array}$}} & \multirow{2}{*}{\multicolumn{2}{|c|}{$\begin{array}{l}\text { Total } \\
(\mathrm{N}=80)\end{array}$}} \\
\hline & & & & & & & & & & & & \\
\hline & $\%$ & SD & $\%$ & SD & $\%$ & SD & $\%$ & SD & $\%$ & SD & $\%$ & SD \\
\hline grammatical accuracy & 19 & .403 & 39 & .502 & 29 & .470 & 38 & .518 & 43 & .507 & 34 & .476 \\
\hline pronunciation & 50 & .516 & 67 & .485 & 47 & .514 & 50 & .535 & 81 & .402 & 61 & .490 \\
\hline my ability to understand spoken language & 56 & .512 & 67 & .485 & 53 & .514 & 63 & .518 & 57 & .507 & 59 & .495 \\
\hline my ability to make myself understood in speaking & 63 & .500 & 78 & .428 & 71 & .470 & 88 & .354 & 81 & .402 & 75 & .436 \\
\hline cultural understanding & 56 & .512 & 33 & .485 & 59 & .507 & 38 & .518 & 48 & .512 & 48 & .503 \\
\hline self-confidence in speaking German & 75 & .447 & 67 & .485 & 65 & .493 & 88 & .354 & 57 & .507 & 68 & .471 \\
\hline my motivation to experiment with new technolog & 19 & .403 & 78 & .428 & 53 & .514 & 13 & .354 & 43 & .507 & 45 & .501 \\
\hline my motivation to investigate a topic & 69 & .479 & 78 & .428 & 76 & .437 & 25 & .463 & 62 & .498 & 66 & .476 \\
\hline
\end{tabular}

Table 10

Percentage of Students Answering "Yes" to "Making individualized choices about the format, content, and timing of written presentations has helped me most in these areas..."

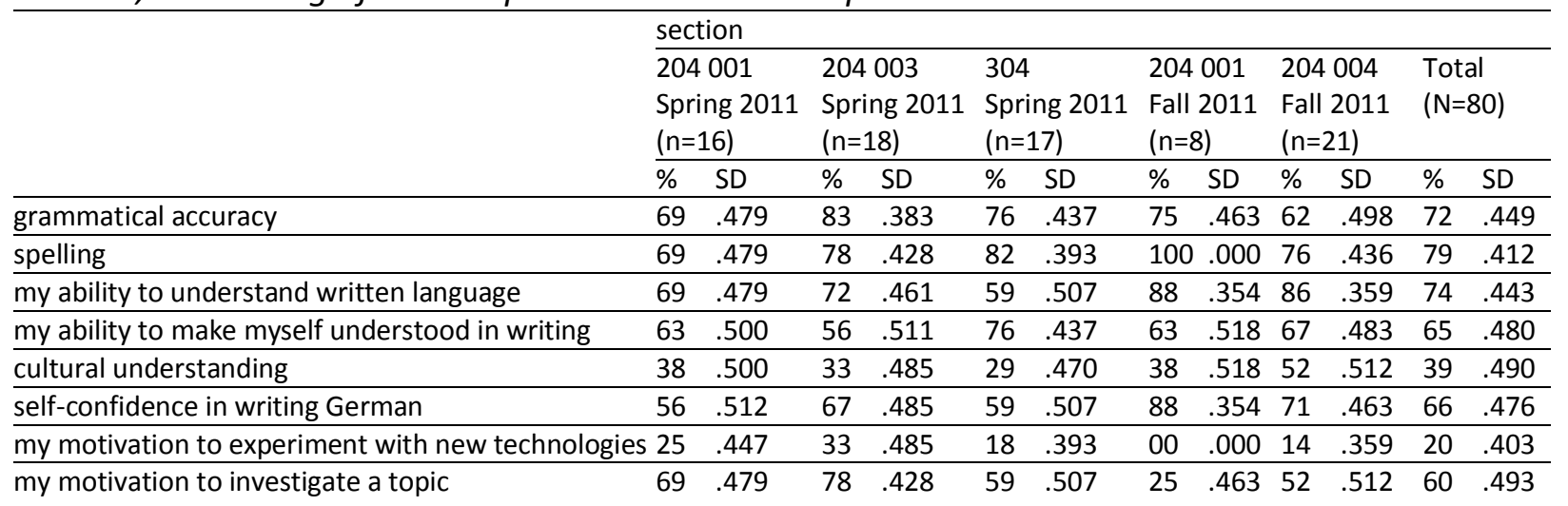

Tables 9 and 10 show that the students viewed the spoken and written projects as

advantageous to their language learning in different ways. The biggest differences between the two types of projects are the areas of grammatical accuracy and motivation to experiment with new technologies. The students believed that written projects helped them more with grammatical accuracy than spoken projects. This could be attributed to the fact that when writing, students typically have more time to think about sentence construction, word order, verb conjugation, and case endings. When speaking, students are more occupied with pronunciation and finding the right words to make themselves understood. Both of these areas 
were reported to be improved more by spoken projects, than was, for example, grammatical accuracy. The motivation to experiment with new technologies was likewise affected more by work on spoken projects than on written projects. One reason for this difference is the design of the work cycle projects. Except for one type of task, the written projects always had to be typed and submitted to the teacher as a printed copy, even if the topic, format, or approach was different from a traditional essay. The spoken projects, on the other hand, could be completed in the form of PowerPoint presentations, audio productions, short films, or roleplays.

The analysis of this data also shows that the choices made in relation to spoken projects benefited the students' self-confidence and helped them improve their ability to make themselves understood in German. The written projects affected most significantly the areas of spelling, ability to understand as well as making oneself understood through writing, and selfconfidence in writing. Interestingly, the students reported that their written projects also helped them more with understanding written language, rather than making themselves understood through writing. Due to the fact that the primary objective of these projects was to produce a written project, one would expect a bigger perceived benefit in terms of production rather than reception.

Reflective statements. In the reflective statements, the students were also asked to address the aspects of their learning that were benefited most by the autonomous learning choices they made. When the students described in which area of language learning they felt they most improved, a particular language skill (i.e., listening, speaking, writing, or reading) was the most common strand: 
I feel as though I managed to make substantial progress when it comes to my ability to speak in German. I feel that a portion of the work-cycle being dedicated to speaking German has helped me to learn to be confident when I'm speaking, in any language. I also feel that my reading and listening skills have improved, to a somewhat lesser extent. I can now read articles in German newspapers and magazines like Der Spiegel and comprehend what they are saying instead of picking out only one or two words per page.

The above statement confirms the results from the autonomous learning survey, where a majority of students in each section agreed that their self-confidence in speaking improved because of the spoken projects. Interestingly, this student also makes the connection from speaking German to speaking in any language and thus shows evidence of the ability to make connections from his foreign language learning to speaking skills applied outside of the language classroom. In the following passage, the improvement in speaking and writing is mentioned again, along with a concern about the learning of sentence syntax.

Over the course of the semester I have improved in several areas. Overall my writing ability and being able to express myself through writing in most instances has improved, but there is still much to improve in the syntax of sentences to further clear up ideas. My speaking has improved and I feel more comfortable in speaking freely in most situations, as has listening comprehension.

While many students felt that they improved in the areas of writing, speaking, reading, or listening, several students stated that they still needed improvement in the area of grammar. 
This excerpt from the reflective statement of a student in one of the 204 classes during the second phase of the study illustrates this point:

I think if I had to choose one specific area in which I wish I would have put more time, I would choose grammar. Until the last two or three weeks of the semester I still did not understand some of the concepts of verb placement or sentence structure like I should have.

Along the same lines, another student commented:

Adjective endings, case changes, and some verb tenses are difficult for me to perfect. I would have liked to have concentrated more on grammar in German 204. I understand that 203 tends to be the more grammar intensive course, but having more classes in 204 devoted to grammar would have been helpful. Occasional review sessions throughout the semester, rather than reviewing only at the beginning of the semester, would help students hone their reading and writing skills.

Many students reported that their skills had improved in the three modes of communication and in the areas of reading, writing, listening, and speaking. Students expressed frustration, however, with their knowledge of German grammar. This distinction might be based on two factors. First, students perceive German grammar as difficult. This might lead to their assumption that they can never learn and improve enough in this area. In fact, it is very rare that students ever use grammatically perfect language, which reinforces the viewpoint of many that their knowledge of German grammar is insufficient. Nevertheless, it is still possible to communicate successfully, whether in spoken or written form, despite imperfect grammar. The key to helping students understand the limits of accuracy is to explain to them the 
importance of proficiency, not perfection. This notion of proficiency emphasizes a second point related to mixed perceptions of improvement: It is easier for the students to experience success and gain self-confidence when they used proficiency-based rather than perfection-based communication. Based on a proficiency scale, an act of communication can ultimately be successful, even when the grammatical structures used are not perfect. Proficiency-based learning reaffirms the students' perception that they can successfully read, write, listen, and speak when communicating, but that they can never perfect their understanding and application of grammatical concepts.

Addressing this concern is ultimately one of the main challenges for foreign language teachers who want to maximize the students' excitement and motivation to learn a foreign language through learner autonomy. Finding the balance between instruction that is focused on teaching the mechanics of a foreign language on the one hand, and creating room for creative freedom in terms of content and format on the other hand, is difficult. The different ways to find this balance depend greatly on the setting in which the teachers and students come together. In chapter 5 , the implications of these findings for foreign language teaching and learning practice will be discussed further. 


\section{Chapter 5}

\section{Summary and Conclusion}

The success of autonomous learning in the classroom is based on the question of whether true autonomy can ever be reached in the institutional setting. Based on the hierarchies formed between students, faculty, administrators, and staff, the institution is founded upon a system of power structures that are difficult to recognize and to overcome. The relationship of teachers and students is based on power, as exhibited by the teacher's determination of instructional procedures and the evaluations of the students' performance in terms of grades. This unequal distribution of power among the roles of individuals interacting in classrooms and lecture halls obviously posit limitations to learner autonomy. Other hindrances to autonomy are inherent to the larger institutional context, which determines class length and class size for the sake of scheduling, as well as prescribes curricula across classes for the sake of coherence of programs of study. In consideration of these limitations to learner autonomy, one could assume that the only true autonomous learning of foreign languages takes place in immersion settings.

Based on the inherent power structures within the institutional environment, Luke (2006) asks whether it is possible to ever move beyond the power relationships within which students and teachers interact. In that vein, he poses two important questions to which this study has sought to provide an answer through a classroom-based and learner-based approach to learner autonomy: (1) how do teachers encourage and facilitate the students' transition from traditional settings to environments that focus on learner autonomy, and (2) how can teachers support their students in using their heightened level of autonomy effectively? 
The National Standards for Foreign Language Education (National Standards for Foreign Language Education Project, 1999) - the "five Cs" of communication, cultures, connections, comparisons, and communities - as well as the model of communicative competence (CelceMurcia, Dörnyei, \& Thurrell, 1995) can serve as frameworks that guide foreign language teachers in the implementation of autonomous learning. Thus, foreign language instruction based on the five $\mathrm{Cs}$ is an effective way to bring autonomy into foreign language learning. For example, by addressing the standard of Connections, teachers can support learner autonomy by encouraging students to connect their learning of a foreign language to other disciplines that are of most interest to them. Also, by addressing the standard of Communities, the development of learner autonomy can contribute to increase lifelong learning that transcends the institutional learning setting. Eventually, learner autonomy can empower students to access the cultural and linguistic lore of the target culture by themselves, which addresses the standards of Cultures and Comparisons. Similarly, by designing and providing instruction that addresses all parts of communicative competence (linguistic competence, socio-cultural competence, actional competence, strategic competence, and discourse competence) foreign language teachers can also foster learner autonomy.

Recognizing the institutional constraints on autonomous learning, this chapter contains a summary of the study results and a description of how they may be used to shape curricula and classroom practices in the future. Based on the effect of learner autonomy on the competencies, the implications for the practice of foreign language teaching and learning are described. To conclude, the limitations of this research and ways in which this research can be extended are also described. 


\section{Summary}

Across the different types of data gathered and used for this research, three central themes emerged from the analysis: first, the students' positive reactions to choices in regards to content and format of project work, second, the need for learner training to articulate specific learning goals and challenges, and third, an apparent tension between appreciation of choices and requests for a structured learning environment, especially in terms of grammar instruction and frequency of assessments.

In general, the findings of this study show evidence that an overwhelming majority of the students involved in this study reacted very positively to an autonomous learning environment. Evidence included high scores on the learner autonomy survey and primarily positive responses to the learning journals and reflective statements. One of the most positive aspects of autonomous learning from the students' perspective was the ability to choose the focus and format of course content. Generally, this is encouraging to educators who strive to make learner autonomy a priority in their teaching. The German 204 courses in which the autonomous learning format was used have retained the work cycle format, as has the 304 course. Despite the mostly positive results, there were also a small number of students who openly disapproved of the course structure. Also, several students made suggestions as to how they thought the course structure could have worked better for them. The most remarkable trend in the analysis of this data was an apparent contrast between appreciation for autonomous learning choices on the one hand, and requests for more targeted instruction and practice on grammar, as well as more frequent tests and quizzes on the other hand. These findings, in particular, provide valuable insights into areas that need to be addressed if learner 
autonomy is to become a more broadly applied concept in foreign language teaching and learning.

The contrast in the findings notwithstanding, the students unanimously reported an increase in their level of motivation based on the autonomous learning choices. They also showed evidence of this in their reflective statements. In terms of the areas that are most benefited by autonomous learning choices, the data showed that written work helped the students to develop grammatical accuracy and improved their ability to express themselves in writing. In respect to their work on spoken projects, the students reported the biggest benefits in their self-confidence to speak German in front of other people and their likeliness to experiment with new technologies.

The differentiation shown by the students in their evaluation of the most-benefited areas of language learning suggests that autonomous learning affects the competencies involved in language learning in different ways. For example, based on the reported improvement in the ability to understand and make oneself understood in writing or speaking, it is evident that the development of actional competence can be adequately addressed in an autonomous learning environment, if only quantitatively. Furthermore, there was also evidence that the ability to make connections increased based on the ability to make autonomous learning choices. This trend was illustrated in several reflective statements in which students emphasized their appreciation of the ability to practice and use German when working on topics of personal interest and relevance. In the learning journals and reflective statements, the students made frequent references to new insights they gained about contemporary and historical German-speaking society and culture. Many students used their work cycle projects 
to investigate topics like uses of modern media and technology, the views of members of German-speaking cultures on, for example, environmental issues and multiculturalism, or the historical development of student fraternities in Germany. All of these topics relate to sociocultural competence and thus demonstrate how this part of language learning is addressed in an autonomous learning environment.

While the above-mentioned competencies were positively affected by the approach used in this study, the repeated requests by students for more grammar instruction and additional assessments suggests that they desired more practice in the analysis and use of language structures. In terms of the communicative competence model, linguistic competence seems to have benefited from autonomous learning less than other areas of the model. Any implementation of autonomous learning in foreign language classrooms therefore needs to take into consideration how part of linguistic competence can be expanded through a contentbased approach to the cultural material being addressed in class.

\section{Implications for Foreign Language Teaching and Learning}

Providing students with autonomous learning choices involves them in decision-making processes that ultimately improve their learning experience. It is therefore advisable for foreign language educators to design their classes in a way that allows for learner autonomy through choices about the way in which the students want to learn the language. Learner autonomy can focus on choices related to the topics or the format of activities and projects, for example through a work cycle structure. By making choices, students are able to incorporate their strengths and interests and thus make the most of the learning experience. For the teacher, it can be very rewarding to see the variety of topics and the creativity the students bring into the 
classroom. It is impressive to see how passionate students can be about the topics they choose to work on and how much they desire for their fellow students to know about their topic of interest. Ultimately, the autonomous learning framework is successful because it allows students to highlight and build on what they know rather than focus on what they do not know. Instituting an autonomous learning framework does not, however, come without difficulty. There are several limitations when implementing principles of learner autonomy in traditional learning environments, such as college classrooms. The expectations of the students, time constraints, and objectivity in student assessment all put constraints on the way in which autonomy can be implemented. It is therefore the biggest challenge to find an approach that balances notions of learner autonomy, such as individuality, flexibility, student responsibility, and openness, with the need for a supportive structure that takes time constraints, student expectations, and fair assessment procedures into consideration.

While learner autonomy can have positive effects on learning, the findings of this study also have shown the students' desire for structure in their learning environment. Indeed, it is also in the interest of the teacher to provide a well-structured learning environment. In the arena of classroom structure, the teacher and students can come together to find a compromise through a flexible structure that allows for many choices while still guiding the student. The creation of such a structure, however, requires the teacher to give up some degree of control if learners are to take more responsibility for the learning process. If foreign language instructors are serious about training their students to become more autonomous language learners, they need to be willing to give up some of the power that is associated with their role. The challenge for foreign language educators then lies in finding the balance 
between room for autonomy and a structured learning environment. This can be done, for example, by providing a clearly laid out course calendar at the beginning of the course that gives the students an idea of what to expect each day. It is also imperative to articulate and emphasize the advantages and benefits of autonomous learning choices for the students.

Moreover, it is important for foreign language teachers to acknowledge the students' beliefs and expectations about language learning (Cotterall, 1995; Gan, 2004). In the reflective statements written by the 204 students, many students referred to their experiences in the class they had taken the previous semester, pointing out the emphasis put on grammar. Therefore the expectations they had coming in to the class did not always seem to match with the way they were learning in the autonomous learning environment. This highlights the importance of managing and explaining the articulation between courses regardless of format and the guidance necessary for students to become acquainted and comfortable with an autonomous learning framework. As Carson (2010) and Trebbi (2003) point out, learner autonomy is a process of socialization and requires curricular approaches for the most effective implementation of such a framework in practice.

To summarize, this study shows that autonomous learning can make a distinctly positive impact on the way in which students perceive foreign language learning. This is encouraging to foreign language educators, who seek to implement principles of learner autonomy in their teaching. Several factors play a role in the learners' receptiveness to this approach: the learners' and teachers' need for structure, the constraints imposed by the particular setting or institution, and the need to address each part of language learning (actional competence, socio- 
cultural-competence, linguistic competence, etc.) in a sufficient way. Any application of the principles of autonomous learning therefore needs to heed to these factors.

\section{Limitations of the Study}

An array of factors strengthens the findings of this study. First, similar results were obtained in five different class sections. The sections included students from different levels of language proficiency and were taught at different points in time. Although the format of the instruction was changed based on the feedback of the students who participated in the first phase of the study, the findings are consistent and did not show a significant difference in how the students perceived language learning in a setting that emphasized learner autonomy. This suggests that the instructional elements that focused on learner autonomy, which did not change between the two phases, were truly the most important reason for the students' positive reactions. The students' perception of learner autonomy was also consistent between the 204 and 304 courses, which were taught by different instructors. This is an additional factor that strengthens the study's findings, for the teachers did not significantly affect the way in which students reacted to learner autonomy.

There are, however, also several limitations to this research: This study was carried out within the framework of participatory action research (Kemmis \& McTaggart, 2000; Kidd \& Kral, 2005). In accordance with the tenets of action research, the primary purpose of this study was to reflect upon and inform the practice of foreign language teaching and learning in a particular setting. The findings of this research are consequently limited in their generalizability. Also, in any educational setting in which the teacher and the students work closely together and are in a power-based relationship defined by the institutional context, many personal factors are 
involved. In an action research setting such as the present one, where the teacher researcher and the student participants interact on a daily basis, and within established power relationships, this holds true as well. The interpersonal dynamics between the teachers and students involved in this study hence represent a potential confounding variable to its outcomes. In fact, the centrality of the teacher role was underscored by the work of Breen and Mann (1997), Ho and Crookall (1995), Little (1995), and Smith and Vieira (2009). They showed that the teacher has a great impact in fostering autonomy within their students. The findings of this study are therefore highly context-bound, as the students might have reacted to the autonomous learning environment in a certain way simply because they liked or disliked the teachers.

This leads to an important point about the students that participated in this study. Based on the reputation of German among college students as being a difficult language to learn, it is possible that the implementation of this research with German students only had an effect on the outcomes of this work. As the data show, a large number of the students, especially the ones at the 204 level, were enrolled in German classes to fulfill a foreign language requirement for their program of study. The fact that they chose German could mean that these students were more motivated language learners than many others, who choose allegedly easier foreign language classes to fulfill their requirements. Thus, the students who participated in this study were possibly more apt to take charge of their own learning.

Third, this study focused on student perception of learner autonomy and can therefore make only limited assertions about the relationship between learner autonomy and achievement in foreign language learning. Whether learner autonomy in fact has an objectively 
measurable impact on learner achievement remains an issue to be investigated in future studies. Certain problems need to be addressed when attempting to objectively measure the impact of learner autonomy on the development of language proficiency. For example, it is difficult to create a valid measurement, when the students exercise autonomy and therefore take different routes and set individual emphases in their foreign language learning. In the context of this study, there was no reliable and valid way to measure the achievement of the students. However, there was a valid and reliable way to measure the perception of the students through the different evaluative methods applied in the study.

The assumptions about the connection between learner autonomy and the development of language proficiency based on the research are somewhat twofold. On the one hand, there is reason to believe that the increased level of motivation that the students have shown in this study can contribute to a higher achievement level in autonomous learning settings as compared to settings with a lesser degree of learner autonomy. On the other hand, there is research that contradicts this assumption. First, Gan (2004), in a study of the learning strategies and beliefs of Chinese learners of English, showed that positive attitudes toward selfdirected language study (i.e., language learning in an autonomous setting) and achievement on a standardized test of English proficiency were not significantly correlated. Second, Talmadge and Pascarella (1984) discovered in a study on the effect of cooperative learning strategies on teacher practice, student perceptions, and student achievement that the hypothesis that the "degree of cooperation in the classroom learning environment would have a direct influence on student achievement" was ultimately not supported (p. 174). Third, the data of the present study also did not show significant correlations between the students' responses to the 
autonomous learning environment and their self-assessment of their competence in German. All of these factors indicate that positive attitudes towards autonomous language learning might not have a one-to-one correlation with higher achievement scores in the language, even if they lead to the students' more active engagement with the material.

\section{Areas of Further Research}

Logically, the limitations of this study also suggest areas in which future research on learner autonomy in foreign language learning can be developed. There is still no conclusive evidence about the relationship between learner autonomy and quantitatively assessed proficiency levels in language learning. The established correlation between level of motivation and achievement (Hernandez, 2006; Masgoret \& Gardner, 2003), however, suggests that there could be a positive relationship between learner autonomy and achievement related to the effect of learner autonomy on motivation. An experimental or quasi-experimental study that can reliably address these issues would have to be conducted in a controlled environment attempting to isolate the independent variable of degree of learner autonomy as much as possible. The measures used in this study, the self-assessment survey in particular, would then be combined with measures of language proficiency like an oral proficiency test or Integrated Performance Assessments.

A second direction for further research rests on the findings of this study that suggest there is a connection between tolerance, or intolerance, of ambiguity and the readiness and ability of students to learn in an environment that fosters learner autonomy. A specific approach for further research is therefore to combine measures of tolerance of ambiguity, for example the one designed by Ely (1989), and this study's autonomous learning survey. This 
would also contribute to a better understanding about how different types of learners react to autonomous learning environments.

To deepen the understanding of how students with different learning styles possibly react in different ways to autonomous learning environments, a case study approach can also be valuable. A case study can be especially insightful as a follow-up study to the present one. For example, a measure of the students learning styles could be given at the beginning of the study. A small number of students representing different learner types would then be followed closely over the course of study and data could be collected from learning journals and reflective statements. This kind of research would also address the still-to-be answered question whether autonomous learning in fact allows students to capitalize on their learning styles and their ability to develop personal learning strategies.

Lastly, the knowledge base on learner autonomy in foreign language learning still needs to be developed on a broader front, for example by conducting studies that include data from students learning different foreign languages. Moreover, as mentioned previously, finding a practical balance between a structured learning environment and a maximum of autonomy is difficult. Thus, there is also a need for more action research that describes, observes, and evaluates implementations of autonomous learning in practice. It is only by providing concrete and feasible examples of curricula and classroom procedures that foreign language educators will be more likely to give autonomous learning a chance in their own classrooms.

\section{Conclusion}

This study has shown that the tenets of Freire (1970) and Foucault (1995) have a place in foreign language education and can be addressed in different ways on the learner autonomy 
continuum. Considering the full breadth of the learner autonomy spectrum (from fully controlled to fully self-directed and autonomous), the level of autonomy and changes to the traditional power structures in educational institutions were relatively small in this study but initiated large changes in terms of the students' approach to the material. While on the learner autonomy continuum, this research may be located closer to the end of controlled learning environments, given the institutional setting with its strict power confines, the autonomy implemented in the study offered students a freer environment in which to capitalize on the learning strengths and identify their learning weaknesses. Given that the students themselves requested more structure in the courses suggests that there is a limit to how open and autonomous foreign language learning environments can be in postsecondary institutions.

This desire for structure also shows the difficulties that arise for students when they are used to learning a language in a very structured format and then are expected to make autonomous decisions regarding their learning from one semester to the next. Consequently, learner autonomy is a goal that needs to be implemented across the curriculum. It is therefore desirable that there is greater articulation between language classes that are part of a larger sequence. In practice, the extent of learner autonomy will vary depending on the language proficiency level of the students, but it can be implemented at each level. For example, in beginning level classes, teachers and learners can focus on strategy instruction and the specific identification of learner strengths and weaknesses. At an intermediate language proficiency level, learners are then able to capitalize more on their strengths and weaknesses. They will then be more ready and will benefit more from freedom for create choices in regards to content and format of learning activities and projects. Finally, language learners at advanced 
levels can benefit from autonomy by applying their language learning to their respective professional fields or by preparing themselves for graduate studies.

Despite the constraints of large institutions of education, even small changes in the traditional power structure can cause several reactions. This study has uncovered some of them. Autonomous learning is an approach that opens up ever new learning experiences for the students and the teachers because the content and the topics brought into the classroom will be as different as the individual learners themselves. Autonomous learning primarily addresses the parts of language learning that consist of actional competence, socio-cultural competence, and the standard focused on making connections. It also has a positive effect on the learners' level of motivation as well. With the ability to better understand and make oneself understood with the language, a deeper understanding of the target cultures' socio-cultural customs, the ability to make connections to personal interests, and a higher level of motivation, the learners are more likely to continue the learning process outside of the classroom. In this way, autonomous learning can also address the yet elusive standard of lifelong learning - the learners' interest and confidence to use the language outside of class and for personal enjoyment. Reaching this goal with their students remains the great desire of every language educator. The autonomous learning classroom offers students and teachers a good path toward achieving this objective together. 


\section{References}

Akaranithi, A., \& Panlay, S. (2007). Tensions in policy and practice in self-directed learning. In A. Barfield \& S. Brown (Eds.), Reconstructing autonomy in language education: Inquiry and innovation (pp. 43-55). New York, NY: Palgrave Macmillan.

Barfield, A., \& Brown, S. H. (Eds.) (2007). Reconstructing autonomy in language education. New York, NY: Palgrave Macmillan.

Benson, P. (1997). The philosophy and politics of learner autonomy. In P. Benson \& P. Voller (Eds.), Autonomy and independence in language learning (pp. 18-34). London, England: Longman.

Benson, P. (2001). Teaching and researching autonomy in language learning. Harlow, England: Longman.

Benson, P. (2007). Autonomy in language teaching and learning. Language Teaching, 40(1), 2140.

Bentz, V. M., \& Shapiro, J. J. (1998). Mindful inquiry in social research. Thousand Oaks, CA: Sage.

Breen, M. P., \& Littlejohn, A. (Eds.) (2000a). Classroom decision making: Negotiation and process syllabuses in practice. Cambridge: University Press.

Breen, M. P., \& Littlejohn, A. (2000b). The significance of negotiation. In M. P. Breen \& A. Littlejohn (Eds.), Classroom decision making: Negotiation and process syllabuses in practice (pp. 5-38). Cambridge: University Press.

Breen, M. P., \& Mann,S. J. (1997). Shooting arrows at the sun: Perspectives on a pedagogy for autonomy. In P. Benson \& P. Voller (Eds.), Autonomy and independence in language learning (pp. 132-149). London, England: Longman. 
Broady, E., \& Kenning, M. (Eds.) (1996). Promoting learner autonomy in university language teaching. London, England: Association for French Language Studies.

Burkert, A., \& Schwienhorst, K. (2008). Focus on the student teacher: The European portfolio for student teachers of languages (EPOSTL) as a tool to develop teacher autonomy. Innovation in Language Learning and Teaching, 2(3), 238-252.

Canale, M., \& Swain, M. (1980). Approaches to communicative competence. Singapore: Seameo regional language centre.

Caracelli, V. J., \& Greene, J. C. (1993). Data analysis strategies for mixed-method evaluation designs. In V. L. Plano Clark \& J. W. Creswell (Eds.), The mixed methods reader (pp. 151158). Thousand Oaks, CA: Sage.

Carson, L. (2010). Innovation and autonomy in an institution-wide language programme. In B. O’Rourke \& L. Carson (Eds.), Language learner autonomy: Policy, curriculum, classroom (pp. 151-167). Bern, Switzerland: Peter Lang.

Celce-Murcia, M., Dörnyei, Z., \& Thurrell, S. (1995). Communicative competence: A pedagogically motivated model with content specifications. Issues in Applied Linguistics, 6(2), 5-35.

Cheng, H., \& Dörnyei, Z. (2007). The use of motivational strategies in language instruction: The case of EFL teaching in Taiwan. Innovation in Language Learning and Teaching, 1(1), 153-174.

Chiu, C. Y. (2008). The discourse of an English teacher in a cyber writing course: Roles and autonomy. The Asian EFL Journal, 10(1), 79-110. 
Ciekanski, M. (2007). Fostering learner autonomy: Power and reciprocity in the relationship between language learner and language learning adviser. Cambridge Journal of Education, 37(1), 111-127.

Cotterall, S. (1995). Readiness for autonomy: Investigating learner beliefs. System, 23(2), 195205.

Cotterall, S. (2000). Promoting learner autonomy through the curriculum: principles for designing language courses. ELT Journal, 54(2), 109-117.

Cotterall, S., \& Crabbe, D. (Eds.) (1999). Learner autonomy in language learning: Defining the field and effecting change. Frankfurt a. M., Germany: Peter Lang.

Dam, L. (2008). In-service teacher education for learner autonomy. Independence, 44, 20-26.

Darasawang, P., Singhasiri, W., \& Keyuravong, S. (2007). Developing student support in selfaccess centres. In A. Barfield \& S. Brown (Eds.), Reconstructing autonomy in language education: Inquiry and innovation (pp. 167-179). New York, NY: Palgrave Macmillan.

Deci, E. L., \& Ryan, R. M. (1985). Intrinsic motivation and self-determination in human behavior. New York, NY: Plenum Press.

Deci, E. L., Vallerand, R. J., Pelletier, L. G., \& Ryan, R. M. (1991). Motivation and education: the self-determination perspective. Educational Psychologist, $26(3$ \& 4), 325-346.

Dewey, J. (1966). Democracy and education. New York, NY: Free Press.

Dickinson, L. (1995). Autonomy and motivation: A literature review. System, 23(2), 165-174.

Dörnyei, Z., \& Csizer, K. (1998). Ten commandments for motivating language learners: results of an empirical study. Language Teaching Research, 2(3), 203-229. 
Edelsky, C. (2006). With literacy and justice for all: Rethinking the social in language and education. Mahwah, NJ: Lawrence Erlbaum.

Ely, C. M. (1989). Tolerance of ambiguity and uses of second language strategies. Foreign Language Annals, 22(5), 437-445.

Field, J. (2007). Looking outwards, not inwards. ELT Journal, 61(1), 30-38.

Foucault, M. (1995). Discipline and punish: The birth of the prison. New York, NY: Vintage.

Freire, P. (1970). Pedagogy of the oppressed. New York, NY: Seabury Press.

Gan, Z. (2004). Attitudes and strategies as predictors of self-directed language learning in an EFL context. International Journal of Applied Linguistics, 14(3), 389-402.

Gay, L. R., Mills, G. E., \& Airasian, P. (2009). Educational Research. Upper Saddle River, NJ: Pearson.

Greene, J. C., Caracelli, V. J., \& Graham, W. F. (1989). Toward a conceptual framework for mixed-method evaluation designs. In V. L. Plano Clark \& J. W. Creswell (Eds.), The mixed methods reader (pp. 151-158). Thousand Oaks, CA: Sage.

Gremmo, M. J., \& Riley, P. (1995). Autonomy, self-direction and self access in language teaching and learning: The history of an idea. System, 23(2), 151-164.

Grima, A. (2000). Learning to learn. In M. Byram (Ed.), Routledge encyclopedia of language teaching \& learning (pp. 351-353). Routledge. Retrieved from Education Research Complete database.

Guba, E. G., \& Lincoln, Y. S. (1994). Competing paradigms in qualitative research. In N. K. Denzin \& Y. S. Lincoln (Eds.), Handbook of qualitative research (pp. 105-117). Thousand Oaks, CA: Sage. 
Hernandez, T. (2006). Integrative Motivation as a Predictor of Success in the Intermediate Foreign Language Classroom. Foreign Language Annals, 39(4), 605-617.

Ho, J., \& Crookall, D. (1995). Breaking with Chinese cultural traditions: Learner autonomy in English language teaching. System, 23(2), 235-243.

Holec, H. (1981). Autonomy in foreign language learning. Oxford, England: Pergamon.

Hymes, D. H. (1972). On communicative competence. In J. B. Pride \& J. Holmes (Eds.), Sociolinguistics: Selected readings. Harmondsworth, England: Penguin.

Kemmis, S., \& McTaggart, R. (2000). Participatory Action Research. In N. K. Denzin \& Y. S. Lincoln (Eds.), Handbook of qualitative research (pp. 567-606). Thousand Oaks, CA: Sage.

Kennedy, J., \& Pinter, A. (2007). Developing teacher autonomy through teamwork. In A. Barfield \& S. Brown (Eds.), Reconstructing autonomy in language education: Inquiry and innovation (pp. 209-221). New York, NY: Palgrave Macmillan.

Kidd, S. A., \& Kral, M. J. (2005). Practicing participatory action research. Journal of Counseling Psychology, 52(2), 187-195.

Kohonen, V. (2003). Student autonomy and teachers' professional growth: Fostering a collegial culture in language teacher education. In D. Little, J. Ridley, \& E. Ushioda (Eds.), Learner autonomy in the foreign language classroom (pp. 147-159). Dublin, Ireland: Authentik.

Kuhn, T. S. (1996). The structure of scientific revolutions. Chicago, IL: University of Chicago. Lamb, T., \& Reinders, H. (Eds.). (2008). Learner and teacher autonomy: Concepts, realities, responses. Amsterdam, the Netherlands: John Benjamins. 
Legenhausen, L. (2003). Second language acquisition in an autonomous learning environment. In D. Little, J. Ridley, \& E. Ushioda (Eds.), Learner autonomy in the foreign language classroom (pp. 65-77). Dublin, Ireland: Authentik.

Legenhausen, L. (2010). Group work, weak learners and the autonomous classroom: Indirect support for the interaction hypothesis?. In B. O’Rourke \& L. Carson (Eds.), Language learner autonomy: Policy, curriculum, classroom (pp. 29-44). Bern, Switzerland: Peter Lang.

Little, D. (1995). Learning as dialogue: The dependence of learner autonomy on teacher autonomy. System, 23(2), 175-181.

Little, D. (1997). Responding authentically to authentic texts: A problem for self-access language learning?. In P. Benson \& P. Voller (Eds.), Autonomy and independence in language learning (pp. 225-236). London, England: Longman.

Little, D. (2000). Self-access. In M. Byram (Ed.), Routledge encyclopedia of language teaching \& learning (pp. 539-541). Routledge. Retrieved from Education Research Complete database.

Little, D. (2007). Language learner autonomy: Some fundamental considerations revisited. Innovation in Language Learning and Teaching, 1(1), 14-29.

Little, D., Ridley, J., \& Ushioda, E. (Eds.) (2003). Learner autonomy in the foreign language classroom: Teacher, learner, curriculum and assessment. Dublin, Ireland: Authentik.

Luke, C. (2006). Fostering Learner Autonomy in a Technology-Enhanced, Inquiry-Based Foreign Language Classroom. Foreign Language Annals, 39(1), 71-86. 
Masgoret, A. M., \& Gardner, R. C. (2003). Attitudes, Motivation, and Second Language Learning: A Meta-Analysis of Studies Conducted by Gardner and Associates. Language Learning, 53, 167-210.

Marsh, C., Richards, K., \& Smith, P. (2001). Autonomous learners and the learning society: Systematic perspectives on the practice of teaching in higher education. Educational Philosophy and Theory, 33(3-4), 381-395.

McDevitt, B. (2004). Negotiating the syllabus: A win-win situation?. ELT Journal, 58(1), 3-9. McGrath, I. (2000). Teacher autonomy. In B. Sinclair, I. McGrath, \& T. Lamb (Eds.), Learner autonomy, teacher autonomy: Future directions. (pp. 100-110). Harlow, England: Pearson.

Mills, G. E. (2003). Action research: A guide for the teacher researcher. Upper Saddle River, NJ: Pearson Education.

Moll, L., Amanti, C., Neff, D., \& González, N. (2005). Funds of knowledge for teaching: Using a qualitative approach to connect homes and classrooms. In N. González, L. C. Moll, \& C. Amanti (Eds.), Funds of knowledge (pp. 71-89). Mahwah, NJ: Lawrence Erlbaum.

Morgan, D. L. (2007). Paradigms lost and pragmatism regained: Methodological implications of combining qualitative and quantitative methods. In V. L. Plano Clark \& J. W. Creswell (Eds.), The mixed methods reader (pp. 151-158). Thousand Oaks, CA: Sage.

Morse, J. M. (1991). Approaches to qualitative-quantitative methodological triangulation. In V. L. Plano Clark \& J. W. Creswell (Eds.), The mixed methods reader (pp. 151-158). Thousand Oaks, CA: Sage. 
National Standards for Foreign Language Education Project. (1999). Standards for foreign language learning in the 21st century. Yonkers, N.Y: National Standards in Foreign Language Education Project.

Natri, T. (2007). Active learnership in continuous self- and peer-evaluation. In A. Barfield \& S. Brown (Eds.), Reconstructing autonomy in language education: Inquiry and innovation (pp. 108-119). New York, NY: Palgrave Macmillan.

Newstetter, W. (2000). Reality therapy: Using negotiated work in a technical-writing class. In M. P. Breen \& A. Littlejohn (Eds.), Classroom decision making: Negotiation and process syllabuses in practice (pp. 176-184). Cambridge: University Press.

Nicoll, H. (2007). Seeking autonomy in a lecture course. In A. Barfield \& S. Brown (Eds.), Reconstructing autonomy in language education: Inquiry and innovation (pp. 120-130). New York, NY: Palgrave Macmillan.

Nix, M., \& Barfield, A. (2009). Autonomy and control in curriculum development: Are you teaching what we all agreed?. In R. Pemberton, S. Toogood, \& A. Barfield (Eds.), Maintaining control: Autonomy and language learning (pp. kindle book!). Hong Kong, Japan: University Press.

O’Rourke, B., \& Carson, L. (Eds.) (2010). Language learner autonomy: Policy, curriculum, classroom. Bern, Switzerland: Peter Lang.

O’Rourke, B., \& Schwienhorst, K. (2003). Talking text: Reflections on reflection in computermediated communication. In D. Little, J. Ridley, \& E. Ushioda (Eds.), Learner autonomy in the foreign language classroom (pp. 47-60). Dublin, Ireland: Authentik. 
Partnership for 21st Century Skills (2011). Framework for 21st century learning. Retrieved from http://www.p21.org/storage/documents/1._p21_framework_2-pager.pdf

Pennycook, A. (1997). Cultural alternatives and autonomy. In P. Benson \& P. Voller (Eds.), Autonomy and independence in language learning (pp. 35-53). London, England: Longman.

Plano Clark, V. L., \& Creswell, J. W. (Eds.). (2008). The mixed methods reader. Thousand Oaks, CA: Sage.

Porto, M. (2007). Learning diaries in the english as a foreign language classroom: A tool for accessing learners' perceptions of lessons and developing learner autonomy and reflection. Foreign Language Annals, 40(4), 672-696.

Reinders, H., \& Lewis, M. (2006). An evaluative checklist for self-access materials. ELT Journal, $60(3), 272-278$.

Reinders, H., \& Lewis, M. (2008). Materials evaluation and teacher autonomy. In T. Lamb \& H. Reinders (Eds.), Learner and teacher autonomy: Concepts, realities, responses (pp. 205215). Amsterdam, The Netherlands: John Benjamins.

Ridley, J. (2003). Learner's ability to reflect on language and on their learning. In D. Little, J. Ridley, \& E. Ushioda (Eds.), Learner autonomy in the foreign language classroom (pp. 7889). Dublin, Ireland: Authentik.

Rivers, W. P. (2001). Autonomy at all costs: An ethnography of metacognitive self-assessment and self-management among experienced language learners. Modern Language Journal, $85,279-290$.

Rubin, J. (1975). What the "good language learner" can teach us. TESOL Quarterly, 9(1), 41-51. 
Rüschoff, B. (2010). Authenticity in language learning revisited: materials, processes, aims. In B. O’Rourke \& L. Carson (Eds.), Language learner autonomy: Policy, curriculum, classroom (pp. 121-135). Bern, Switzerland: Peter Lang.

Scharle, A., \& Szabo, A. (2000). Learner Autonomy: A guide to developing learner responsibility. Cambridge: University Press.

Schmenk, B. (2005). Globalizing learner autonomy. TESOL Quarterly, 39(1), 107-118.

Schwienhorst, K. (2003). Learner autonomy and tandem learning: Putting principles into practice in synchronous and asynchronous telecommunications environments. Computer Assisted Language Learning, 16(5), 427-443.

Sheerin, S. (1997). An exploration of the relationship between self-access and independent learning. In P. Benson \& P. Voller (Eds.), Autonomy and independence in language learning (pp. 54-65). London, England: Longman.

Sinclair, B. (2000). Learner autonomy: The next phase?. In B. Sinclair, I. McGrath, \& T. Lamb (Eds.), Learner autonomy, teacher autonomy: Future directions (pp. 4-14). Harlow, England: Pearson.

Sinclair, B., McGrath, I., \& Lamb, T. (Eds.). (2000). Learner autonomy, teacher autonomy: Future directions. Harlow, England: Pearson.

Slembrouck, S. (2000). Negotiation in tertiary education. In M. P. Breen \& A. Littlejohn (Eds.), Classroom decision making: Negotiation and process syllabuses in practice (pp. 138149). Cambridge: University Press.

Smith, J. K. (1983). Quantitative versus qualitative research: An attempt to clarify the issue. Educational Researcher, 12, 6-13. 
Smith, R., \& Vieira, F. (2009). Teacher education for learner autonomy: building a knowledge base. Innovation in Language Learning and Teaching, 3(3), 215-220.

Smith, R. C. (2000). Starting with ourselves: Teacher-learner autonomy in language learning. In B. Sinclair, I. McGrath, \& T. Lamb (Eds.), Learner autonomy, teacher autonomy: Future directions. (pp. 89-99). Harlow, England: Pearson.

Spratt, M., Humphreys, G., \& Chan, V. (2002). Autonomy and motivation: Which comes first?. Language Teaching Research, 6(3), 245-266.

Stringer, E. T. (1999). Action research. Thousand Oaks, CA: Sage.

Talmadge, H., \& Pascarella, E. T. (1984). The influence of cooperative learning strategies on teacher practices, student perceptions of the learning environment, and academic achievement. American Educational Research Journal, 21(1), 163-179.

Tashakkori, A., \& Teddlie, C. (1998). Introduction to mixed method and mixed model studies in the social and behavioral sciences. In V. L. Plano Clark \& J. W. Creswell (Eds.), The mixed methods reader (pp. 7-26). Thousand Oaks, CA: Sage.

Tashakkori, A., \& Teddlie, C. (Eds.). (2003). Handbook of mixed methods in social and behavioral research. Thousand Oaks, CA: Sage.

Teddlie, C., \& Tashakkori, A. (Eds.). (2009). Foundations of mixed methods research. Thousand Oaks, CA: Sage.

Thomsen, H. (2003). Scaffolding target language use. In D. Little, J. Ridley, \& E. Ushioda (Eds.), Learner autonomy in the foreign language classroom (pp. 29-46). Dublin, Ireland: Authentik. 
Toogood, S., \& Pemberton, R. (2007). Support structures for self-access learning. In A. Barfield \& S. Brown (Eds.), Reconstructing autonomy in language education: Inquiry and innovation (pp. 180-195). New York, NY: Palgrave Macmillan.

Trebbi, T. (2003). Curriculum development and learner autonomy in the foreign language classroom: constraints and possibilities. In D. Little, J. Ridley, \& E. Ushioda (Eds.), Learner autonomy in the foreign language classroom (pp. 166-184). Dublin, Ireland: Authentik.

Ushioda, E. (2003). Motivation as a socially mediated process. In D. Little, J. Ridley, \& E. Ushioda (Eds.), Learner autonomy in the foreign language classroom (pp. 90-102). Dublin, Ireland: Authentik.

Victori, M., \& Lockhart, W. (1995). Enhancing metacognition in self-directed language learning. System, 23(2), 223-234.

Vieira, F. (1999). Pedagogy for autonomy: Teacher development and pedagogical experimentation - an in-service teacher training project. In S. Cotterall \& D. Crabbe (Eds.), Learner autonomy in language learning: Defining the field and affecting change (pp. 149-158). Frankfurt am Main, Germany: Peter Lang.

Vieira, F. (2007). Teacher development through inquiry. In A. Barfield \& S. Brown (Eds.), Reconstructing autonomy in language education: Inquiry and innovation (pp. 15-29). New York, NY: Palgrave Macmillan.

Vieira, F. (2009). Enhancing pedagogy for autonomy through learning communities: Making our dream come true?. Innovation in Language Learning and Teaching, 3(3), 269-282. 
Voller. P. (1997). Does the teacher have a role in autonomous learning?. In P. Benson \& P. Voller (Eds.), Autonomy and independence in language learning (pp. 98-113). London, England: Longman.

Vygotsky, L. S. (1978). Mind in society. Cambridge, MA: Harvard University Press.

Wenden, A. L. (1995). Learner training in context: A knowledge-based approach. System, 23(2), 183-194.

Wenden, A. L. (2002). Learner development in language learning. Applied Linguistics, 23(1), 3255.

Yang, N. D. (1998). Exploring a new role for teachers: promoting learner autonomy. System, 26, 127-135.

Young, J. T., Hafner, C. A., \& Fisher, D. W. (2007). Shifting sands: Supporting teachers in facilitating independent learning. In A. Barfield \& S. Brown (Eds.), Reconstructing autonomy in language education: Inquiry and innovation (pp. 196-208). New York, NY: Palgrave Macmillan. 


\section{Appendix A}

\section{Work Cycle 1 (Kindheit, Jugend, Erwachsensein)}

\section{Mögliche schriftliche Projekte:}

- $\quad$ eine Biografie

- $\quad$ ein Tagebucheintrag aus der Perspektive einer berühmten deutschsprachigen Person

- $\quad$ ein Aufsatz über das deutsche Jugendschutzgesetz

- $\quad$ ein Aufsatz über das deutsche Schulsystem

- $\quad$ ein Kommentar zu einem Text oder einem anderen Thema

- $\quad$ einen Leserbrief schreiben

Organisatorisches

- $\quad$ Die schriftlichen Projekte sollen ca. 100 Wörter lang sein.

- Jeder darf eine Karteikarte (index card) mit Vokabeln mitbringen.

- $\quad$ Der zweite Entwurf (draft) wird in doppelzeiligem Format getippt.

\section{Karteikarte}

You are allowed to bring ONE 3x5" index card with vocabulary (noun + article, verbs in the infinitive, adjectives without endings) to the written presentational.

The card may NOT contain the following things:

- English Translations (!!!!)

- Conjugation Tables (e.g. adjective endings)

- Conjugated Verbs (e.g. simple past forms)

- Full Sentences or sentence fragments

- Tiny Handwriting/Printouts (so you can fit an entire dictionary on it)

The cards will be checked. If they are not according to standards they will be confiscated.

\section{Mögliche mündliche Projekte:}

- $\quad$ eine Präsentation über eine Jugendbewegung in Deutschland

- $\quad$ eine Präsentation über das deutsche Jugendschutzgesetz

- $\quad$ eine Präsentation über das deutsche Schulsystem

- $\quad$ ein Rollenspiel

- $\quad$ eine Diskussion mit einem Partner aufnehmen (to record)

- $\quad$ ein Kurzfilm

- $\quad$ eine soundscape

- $\quad$ eine Powerpoint Präsentation zu einem Thema mit Bezug zu Kindheit, Jugend, Erwachsensein

Organisatorisches:

- $\quad$ ungefähr 3-5 Minuten pro Person

- frei gesprochen

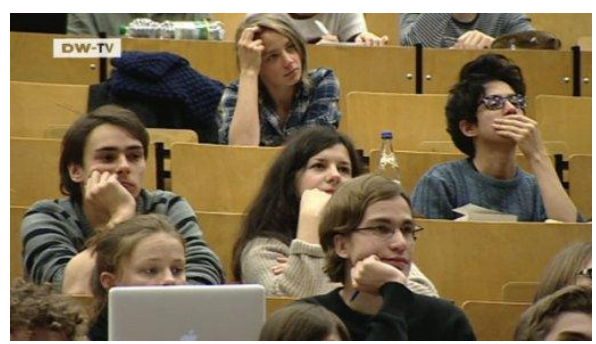




\section{Appendix A}

\section{Work Cycle 2 (Medien und Technik)}

\section{Mögliche schriftliche Projekte:}

- ein Zeitungsartikel, z.B. "Das Internet/Telefon/E-Mail, etc. wird erfunden"

- ein Aufsatz, z.B. "Mein Medientagebuch"

- Reaktion auf einen deutschen Film/eine deutsche Fernsehsendung

- Reaktion auf einen deutschsprachigen Zeitungs- oder Zeitschriftenartikel (z.B. aus dem Spiegel, FAZ, tagesschau.de, etc.)

- einen Leserbrief

- $\quad$ eine Medienkritik

Organisatorisches

- $\quad$ Die schriftlichen Projekte sollen ca. 100 Wörter lang sein.

- Jeder darf eine Karteikarte (index card) mit Vokabeln mitbringen.

- $\quad$ Der zweite Entwurf (draft) wird in doppelzeiligem Format getippt.

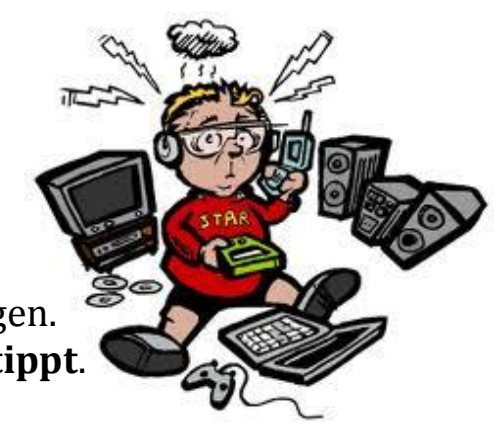

Karteikarte

You are allowed to bring ONE 3x5" index card with vocabulary (noun + article, verbs in the infinitive, adjectives without endings) to the written presentational.

The card may NOT contain the following things:

- English Translations (!!!!)

- Conjugation Tables (e.g. adjective endings)

- Conjugated Verbs (e.g. simple past forms)

- Full Sentences or sentence fragments

- Tiny Handwriting/Printouts (so you can fit an entire dictionary on it)

The cards will be checked. If they are not according to standards they will be confiscated.

\section{Mögliche mündliche Projekte:}

- $\quad$ eine Filmkritik (z.B., eine Siskel \& Ebert Parodie)

- Produktion eines Werbespots (für ein Handy, I-Pod, 3D Fernseher, etc.)

- Produktion einer Talkshow, z.B. „Mein Handykind spielt verrückt! Was soll ich tun?“

- ein Interview/eine Umfrage mit anderen Studenten, z.B. "Wie informierst du dich?”

- $\quad$ eine Videokritik im Tosh.0-Stil

- Xtranormal-Projekt zum Thema (www.xtranormal.com)

Organisatorisches:

- $\quad$ ungefähr 3-5 Minuten pro Person

- frei gesprochen

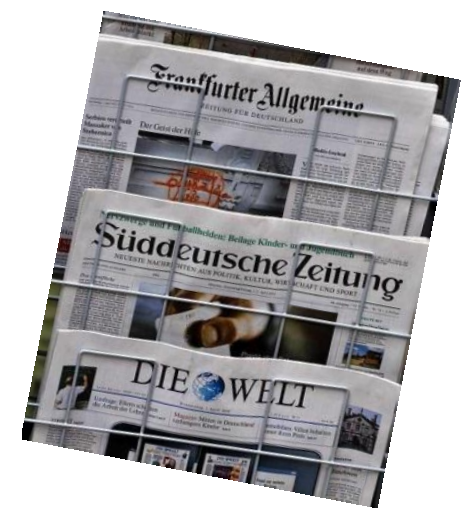




\section{Appendix A}

\section{Work Cycle 3 „Die öffentliche Meinung“}

Mögliche mündliche Projekte (ungefähr 3-5 Minuten pro Person, frei gesprochen):

- Führe ein spontanes Rollenspiel zum Thema „Globale Probleme und Lösungen“ mit einem Partner auf (keine geschriebenen Notizen!)

- Produziere einen Wahlkampfspot

- Nimm eine Wahlkampfrede auf

- Filme einen Bericht über ein Umweltproblem

- Halte eine Diskussionsrunde zu einem Thema (maximal in Dreiergruppen, keine geschriebenen Notizen!)

- Mache eine mündliche Umfrage und frage Klassenkameraden nach ihrer Meinung

- Erstelle eine kommentierte Powerpoint Präsentation (keine geschriebenen Notizen!)

- Hast du andere Ideen zu diesem Thema?
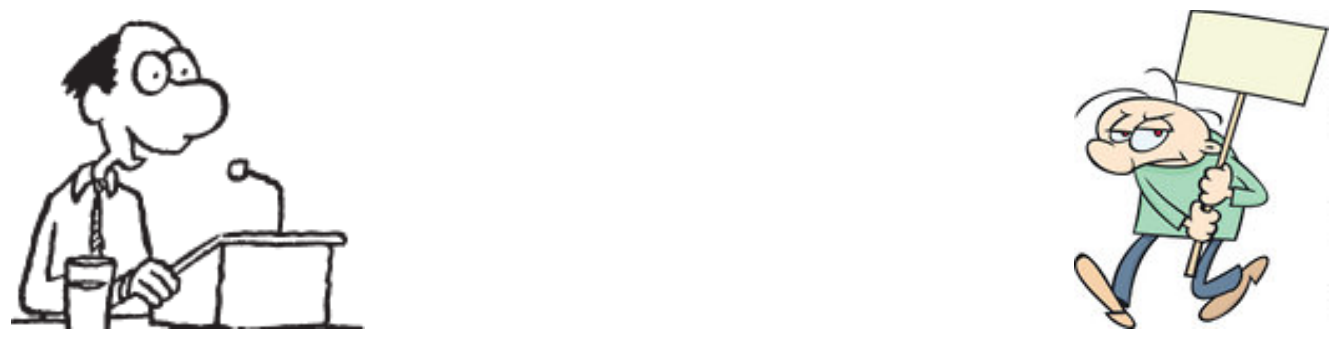

Mögliche schriftliche Projekte (ungefähr eine Seite lang, doppelzeilig, Schriftgröße 12):

- Schreibe das Parteiprogramm einer Studentenpartei

- Schreibe einen Aufsatz über ein Problem und mögliche Lösungen

- Schreibe einen Leserbrief an eine Zeitung oder Zeitschrift (zum Thema)

- Erstelle ein Pamphlet/eine Broschüre, um Aufmerksamkeit für ein Problem zu erzeugen

- Erstelle einen "green plan" für deinen Haushalt

- Mache eine Umfrage zum Thema Umweltschutz: Befrage drei Klassenkameraden und fasse die Ergebnisse zusammen.

- Hast du andere Ideen zu diesem Thema?
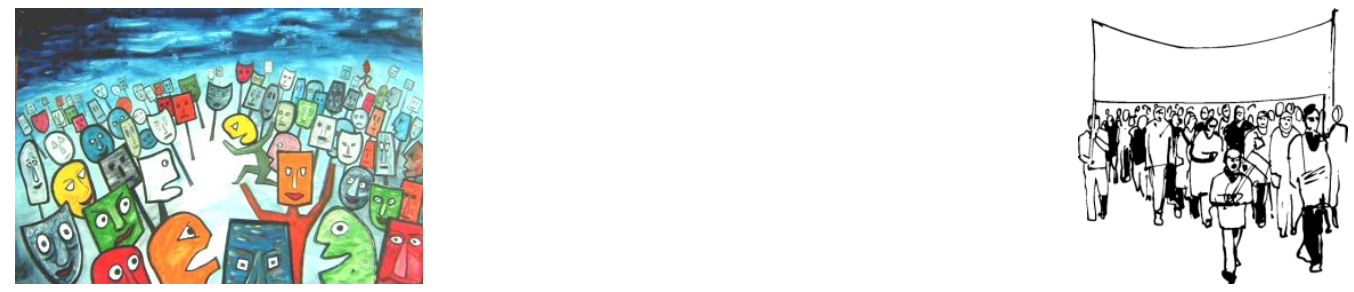


\section{Appendix B}

\section{Outline of Learning Journal Spring 2011}

To be completed by every participant at the end of each work cycle.

1. What was your goal for this work cycle in respect to learning German?

2. How have you used the class time during this work cycle?

3. What have you learned during this work cycle?

4. Which part of this work cycle has helped you most to improve your German?

5. Which part of the work cycle has helped you least to improve your German?

6. In what way has your teacher been most helpful over the course of this work cycle? 
7. Where do you see the biggest challenges for yourself in respect to your language learning?

8. What changes in the way in which the class is taught would make the class more beneficial to you? 


\section{Appendix B}

\section{Outline of Learning Journal Fall 2011}

\section{Vor dem Arbeitszyklus: Meine Ziele}

1. Wie wichtig sind diese Aspekte?

\begin{tabular}{|l|l|l|l|}
\hline & Nicht so wichtig & wichtig & Sehr wichtig \\
\hline Vokabular & & & \\
\hline Grammatik & & & \\
\hline Inhalt & & & \\
\hline Sprechen & & & \\
\hline Schreiben & & & \\
\hline “Wohlfühlfaktor” & & & \\
\hline
\end{tabular}

2. Was möchtest du verbessern? (Z.B. “Ich möchte zehn neue Wörter lernen.”)

3. Was könnte dir dabei helfen, dieses Ziel zu erreichen? (Z.B. "Flashcards machen.”)

4. Wieviel Zeit wirst du deiner Meinung nach brauchen, um diese Ziele zu erreichen? 


\section{Während des Arbeitszyklus}

Was sind deiner Meinung nach die 10 wichtigsten Wörter in diesem Arbeitszyklus? Schreibe hier die Wörter, sowie andere Vokabeln, die du nicht verstehst. Schreibe jeweils das Wort und eine Definition auf Deutsch. Denke an Synonyme, Gegenteile, Umschreibung, usw.

\section{Wort Beschreibung}

1.

2.

3.

4 .

5.

Welche neuen Strukturen lernst du? Wie lernst du sie?

Was findest du bei diesem Arbeitszyklus schwierig? Warum?

\section{Nach dem Arbeitszyklus}

- Hast du deine Ziele erreicht? Ja teilweise nein

- Was hat dir dabei geholfen (Zeit im Kurs, Hilfe vom Lehrer, Lernen zuhause, Hausaufgaben, etc.)?

- Was würdest du nächstes Mal anders machen, um deine Ziele zu erreichen?

- Andere Kommentare? 
Appendix C

Self-Assessment Survey of Language Proficiency

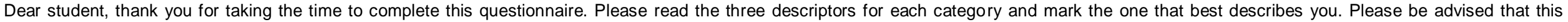
survey will not affect your grade in any way, so we encourage you to be honest.

\begin{tabular}{|c|c|c|c|c|}
\hline & $\begin{array}{l}4 \\
\begin{array}{c}\text { Above expectation for } \\
\text { my level }\end{array}\end{array}$ & $\begin{array}{l}3 \\
\begin{array}{l}\text { Meets expectation for } \\
\text { my level }\end{array}\end{array}$ & $\begin{array}{c}2 \\
\text { Approaching } \\
\text { expectations for my } \\
\text { level }\end{array}$ & $\begin{array}{l}1 \\
\begin{array}{c}\text { Below expectation for } \\
\text { my level }\end{array}\end{array}$ \\
\hline \multicolumn{5}{|l|}{ Linguistic Competence } \\
\hline \multicolumn{5}{|l|}{$\begin{array}{l}\text { Language control: My ability to engage in basic conversations and provide/obtain } \\
\text { detailed information is ... }\end{array}$} \\
\hline \multicolumn{5}{|l|}{$\begin{array}{l}\text { Language control: My ability to express feelings and emotions and exchange } \\
\text { opinions in German is... }\end{array}$} \\
\hline \multicolumn{5}{|l|}{$\begin{array}{l}\text { Vocabulary Usage: My ability to recognize and produce common words and } \\
\text { concepts necessary for carrying on basic conversations in German-speaking } \\
\text { cultures is... }\end{array}$} \\
\hline \multicolumn{5}{|l|}{$\begin{array}{l}\text { Analyzing language } \\
\text { I have a rich understanding of how the grammar of the language works. }\end{array}$} \\
\hline \multicolumn{5}{|l|}{ Socio-cultural Competence } \\
\hline \multicolumn{5}{|l|}{$\begin{array}{l}\text { My understanding of the practices (i.e., behavior, attitudes, values, rituals) and } \\
\text { products (i.e., music, food, art, films, tv programs) of German-speaking cultures is... }\end{array}$} \\
\hline \multicolumn{5}{|l|}{$\begin{array}{l}\text { My understanding of the perspectives and viewpoints of members of German- } \\
\text { speaking cultures on a variety of topics (the environment, media, holidays, family, } \\
\text { relationships, history, multicultural society) is... }\end{array}$} \\
\hline \multirow{2}{*}{\multicolumn{5}{|c|}{$\begin{array}{l}\text { My understanding of how the products, practices, and perspectives of my home } \\
\text { culture relate to those in the German-speaking culture is... } \\
\text { Actional Competence }\end{array}$}} \\
\hline & & & & \\
\hline \multicolumn{5}{|l|}{$\begin{array}{l}\text { Comprehensibility: My ability to make myself understood on a variety of topics } \\
\text { using spoken language is... }\end{array}$} \\
\hline \multicolumn{5}{|l|}{$\begin{array}{l}\text { Comprehensibility: My ability to make myself understood on a variety of topics } \\
\text { using written language is... }\end{array}$} \\
\hline \multicolumn{5}{|l|}{$\begin{array}{l}\text { Comprehension : My ability to understand and interpret spoken language on a } \\
\text { variety of topics is... }\end{array}$} \\
\hline \multicolumn{5}{|l|}{$\begin{array}{l}\text { Comprehension : My ability to understand and interpret written and spoken } \\
\text { language on a variety of topics is... }\end{array}$} \\
\hline \multicolumn{5}{|l|}{ Strategic competence } \\
\hline \multicolumn{5}{|l|}{$\begin{array}{l}\text { My ability to maintain communication by using circumlocution (i.e., using other } \\
\text { words to describe what I want to say in German is...) }\end{array}$} \\
\hline \multicolumn{5}{|l|}{$\begin{array}{l}\text { My ability to maintain communication by using gestures, body language, and other } \\
\text { strategies to what I want to say in German is... }\end{array}$} \\
\hline \multicolumn{5}{|l|}{$\begin{array}{l}\text { My ability to clarify something I have not understood by asking someone to repeat } \\
\text { or rephrase what was said is... }\end{array}$} \\
\hline \multicolumn{5}{|l|}{ Making Connections } \\
\hline \multicolumn{5}{|l|}{$\begin{array}{l}\text { My ability to use what I have learned in German class to understand better what I } \\
\text { am learning in other subject areas is... }\end{array}$} \\
\hline \multicolumn{5}{|l|}{$\begin{array}{l}\text { My ability to see connections (historical, artistic, cultural, political, etc.) between } \\
\text { what I have learned in German class and in other subject areas is... }\end{array}$} \\
\hline \multicolumn{5}{|l|}{ Lifelong Learning } \\
\hline \multicolumn{5}{|l|}{$\begin{array}{l}\text { My interest and confidence in using the language outside of class (e.g., at } \\
\text { Stammtisch or during other extracurricular activities) is... }\end{array}$} \\
\hline $\begin{array}{l}\text { My interest and confidence in using the language for personal enjoyment (e.g. at } \\
\text { concerts, while surfing the web, for reading pleasure, in German-speaking cultures, } \\
\text { etc.) is... }\end{array}$ & & & & \\
\hline
\end{tabular}


1. I am majoring or plan to (double) major in German? yes no

Other major(s):

2. I am minoring or plan to minor in German.

Other Minor(s):

3. Is German a required course?

yes no

4. At what level do you see your interest in German? Please check one.

very interested interested

a little interested

not very interested

\section{Connections to other disciplines}

3. I am able to make connections between my knowledge of German and other subject areas.

no

4. My study of German has helped me in my learning of other subjects. yes no

If so, explain in which subjects and how:

\section{Lifelong Learning}

3. I use German in activities outside of class.

yes no

If yes, I participate in the following activities.

\begin{tabular}{|c|c|}
\hline Language honorary societies & Language clubs \\
\hline Language tables & German-language films \\
\hline
\end{tabular}

Others

4. I use German for personal enjoyment in activities outside of class. yes no If yes, check all that apply.

$\begin{array}{lll}\text { listening to music } & \ldots \quad \begin{array}{l}\text { communicating with German speakers in writing or } \\ \text { speech } \\ \text { watching movies }\end{array} \quad \text { reading for personal enjoyment }\end{array}$

Others

5. Have you studied abroad? yes no

If yes, where?

What were the greatest benefits of your study abroad experience?

6. If you have not yet studied abroad, are you planning to do so? yes no If yes, where?

What do you expect the greatest benefits to be? 


\section{Appendix D}

\section{Instructions for Reflective Statement}

Make copies of all your materials and collect them in a folder. The copies can be double-sided. Please do not hand in original texts!

\section{checklist}

original versions of all learning journals

all written projects

printouts of presentation slides (6 slides per page) or reference to other spoken projects (e.g. link)

rubrics with grades for the projects

quizzes

reflective statement (3 pages)

\section{reflective statement}

Write a 3 page essay in which you describe your view of the material worked on in the course as well as your evaluation of your own learning process. Use the following questions as a guideline for your essay:

- What did you learn in terms of content that surprised you or that you were not aware of before?

- What is your opinion of the topics and materials used in class? (text book, activities, worksheets, articles, films, etc.)?

- What did you like best/least about the course?

- How did your learning develop during the course of the semester? Did you make progress? In which areas (vocabulary, writing, speaking, reading, listening, ability to express opinions, etc.)

- What would you have liked to work on more (topics, grammar, vocabulary, etc.)?

- $\quad$ Did you find the format of the course helpful/not helpful? Why?

- In what ways did the ability to make your own decisions about materials and activities help you to learn the material? Or, did you find the format less helpful?

- What suggestions would you make for the future? 


\section{Appendix E}

\section{Autonomous Learning Survey}

\begin{tabular}{|c|c|c|c|c|c|}
\hline & $\begin{array}{l}\text { Strongly } \\
\text { Agree }\end{array}$ & Agree & $\begin{array}{l}\text { Neither } \\
\text { Agree nor } \\
\text { Disagree }\end{array}$ & Disagree & $\begin{array}{l}\text { Strongly } \\
\text { Disagree }\end{array}$ \\
\hline $\begin{array}{l}\text { 1. I enjoy having the opportunity to make } \\
\text { individualized choices about how I learn } \\
\text { German. }\end{array}$ & & & & & \\
\hline $\begin{array}{l}\text { 2. The ability to make individualized choices } \\
\text { about the format, content, and timing of } \\
\text { projects has increased my level of } \\
\text { motivation to learn German. }\end{array}$ & & & & & \\
\hline $\begin{array}{l}\text { 3. The ability to make individualized choices } \\
\text { about the format, content, and timing of } \\
\text { projects has improved my awareness about } \\
\text { the way I learn best. }\end{array}$ & & & & & \\
\hline $\begin{array}{l}\text { 4. I would like to have more teacher guidance } \\
\text { in choices about the format and content of } \\
\text { projects. }\end{array}$ & & & & & \\
\hline $\begin{array}{l}\text { 5. I would like to have less teacher guidance in } \\
\text { choices about the format and content of } \\
\text { projects. }\end{array}$ & & & & & \\
\hline $\begin{array}{l}\text { 6. Identifying my difficulties and preferences } \\
\text { with regard to course materials in the form } \\
\text { of a journal has helped me to identify how I } \\
\text { learn best. }\end{array}$ & & & & & \\
\hline $\begin{array}{l}\text { 7. The ability to make individualized choices } \\
\text { about the format of projects has increased } \\
\text { my motivation to learn German. }\end{array}$ & & & & & \\
\hline $\begin{array}{l}\text { 8. The ability to make individualized choices } \\
\text { about the content of projects has increased } \\
\text { my motivation to learn German. }\end{array}$ & & & & & \\
\hline $\begin{array}{l}\text { 9. The ability to make individualized choices } \\
\text { about the timing of projects has increased } \\
\text { my motivation to learn German. }\end{array}$ & & & & & \\
\hline
\end{tabular}




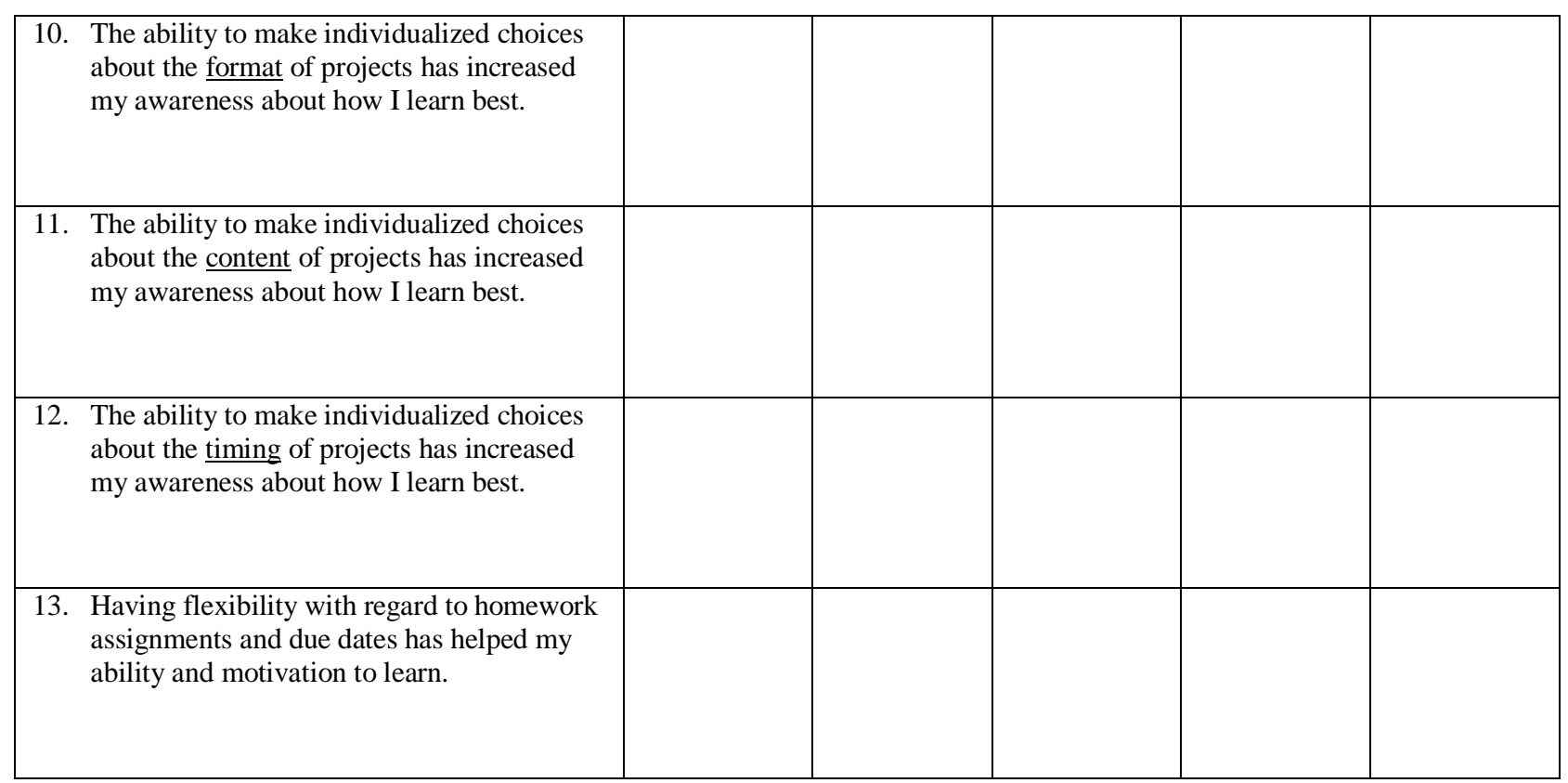

14. Please elaborate on the items for which you marked "strongly agree" or "strongly disagree".

15. Making individualized choices about the format, content, and timing of spoken presentations has helped me most in these areas (please check all that apply):

$\square$ grammatical accuracy

$\square \quad$ cultural understanding

$\square$ pronunciation

$\square$ self-confidence in speaking German

$\square \quad$ my ability to understand spoken language

$\square$ my motivation to experiment with new technologies

$\square \quad$ my ability to make myself understood in speaking

$\square$ my motivation to investigate a topic

other, please specify:

16. Making individualized choices about the format, content, and timing of written presentations has helped me most in these areas (please check all that apply):

$\square$ grammatical accuracy

$\square \quad$ cultural understanding

$\square \quad$ spelling

$\square \quad$ self-confidence in writing German

$\square \quad$ my ability to understand written language

$\square$ my motivation to experiment with new technologies

$\square \quad$ my ability to make myself understood in writing

$\square$ my motivation to investigate a topic

other, please specify: 


\section{Appendix F}

\section{Code Book}

The table below shows an overview of the categories that emerged from the analysis of the learning journals and the reflective statements. The categories of "ability to make connections" and "effect on motivation" also served as codes, and are thus not broken down into separate codes. The remaining categories include several codes. The different codes were used to further differentiate and qualify the student responses in relation to the broader categories. An exemplary statement is provided for each code.

\begin{tabular}{|c|c|c|}
\hline Category and Description & Code & Example \\
\hline \multirow{4}{*}{$\begin{array}{l}\text { Goal setting. In the learning journals, the } \\
\text { students were asked to identify personal }\end{array}$} & Form/grammar & I would like to improve my grammar. \\
\hline & Vocabulary & I would like to learn words about global problems. \\
\hline & $\begin{array}{l}\text { Particular language skill (i.e., } \\
\text { writing, listening, reading, or } \\
\text { speaking) }\end{array}$ & I would like to be able to respond more quickly. \\
\hline & Content & I would like to learn about the opinions people in \\
\hline
\end{tabular}




\begin{tabular}{|c|c|c|}
\hline & & $\begin{array}{l}\text { Germany have about political and environmental } \\
\text { questions. }\end{array}$ \\
\hline & Culture & $\begin{array}{l}\text { I would like to learn a little bit more about German } \\
\text { culture. }\end{array}$ \\
\hline \multirow{4}{*}{$\begin{array}{l}\text { Biggest challenges. Codes relating to this } \\
\text { category labeled specific areas identified } \\
\text { by the students as being most difficult for } \\
\text { them. }\end{array}$} & Form/grammar & $\begin{array}{l}\text { I had a lot of trouble with Passive, Perfekt, and } \\
\text { Imperfekt sentences. I studied and did a lot of } \\
\text { exercises but they were not enough I guess. }\end{array}$ \\
\hline & Vocabulary & $\begin{array}{l}\text { Vocabulary is still the roughest part of German for me } \\
\text { and I wish I could've spent more time improving my } \\
\text { knowledge of it. }\end{array}$ \\
\hline & $\begin{array}{l}\text { Particular language skill (i.e., } \\
\text { writing, listening, reading, or } \\
\text { speaking) }\end{array}$ & $\begin{array}{l}\text { The spoken projects were difficult. Speaking in class } \\
\text { can make me nervous. }\end{array}$ \\
\hline & Content & $\begin{array}{l}\text { The school structure in Germany, because it is very } \\
\text { different from the American school structure. }\end{array}$ \\
\hline
\end{tabular}




\begin{tabular}{|c|c|c|}
\hline & Culture & $\begin{array}{l}\text { No student mentioned culture as one of the biggest } \\
\text { challenges. }\end{array}$ \\
\hline \multirow[t]{3}{*}{$\begin{array}{l}\text { Most helpful activities. The learning } \\
\text { activities identified by the students as } \\
\text { most helpful were differentiated by these }\end{array}$} & Teacher support & $\begin{array}{l}\text { Something else that I found extremely helpful was the } \\
\text { office hours of the instructor and the encouragement } \\
\text { received to come by for extra help if confused on a } \\
\text { new concept, and especially to help go through a } \\
\text { paper or speaking presentation, which helps a great } \\
\text { deal and is worth the time. }\end{array}$ \\
\hline & $\begin{array}{l}\text { Class } \\
\text { requirements/homework }\end{array}$ & $\begin{array}{l}\text { The online assignments seemed to help me most, I } \\
\text { suppose this was because of the silent and stress free } \\
\text { environment that I was able to take time to } \\
\text { concentrate on the task at hand and really understand } \\
\text { it. }\end{array}$ \\
\hline & In-class activities & $\begin{array}{l}\text { In the classroom was where I got the majority of my } \\
\text { knowledge from. The games and group activities were }\end{array}$ \\
\hline
\end{tabular}




\begin{tabular}{|c|c|c|}
\hline & & $\begin{array}{l}\text { the most informative aspects, and allowed us to better } \\
\text { know each other and learn from each other. }\end{array}$ \\
\hline & Work cycles & $\begin{array}{l}\text { The work cycle projects were a good way to learn, and } \\
\text { I think they helped my learning of the German } \\
\text { language far better than the IPAs of the first three } \\
\text { German courses. }\end{array}$ \\
\hline & $\begin{array}{l}\text { Out-of-class, self-motivated, } \\
\text { activities }\end{array}$ & $\begin{array}{l}\text { During the semester my learning developed a lot. I } \\
\text { ended up making flashcards for all the chapters of the } \\
\text { book from start to finish during the end of the } \\
\text { semester and upon studying these in my free time I } \\
\text { found that I learned many words. }\end{array}$ \\
\hline $\begin{array}{l}\text { Most improved areas. The statements } \\
\text { made by the students to describe their } \\
\text { most improved areas fell into this } \\
\text { category and were analyzed using these }\end{array}$ & Form/grammar & $\begin{array}{l}\text { Most notably, my understanding of grammar } \\
\text { constructs has improved greatly. Given my new found } \\
\text { understanding of the grammar, everything else fell } \\
\text { into place. }\end{array}$ \\
\hline
\end{tabular}




\begin{tabular}{|c|c|c|}
\hline \multirow[t]{4}{*}{$\begin{array}{l}\text { codes. They correspond with the codes } \\
\text { under "goals" and "biggest challenges". }\end{array}$} & Vocabulary & $\begin{array}{l}\text { Through the work in this class, I learned a lot, mostly } \\
\text { vocabulary. (Translated from a reflective statement } \\
\text { written in German by a German } 304 \text { student: „Durch } \\
\text { die Arbeit dieses Kurses habe ich viel gelernt. Am } \\
\text { meisten ist es Vokabeln.") }\end{array}$ \\
\hline & $\begin{array}{l}\text { Particular language skill (i.e., } \\
\text { writing, listening, reading, or } \\
\text { speaking) }\end{array}$ & $\begin{array}{l}\text { I would also say I made the most progress in my } \\
\text { listening and reading abilities because almost the } \\
\text { entire class was in German. }\end{array}$ \\
\hline & Content & $\begin{array}{l}\text { The topic that I most enjoyed talking about and } \\
\text { learning the German perspective on was energy } \\
\text { sources and the environment. I have always been } \\
\text { interested in nuclear power and alternative sources } \\
\text { for energy since I live so close to Three Mile Island. }\end{array}$ \\
\hline & Culture & $\begin{array}{l}\text { I learned a great deal about the culture in Germany, } \\
\text { which is what I really appreciate and love to learn. }\end{array}$ \\
\hline
\end{tabular}




\begin{tabular}{|c|c|c|}
\hline $\begin{array}{l}\text { Perception of autonomous learning. } \\
\text { There were several ways in which the } \\
\text { students expressed their perception of the } \\
\text { autonomous learning environment. The } \\
\text { codes created within this category specify }\end{array}$ & $\begin{array}{l}\text { Positive perception of } \mathrm{AL} \\
\text { structure }\end{array}$ & $\begin{array}{l}\text { Overall, I believe that because this course was set up } \\
\text { in the way that students made their own decisions on } \\
\text { which activities to do and which type of presentation } \\
\text { or writing project to do, students learned more than if } \\
\text { the course was more structured and strict. }\end{array}$ \\
\hline \multirow{2}{*}{$\begin{array}{l}\text { codes created within this category specify } \\
\text { the students' reactions. }\end{array}$} & $\begin{array}{l}\text { Negative perception of } \mathrm{AL} \\
\text { structure }\end{array}$ & $\begin{array}{l}\text { However, for the homework, I don't feel this freedom } \\
\text { was the best. I felt that I would pick the easiest } \\
\text { assignment and not the one that would help us to } \\
\text { learn the language the most. }\end{array}$ \\
\hline & Favorite part of the class & $\begin{array}{l}\text { My favorite part was the novel and the reading } \\
\text { journals. The reading journals forced me to read. I like } \\
\text { reading in my free time, but when I had to read for } \\
\text { school, I would not read. (Translated from a reflective } \\
\text { statement written in German by a German } 304 \\
\text { student: "Mein Lieblingsteil war das Roman und die }\end{array}$ \\
\hline
\end{tabular}




\begin{tabular}{|c|c|c|}
\hline & & $\begin{array}{l}\text { Lesejournals. Die Lesejournals zwang mich zu lesen. } \\
\text { Ich lese gern in meine Freizeit aber wenn ich für Schule } \\
\text { lesen musste, dann würde ich nicht lesen.“) }\end{array}$ \\
\hline & Least favorite part of class & $\begin{array}{l}\text { The thing I liked the least about this course were the } \\
\text { learning journals. Maybe I didn't put enough emphasis } \\
\text { on the journals for them to be valuable, but I they } \\
\text { often felt unessential to me. }\end{array}$ \\
\hline & Suggestions for change & $\begin{array}{l}\text { I also would have liked to work more on grammar } \\
\text { while in the classroom. I did not feel that there was } \\
\text { enough of an emphasis on grammar throughout the } \\
\text { semester. If more of an emphasis had been placed } \\
\text { upon learning grammar it would have made other } \\
\text { aspects of the class easier to understand. }\end{array}$ \\
\hline \multicolumn{2}{|c|}{$\begin{array}{l}\text { Ability to make connections. Statements in this category/code include } \\
\text { descriptions about how students were able to relate their language }\end{array}$} & $\begin{array}{l}\text { The format of this class has not only helped me to } \\
\text { learn German, but it has also helped me in learning }\end{array}$ \\
\hline
\end{tabular}




\begin{tabular}{|c|c|}
\hline learning to other areas of learning. & $\begin{array}{l}\text { Russian. I have learned various tricks to remembering } \\
\text { German vocabulary for presentations, and that has } \\
\text { carried over into my Russian } 101 \text { class. }\end{array}$ \\
\hline $\begin{array}{l}\text { Effect on motivation. Whenever students made statements about the } \\
\text { effect of the class structure on their perceived level of motivation (either in } \\
\text { a positive or negative way), this category/code was used. In the statements } \\
\text { in this category, students often referred to "making learning fun" or "being } \\
\text { more interested" in learning the language. }\end{array}$ & $\begin{array}{l}\text { Having the ability to choose what type of material and } \\
\text { activities helped me be creative with projects and } \\
\text { make the projects my own. It made the projects more } \\
\text { interesting because we were given so much freedom } \\
\text { as long as a few certain guidelines were followed. No } \\
\text { one person had the same project. We were able to } \\
\text { bring our creative side to the table and make learning } \\
\text { fun. I enjoyed having the ability to take my knowledge } \\
\text { and put it into a project or activity that interests me. }\end{array}$ \\
\hline
\end{tabular}


